Portland State University

PDXScholar

\title{
Strategies for Urban Pollinator Management Using Habitat Monitoring and Restoration Planning in Portland Oregon
}

Fiona Smeaton

Portland State University

Follow this and additional works at: https://pdxscholar.library.pdx.edu/mem_gradprojects

Part of the Environmental Sciences Commons

Let us know how access to this document benefits you.

\section{Recommended Citation}

Smeaton, Fiona, "Strategies for Urban Pollinator Management Using Habitat Monitoring and Restoration Planning in Portland Oregon" (2020). Master of Environmental Management Project Reports. 58.

https://pdxscholar.library.pdx.edu/mem_gradprojects/58

https://doi.org/10.15760/mem.60

This Project is brought to you for free and open access. It has been accepted for inclusion in Master of Environmental Management Project Reports by an authorized administrator of PDXScholar. Please contact us if we can make this document more accessible: pdxscholar@pdx.edu. 


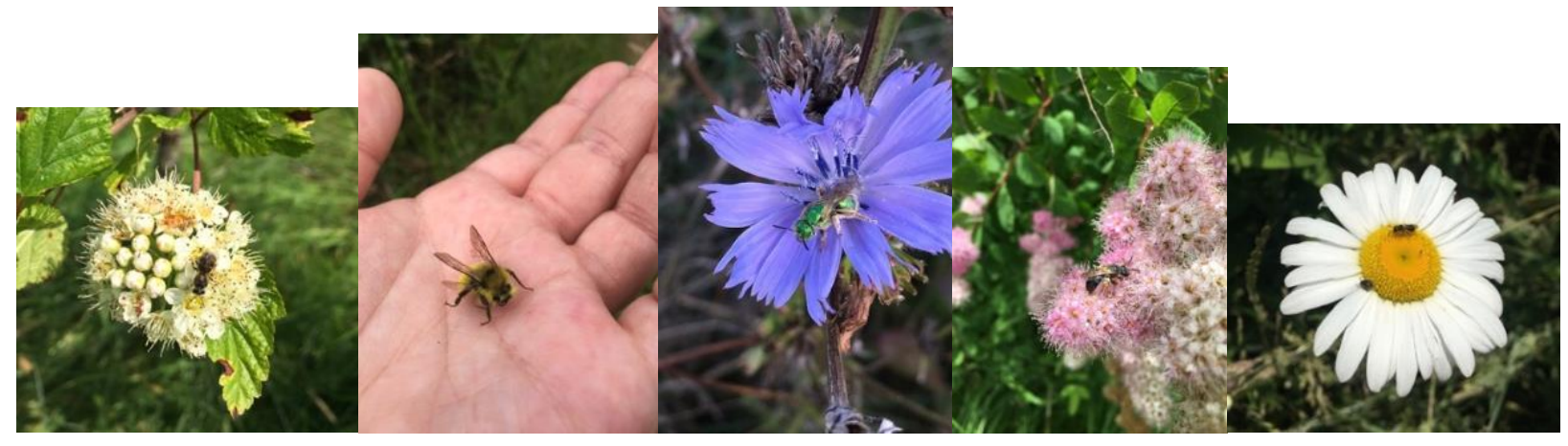

\section{Strategies for Urban Pollinator} Management Using Habitat Monitoring and Restoration Planning in Portland Oregon

Fiona Smeaton

Professional Science Master's

Environmental Science and Management (ESM)

Academic Advisor: Dr. Catherine de Rivera, ESM

Community Partner: Toby Query, Bureau of Environmental Services

Additional Committee Member: Dr. Susan Masta, Biology 


\section{Preface}

Pollinators are essential to the health and continuation of ecosystems across the planet. The keystone ecological services provided by pollinator species are irreplaceable and have allowed plants and animals, including humanity, to survive, grow, and thrive. We benefit from the fruits of their labor every time we leave the house, or sit down for a meal, never realizing how tenuous our ecosystem might be. The conversion of pollinator habitat to human use, and resulting impact of habitat loss, is among the greatest threats to these industrious creatures and a key focus of this study. As the march of progress converts prairies and grasslands to agricultural use or other human development, invaluable pollinator populations are being forced to the brink by damage or total loss of habitat. While there is a growing movement amongst farmers to keep pollinator-friendly acreage, the loss of habitat has greatly outpaced this movement, especially for native species. As our population, and therefore landscape, continues to trend towards increased urbanization it is important to understand how we can create and maintain healthy urban pollinator networks, and that we demonstrate to the public the full worth and reward of the mutualistic relationship between humanity and pollinators.

Using a case study approach with site by site comparison of urban pollinator populations in Portland Oregon, this research highlights the management needs essential to planning an urban restoration project aimed at benefitting the greatest amount of native insect pollinators. This goal requires synthesis of the relevant background research, which is presented in Chapter 1 of this document. There is a wealth of knowledge out there and sifting through it all to find urbanspecific information can be daunting. Chapter 2 explores the field work and analysis used to understand how best to recommend improvements to each local urban site. Specifically, it provides data analysis from monitoring performed on a selection of City of Portland's Bureau of Environmental Services (BES), and Tualatin Hills Parks and Recreation properties in the summer of 2019 in order to demonstrate how the process could take place. To demonstrate how targeted pollinator monitoring can inform what restoration is needed at an urban site or network of sites, I provide data analysis... This research is meant to provide advice on how to monitor an urban site with low diversity and activity for a natural area with low biological activity in order to plan for restoration practices that will increase productivity by making it more conducive for pollinators. It is also meant as an educational tool. There is still so much to be discovered about the world of pollinators: ongoing monitoring and observation along with incorporating new science are essential to protect them in an ever-changing world.

This collection of materials aims to provide the guidance needed to find a project site, perform the necessary preparatory work and site monitoring in order to determine the best future management strategies. I hope that this will provide clarity on supporting insect pollinators specifically in city settings with climate conditions of the Pacific Northwest. Thank you for taking the time to learn about the incredible world of insect pollinators. I hope, after reading this case study you are moved to observe, protect and support these keystone species wherever you can. 
Table of Contents

I. Abstract

II. Chapter 1: Literature Review

A. The Urban Ecology of Bees

B. Background

1. Role of Insect Pollinators in Natural Ecosystem Dynamics

2. Ecosystem Services of Insect Pollinators

3. Threats to pollinators

a. Habitat Loss and Fragmentation

b. Neonicotinoid Insecticides

c. Diseases and Pathogens

d. Climate Change

e. Non-native and Invasive Species

f. Genetic Diversity

g. Compounding Impacts

4. Native Bees of Oregon

a. Identification

b. General Phenology

c. Life Cycle of Solitary Bees

d. Solitary versus Social Bees

e. Ground versus Above Ground Nesters

5. Note on Non-Native Honeybees

6. Oregon Native Pollinator Habitat

7. Invasive and Non-Native Plants as Pollinator Habitat

III. Chapter 2: Case study: Site Comparison Study

A. Case Study Introduction

Research Questions

B. Methods

Community Partner and Site Selection

Site Descriptions and Timeline

Pollinator Surveys at Sites

a. The Xerces Society protocol

b. Morphogroup Descriptions

Collection Cups- Pinning and Identification

Soil Samples

a. Graduated Cylinder Test for Texture

b. Organic Matter Oven Bake Test

Determining Acreage of Sites for Morphogroup-Area Relationship

Taking a Transdisciplinary Approach to Pollinator Habitat Restoration

C. Results

Xerces Monitoring Results 


\section{Plant-Pollinator Networks}

Monthly Activity

Soil Table Results

Morphogroup-Area Relationship

Collection Cups Results

\section{Discussion}

\section{E. Conclusions}

Research Question Analysis

IV. Acknowledgments

V. References

VI. Appendices

1. Useful contacts and trainings

2. Useful plant and pollinator ID guides

3. Additional Tables and Figures

\section{Abstract}

Loss of habitat is a major factor in the decline of insect pollinators. Much of this loss can be attributed to monoculture farming, which is prevalent in Oregon. Depending on the crop this approach to agriculture can create food deserts for native pollinators and presents dangerous exposures to pesticides. The resulting loss of habitat creates an opportunity for research on urban pollinator restoration. Many untapped land sources in urban environments may be improved to support a diverse abundance of pollinators. In this case study I wanted to understand what native bees and other insect pollinators could be observed at varied urban sites across Portland, Oregon, and what floral resources they utilized. I performed pollinator monitoring at 8 sites in the summer of 2019 with assistance from Portland State University (PSU) and community volunteers. Using a variation of The Xerces Society Monitoring Protocol, which organizes bees into 10 morphogroups, we collected observational data on existent pollinators and their use of floral resources. Additionally, collection cups (traps filled with soapy water) were set at five of the sites in order to illustrate which morphogroups may have been present when we were not actively monitoring. This information allowed for deeper analysis of factors that may be supporting or hindering pollinator populations in these urban sites. This monitoring revealed that there are multiple different morphogroups of native bees present at these sites. Many of these native bees as well as flies, wasps and butterflies are utilizing floral species that are non-native and often considered invasive and which typically are the dominant floral resources at these sites. 


\section{Chapter 1: Literature Review Introduction}

\section{A. The Urban Ecology of Bees}

Bees are declining largely due to habitat loss and fragmentation from urbanization. Landscapes that used to be dominated by open meadows and grasslands are now transformed into miles of concrete and asphalt. As insects move across the landscape they are faced with new sets of challenges. The urban gradient describes the transition from natural lands to rural to urban spaces. It is an ordering of sites based off their relation to buildings and infrastructure. Identifying areas within the urban gradient that can support wildlife can have major implications in our future climate and human well-being (Blair, 1999) (Hernandez et al., 2009).

Urban habitats have been shown to have a wide bee diversity as long as there are appropriate floral resources (Plascencia, 2017). It is more important than ever to focus on urban spaces as the loss of habitat in agricultural and rural regions is causing a decline in plant reproductive success through pollination services. One way to mitigate these declines is to investigate urban spaces that may support insect pollinator populations. Cities with gardens can be a kind of sanctuary for biodiversity in bee and plant species (Plascencia, 2017). Local habitat quality is the most valuable aspect of supporting pollinator diversity in the city (Bates et al., 2011).

Urban spaces have this great potential for successful pollinator habitats. Vacant lots can be transformed into landscapes that serve a specific ecological purpose (Nassauer, 2014). School campuses, backyard gardens, bioswales and city parks are just a few examples of possible pollinator habitat that could make a difference in stabilizing declining populations. As long as these sites are pesticide free and provide nesting and floral resources there can be successful populations of native pollinators (Jordan et al., 2019).

\section{B. Background}

\section{Role of Insect Pollinators in Natural Ecosystem Dynamics}

Insects in general provide a hugely important and often overlooked service in natural ecosystem dynamics. They appear in multiple trophic levels as "providers, eliminators and facilitators" (Miller, 1993). This means that when they are under stress and populations are destabilized or eliminated from an ecosystem there will be cascading effects. This is especially evident with insect pollinators, which provide a vital ecosystem role. Insects pollinate flowers by visiting the reproductive parts of flowers and transporting pollen from male stamen to female pistils that then take in the pollen to the ovary for fertilization (Faegri \& Van Der Pijl, 2013). Plants in the angiosperm phylum (Anthophyta, the flowering plants) are all dependent upon pollination for reproduction. A majority of these angiosperms are dependent on animals for pollination (Hu et al., 2008). Many of these flowers have even adapted their appearance to better suit insect pollinators (Rudall, 2020). This mutualistic relationship is often driven by climatic conditions, floral fragrance and temperature impact the structure of plants reproductive structures (Thien et al., 2000). It is currently accepted that $80-90 \%$ of flowering plants rely on animals for this pollination service (Ollerton et al, 2011).

Plant communities are dependent on pollinators in order to stay healthy and productive (Mader et al, 2011), (Steffan-Dewenter \& Westphal, 2008). Without insect pollinators, many 
plants are left without the necessary service required for reproduction. Plants will still continue to bloom, sometimes for decades with it not being apparent why they are declining, until it is observed that pollinators are absent and therefore seed production is not taking place (Mader et al., 2011). Protecting sensitive plants from extinction requires more than just restoring their habitat, it necessitates a deeper understanding of the pollinators with which they have coevolved (Ollerton, 2017).

\section{Ecosystem Services of Insect Pollinators}

Humans are dependent on the ecosystem services that pollinators provide. Every third bite of food consumed by a human comes from a plant that was insect pollinated (Hatfield et al, 2012). There would not be the wide diversity of foods in humans' diet if not for these pollinators. This is why understanding their decline and strategizing methods for their recovery is more essential than ever. The value of having insect pollinators visiting food crops such as those in community gardens is insurmountable. Community gardens have been growing in popularity and have been provided as a possible solution to people living in food deserts in urban spaces, as food insecurity can be mitigated by the local harvests of community gardens (Corrigan, 2011). Not only do community gardens provide healthy foods to lower income neighborhoods but they are also very educational, therapeutic and provide a sense of community for many people (Firth et al., 2011), (Egli et al., 2016). The success of these community gardens in providing fruitful yields is highly dependent on insect pollinators and a diversity of these insects is likely to increase fruit harvest (Albrecht et al., 2012). Additionally, exposure to nature within the city has a multitude of ecosystem services that are amplified in areas that support pollinators. Services such as air filtration and rainwater interception are very beneficial for urban residents and can be seen in pollinator habitats through the plant species selected (Bolund \& Hunhammar, 1999).

\section{Threats to pollinators}

Insect pollinators are facing a wide array of threats that become even more dangerous as they combine. The most serious risks are habitat loss/ fragmentation, exposure to herbicides and insecticides, diseases, pathogens and climate change (Danforth et al., 2019), (Vanbergen et al., 2013). The decline of honeybees has been well studied and often referred to as colony collapse disorder, however, less is known about the reactions of native bees from these combined negative impacts (Kluser et al., 2010). Bumble bee species have been shown to be in decline in Europe and Asia and new studies show this consistency in North America (Camerson et al., 2011). Native solitary bees are understudied and research about their population and possible declines is still in its infancy (Danforth et al., 2019). One study done by the International Union for the Conservation of Nature (IUCN) produced a report documenting the European Red List of Bees (Nieto et al., 2014). This was one of the first studies to show serious decline of solitary and ground nesting bees and to show that this decline is due to not just one threat but a multifaceted web of threats that need to be addressed (Danforth et al., 2019). Figure 1.1 shows the cumulative threats to native pollinators each of which is detailed below. 
Figure 1.1 Cumulative threats to native pollinators (Danforth et al., 2019)

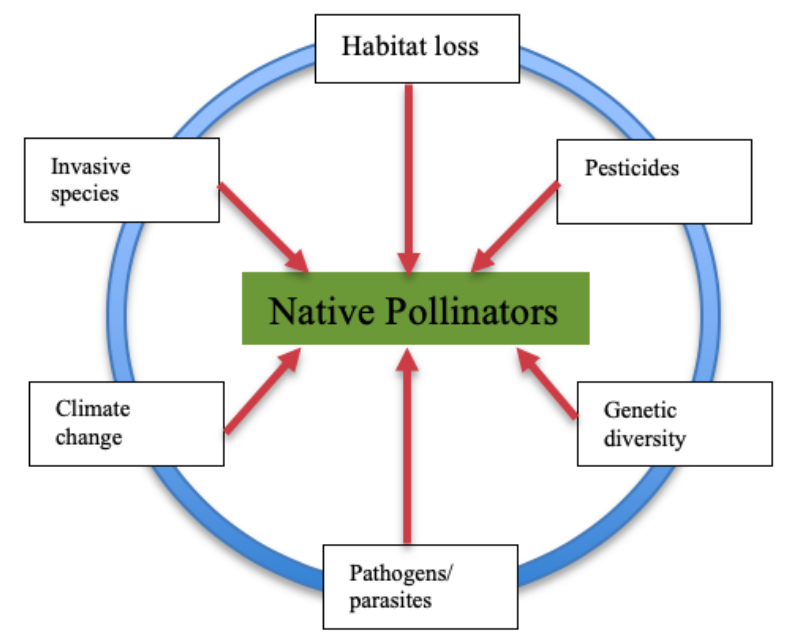

\section{a. Habitat Loss and Fragmentation}

Urbanization and agriculture have a critical impact on gene flow and reproductive success of plant species and their corresponding pollinator species. Disruptions in the landscape can cause declines in the success of these species. Historically pollinators in the Pacific Northwest have had access to acres of continuous plains of prairies, meadows or grasslands filled with native diverse floral species (Bartuszevige et al., 2012). Now the native bees of Oregon are facing threats from the increased fragmentation and vanishing of this continuous landscape with which they evolved (Kimoto et al., 2012). Modern agriculture has a major influence on native bee species. Where there was once a diversity of floral resources there are now rows of single crops that bloom at a specific time and then fruit all at once, causing a period of time where bees do not have any plants in which to forage (Kremen et al., 2002).

Suitable habitat, including appropriate soils and other resources for nesting, is crucial for bees and can be created in urban areas to mitigate habitat loss. The majority of generalist insect pollinators are opportunists when it comes to disturbed habitats (Hernandez et al., 2009). Due to building needs, cities often clear out large trees and shrubs that obstruct usable space. Such clearing of woody plants can similarly happen along roadsides especially for visibility reasons. In these now disturbed lots and roadsides ruderal plant species are able to colonize and spread. Following this, many native pollinators will take advantage of these new floral resources and persist in habitats that were not suitable for them previously (Harrison \& Winfree, 2015). There are cavity nesting bee species that have adapted to built-environments such as buildings or fencing (Danforth et al., 2019). Hence, urban areas can support at least a minimal number of pollinators and can support even more by increasing floral resources and the number of plots.

\section{b. Neonicotinoid insecticides}

One major threat that insect pollinators are facing is exposure to chemicals used in herbicides and insecticides. New studies have emerged frequently over the past few years documenting the effects of certain sets of chemicals on bees (Iwasa et al., 2004), (Di Prisco et al., 2013). However, this research is almost exclusively done on social or eusocial bees, more specifically honeybees and bumble bees (Danforth et al., 2019). There are many unknowns about 
the effects these chemicals are having on solitary bees. There is a specific set of chemicals that have been shown to be the most harmful to bee species (Alkassab et al., 2017). These are called neonicotinoid insecticides and are nicotine based with the idea that they would be more organic than previously used organophosphate insecticides, which showed significant negative impacts on bird and mammal species (Fishel, 2005). Two of the most documented and damaging neonicotinoid insecticides are Imidacloprid and Clothianidin.

While these insecticides are more notoriously used in agriculture, they are still very present within urban green spaces. Clothianidin, for example, is a neonicotinoid insecticide primarily aimed at targeting sucking insects like aphids, thrips, moths and beetles on food and non-food crops (MDH, 2016). This insecticide specifically is used as a systemic, foliar spray or seed treatment. It is used most frequently in soy and canola plants but can be used in fruit and leafy greens as well as ornamental nursery plants (De Perre et al., 2015). As a systemic, clothianidin is taken up by the roots of plants that are exposed to treated soil and the chemical is therefore transferred into the stems, leaves and flowers of the plant (Lawrence et al., 2016). It is even transferred into the pollen and nectar of the plant. Applying this insecticide requires machinery that can produce a large amount of dust. This dust, which is contaminated with clothianidin, can spread and land on aquatic or terrestrial flora and fauna (Georgiadis et al., 2012). Insects flying through this dust at the time of production can be exposed to lethal or sublethal amounts even if they never land on a flower (Biocca et al., 2014). Additionally, between runoff and drift the insecticide can be carried to non-target locations and consequently taken up by non-target plants (Pecenka \& Lundgren, 2015). The fate and transport of this insecticide is detailed in Figure 1.2. This figure shows that all appearances of clothianidin in the environment are from anthropogenic sources and that the receptor of the most impacts are terrestrial invertebrates meaning insect pollinators. Clothianidin has an extremely low LD50 for bees, meaning even very small doses of this neonicotinoid can kill $50 \%$ of a local bee population consistently exposed (Danforth et al., 2019).

Figure 1.2: Neonicotinoid Insecticide Clothianidin and how it enters the environment and is consequently transported to terrestrial invertebrates e.g. insect pollinators. (Lawrence et al., 2016), (MDH, 2016)

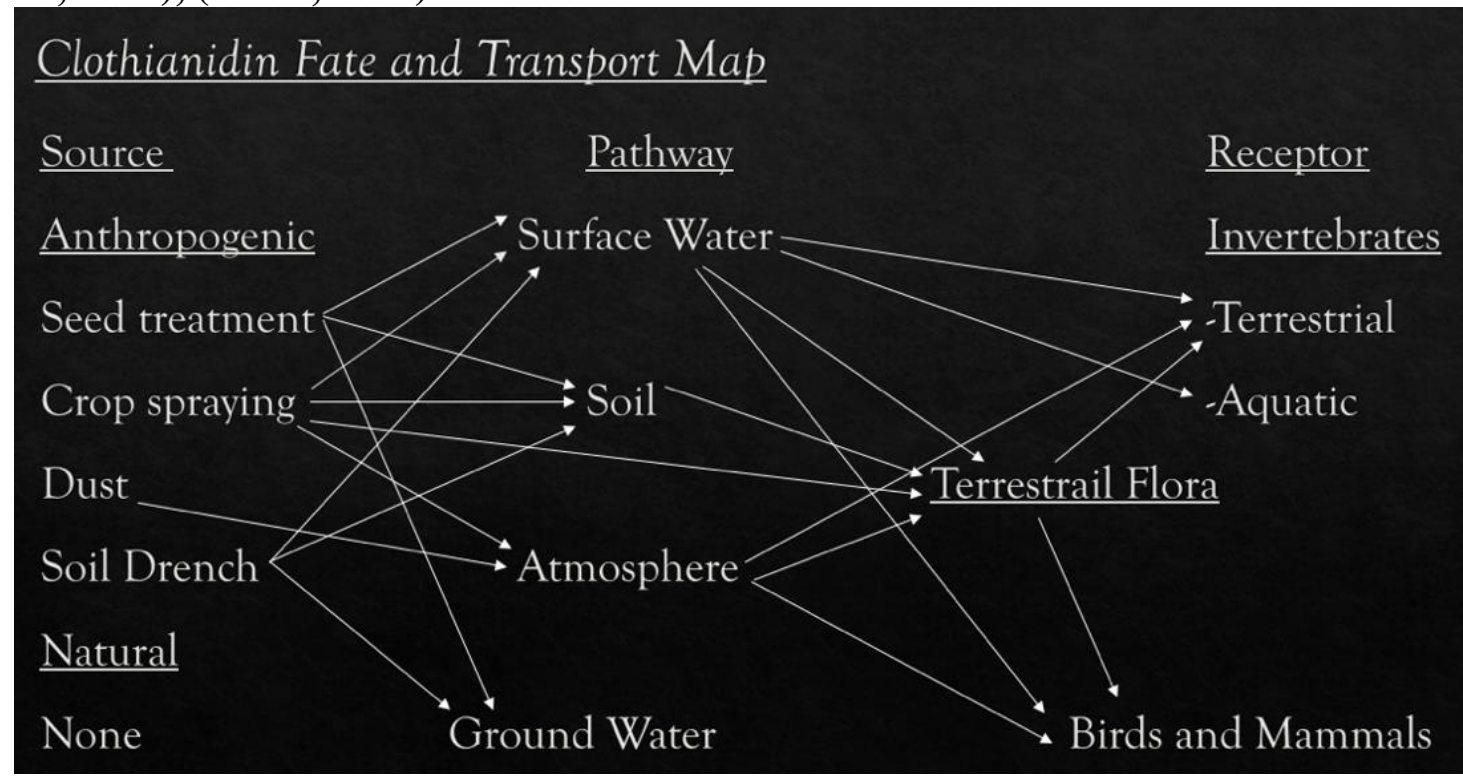




\section{c. Diseases and Pathogens}

There is an increased risk of diseases and pathogens spreading to native bee species from non-native species. As non-native pollinators are introduced to a new environment, as is the case when honeybees or bumble bees are shipped across state lines to pollinate vast monoculture farms, they can introduce native species to pathogens through a process called pathogen spillover (Danforth et al., 2019). Managed honeybees are highly susceptible to pathogens including fungi, bacteria, microsporidia (intracellular gut parasites), trypanosomes (blood parasites) and viruses (Danforth et al., 2019). Studies are emerging to show that there may be a direct connection between these infected honeybees and native bees they come into contact with (Graystock et al., 2016).

Bumble bees have been recorded as having pathogens including Nosema and other viruses after being in contact with infected managed honeybees (McMahon et al., 2015). Additionally, commercially managed bumble bees used for greenhouse crops like tomatoes can also spread pathogens to native bumble bee populations (Danforth et al., 2019) (Graystock et al., 2013). Much less is understood about the link between social and eusocial bees with pathogens and solitary bees. However, there have been cases of native solitary bees showing symptoms of diseases and pathogens as a result of exposure to infected honey or bumble bees (Goulson \& Hughes, 2015). This may appear to be a problem more associated with agricultural settings but as these insects move around a region they can easily enter and spread pathogens with urban pollinators. Additionally, with the increased popularity of backyard beekeepers within city environments native pollinators are more susceptible than ever to exposure to pathogens in urbanized areas (Colla \& Maclvor, 2017).

\section{d. Climate Change}

Yet another threat to pollinator species is the unintended consequences occurring from changes in the climate. Plants and pollinators have coevolved and are dependent upon the other's services (Ollerton et al., 2011). Without floral resources available pollinators will die out and consequently many flowering plants will not reproduce without insect pollination (Miller, 1993). However, as the climate changes new inconsistencies with past patterns evolve and some plants that have coevolved with pollinators are blooming at new times. Offset bloom times limit the times that pollinators are able to actively forage for food (Bartomeus et al., 2011). This adjustment in phenologies for both the plants and pollinators can have a direct negative impact on this essential mutualistic relationship (Bartomeus et al., 2013). This problem is exacerbated when there are fewer plant species for pollinators to forage on. Studies have shown that encouraging diversity of plant species and therefore ensuring differing bloom times, will extend the amount of foraging time for pollinating insects and therefore increase their abundance and richness (Heinrich, 1975), (Havens \& Vitt, 2016), (Mader et al., 2011).

\section{e. Non-native and Invasive Species}

Cities are highly disturbed habitats that are often dominated by non-native and invasive plant species (Francis \& Chadwick, 2015). Whether these plants were brought from other regions intentionally by humans or accidentally they have an impact on how native insects interact with 
the environment. Humans tend to bring horticultural plants with them from their homeland. When these plants are transported across different ecosystems, they can often thrive due to lack of predation, pathogens, or competition from native species (Van Kleunen et al., 2010). This can cause plants to colonize already disturbed habitats much more aggressively than any native plant species would. Even plant species that have not become invasive but just are well adapted enough to survive in a non-native environment may be problematic to native pollinators (Martin $\&$ Stabler, 2002). Some insect pollinators, especially specialists, may not cope well with these non-native or invasive species. However, many pollinators that are generalists, and most urban pollinators are, have become adapted to these plant species and have even come to depend on them for food and nesting resources (Danforth et al., 2019).

Horticultural cultivars have often been manipulated to appeal to the human eye rather than to suit an ecological need. Flowers that have double or triple petals are often much less valuable to insect pollinators than those where they can easily reach the pollen and nectar of the bloom (Knauer \& Schiestl, 2015). Conversely, some horticultural plants can provide more pollen or bloom longer than native plant species extending resources throughout the season (Danforth et al., 2019). The relationships between non-native and invasive species and insect pollinators are incredibly complex and should be evaluated in any restoration project before removal occurs.

\section{f. Genetic Diversity}

A long-standing notion in ecology is that genetic diversity within a population is essential for healthy and productive individuals. Population genetic studies of pollinators are especially important in urban settings where the landscape is highly fragmented and can result in a genetic "bottleneck" (Alves et al., 2011). It is important to understand the immigration and emigration of individuals in a pollinator habitat in order to see how the populations are responding to new environmental factors.

\section{g. Compounding Impacts}

While each of these threats might be manageable on their own, the combined effect of all of them is causing additional stress on insect pollinators. Insects that are already weakened by sublethal pesticide exposure are more likely to harbor pathogens (Vanbergen \& Initiative, 2013). Conversion of land from pollinator habitat to built environments, asphalt, concrete, buildings often requires the use of pesticides that would further weaken populations moving though that area. Habitat fragmentation may cause insects to travel further to forage leading to smaller, weaker offspring (Danforth et al., 2019). The increased amount of invasive species, both plant and insect, lead to additional pesticide treatments. Climate change will likely have the most severe compounding impacts. It will lead to an increase in offset bloom times, foster additional invasive species including pathogens and increase habitat loss through decline in available resources or increased necessity of pesticide treatments (Danforth et al., 2019).

\section{Native Bees of Oregon}

It is estimated that there are at least 500 species of native bees in the state of Oregon; however, data on this exact number is limited (Oregon Bee Atlas, 2018). The Willamette Valley likely has 150-250 species of bees (Jackson, 2019). Learning to identify this highly diverse group 
to species can be daunting and even taxonomic experts struggle with the minute differences that set them apart. Learning to group these species into more manageable categories can help immensely, especially with citizen scientists and volunteers. The following identification guidelines are meant for land managers new to the process of insect identification. It will go over the basics of bee, fly, wasp and butterfly identification. Additional resources can be found in the appendix.

\section{a. Identification}

The main identification guide that was used in this project was The Maritime Northwest Citizen Science Monitoring Guide by the Xerces Society. (https://xerces.org/publications/idmonitoring/maritime-northwest-citizen-science-monitoring)

This guide is focused on native bee identification and so the first step is to distinguish bees from wasps and flies, which can be difficult, especially with mimic species. There are certain characteristics that can help to distinguish these insect groups without having to collect or pin them. Bees have two pairs of wings, large eyes located on either side of their head, and long and bent antennae. Their bodies tend to be rounder, fuller and hairier than flies and wasps. Many female bees have scopa or corbicula that hold large amounts of pollen on their legs or abdomen (Minnerath et al., 2016). Flies tend to have very short antennae, they have large eyes that tend to meet at the top of the head, they only have one set of wings and they tend to be less hairy as well as lack pollen carrying structures, though they do transport grains of pollen that stick to their body (Minnerath et al., 2016). The flight behavior between bees and flies can also reveal their identity. Many flies will hover above or around flowers while bees will not, with the exception of carder bees (Minnerath et al., 2016). Wasps do have two sets of wings but their bodies are narrower and pinched where the abdomen and thorax meet, they have less hair than bees and have coloration directly on their exoskeleton, they also lack pollen carrying structures and only pollinate through few pollen grains that might stick to them after visiting flowers (Minnerath et al., 2016).

\section{b. General Phenology of Bees}

The bee lifecycle is made up of four stages: egg, larva, pupa and adult (Wilson \& Carril, 2015). The time that bees are observed visiting flowers and transporting pollen is a relatively small window of their overall life span. This time frame can range from a few days to weeks and may occur at different times throughout the blooming season. When female adult bees first emerge from their nests they mate and then spend the rest of their life foraging and provisioning for a nest of their own brood (Mader et al., 2011). The timing of their emergence varies greatly across genera and some species will have multiple generations emerge within a single year (Mader et al., 2011).

\section{c. Life Cycle of Solitary Bees}

The life stages of solitary bees vary from those of social bees. The majority of each bees' life is spent in its nest, whether that be underground or in an above ground cavity, and a relatively narrow window of time is spent actively foraging flowers (Wilson \& Carril, 2015). The average amount of time spent foraging is between 10 and 14 days which means that the window of bloom times on flowers they utilize must be synchronized (Danforth et al., 2019). 


\section{d. Solitary versus Social}

Most bees are thought to be social and live in colonies as is the case with honey and bumble bee species. However, under the diverse umbrella of all bee genera many of them are solitary or eusocial. Solitary bees can either live completely alone or form communal nests where females will share a main burrow to individually lay their eggs (Wcislo \& Cane, 1996). Eusocial bees reproductively divide up labor: not all females in a colony will reproduce but rather protect the nest and collect pollen and nectar for the pupating eggs (Danforth et al., 2019). Additionally, social bees operate as a unit and work to raise the young of the colony rather than the individual. Female bees will help to raise eggs that are not their own in order to preserve the genetics of the colony. This can often mean that some females will have longevity within the colony, they may live to raise multiple generations (Danforth et al., 2019). There are many bees that do not fall within the exact parameters of social or solitary. There are bees that form communal nests, as mentioned above as well as eusocial bees, there are also a small portion of bees that are parasitic.

\section{e. Ground versus Above Ground Nesters}

Bee nest placement and nest architecture define vital preferences in terms of habitat. Bees spend the majority of their life inside a nest and the rest of their time foraging and preparing a nest for their own brood. This means that availability of nesting materials is incredibly important in determining where native bees will inhabit and therefore pollinate. The majority of native bees, both solitary and social, nest underground, while others nest in hollow stems of plants or other available cavities. Social bumble bees commonly nest under woody plants or tall grasses (Jordan et al., 2019). Queen bumble bees will often overwinter beneath leaf litter, even in areas where there are no floral resources, before they emerge in spring to start a new colony (Williams et al., 2019).

Soil excavation is by far the most common nesting strategy among solitary bees (Wilson \& Carril, 2015). However, many other solitary bees are wood excavators and will use hollow stems to hide their eggs and will pack their nests with various materials including leaves and mud. Still other solitary bees are renters, meaning they do not excavate a nest but will take their time in picking out an abandoned cavity in which they can create a nest and brood cells. There are other bees that do not fit neatly into one of these categories but rather use a combination of renting and pith nesting (Danforth et al., 2019)

As previously mentioned, ground nesting bees are the most common of the solitary bees and therefore understanding their basic needs will help in practicing the best management decisions. Almost every bee subfamily has a ground nesting bee species. Much is still unknown about the preferences of these ground nesters and it does seem to vary greatly by species. The average cell depth for most bees is 35 centimeters (Danforth et al., 2019). Flooding can be detrimental to some bee nests; however, many are resistant to waterlogged areas. Soil texture can determine which bee species will nest in a specific location and most will show preference to a particular substrate (Cane, 1991). 


\section{Note on Non-Native Honeybees}

The European honeybee is not a native to North America unlike the other wild bees of this guide. They were brought to North America in the early 1600's by European colonizers in order to expand honey production and they quickly spread throughout the United States (Ellis, 2010). They have not evolved alongside the native flora of the Pacific Northwest or the native insects in the area. Honeybees are highly attuned to human activity and are easily managed and transported to fit anthropogenic needs. This means that they can have negative impacts on native wild bees in the area. There have been studies that show that honeybees can deter native bees from a foraging area, especially certain solitary bees that would avoid such direct competition (Goulson et al., 2002). Additionally, the fact that honeybees are non-native to North America provides them with an advantage in the arms race against predators (Shavit et al., 2009).

\section{Oregon Native Pollinator Habitat}

Historically, pollinators in Oregon have depended on prairie or meadow habitat. This habitat has been drastically altered through different urbanization processes. Prairies and oak woodland plant systems in the Pacific Northwest have been highly fragmented and degraded by human use (Bartuszevige et al., 2012). While much is still unknown about how this habitat is evolving in the face of climate change it is known that this ecosystem was once dominant in much of the region. Due to factors including human activity and climate change, prairies have diminished to less than $10 \%$ of the native range (Noland \& Carver, 2011), (Stanley et al., 2011). Prairies are now considered an endangered ecosystem in the Pacific Northwest (Noland \& Carver, 2011). This is incredibly troubling for a wide array of wildlife of the region that depend on this specialized ecosystem. The link between the decline in prairie ecosystems and the decline of insect pollinators is irrefutable.

\section{Invasive and Non-Native Plants as Pollinator Habitat}

Both native and non-native plants can provide vital resources to pollinating insects including many bees. In fact, it may be the case that native plants provide the same amount of bee abundance as non-native plants (Matteson et al., 2011). However, the distinction comes when evaluating the diversity of bee species. While some species may be highly adaptable generalists there are many native bee species that specialize on floral genera and species (Danforth et al., 2019). In an urban setting the majority of bees are generalists and these invasive and non-native plant species may actually be highly beneficial for their survival (Threlfall et al., 2015). Invasive plant species may actually increase the carrying capacity of local native bee populations (Tepedino et al., 2008). 


\section{Chapter 2: Case Study}

\section{A. Introduction}

The diversity of insect pollinators within specific cities is still understudied. This data is meant to address Portland specific questions about pollinators as well as the plant species they were visiting. Studies have shown that continuous monitoring at sites can give a deeper understanding of what pollinators are present and which floral species they have become dependent on (Meiners et al., 2019), (Minnerath et al., 2016). Strategies for collection of these observations vary from evaluating and monitoring to setting lethal collection cups that may help to inform further research. Timing of visitations is also important to note as it will reveal if pollinators are visiting a site due to bloom abundance or their own phenology. The phenology of different pollinator species may vary throughout the season and that may dictate when they are the most active at a site (Danforth et al., 2019). Additionally, bloom times may dictate their visitation (Bartomeus et al., 2013).

Observing the floral associations with insect pollinators, specifically native bees, only tells part of the story for why they may be present at a site. Having available nesting resources is an important factor for attracting bees to an urban environment (Wilson \& Carril, 2015). Testing the soil texture may be a valid indicator as to whether native bees are likely to nest at a site within the city (Cane, 1991). As a site within the city borders impervious surfaces it may deter bees that will not choose to travel along the urban gradient (Hernandez et al., 2009). Therefore, understanding if smaller and more fragmented sites within the city can support a diversity of pollinators could be extremely telling of the future direction of urban management projects.

From this background research, it is clear that further exploring urban spaces as pollinator habitat will help strengthen the fight against their decline. The following questions were investigated in order to better understand existing pollinator behavior at multiple urban sites across Portland Oregon. This site comparison will show the differences in bee populations, grouped into morphogroups, per site. My initial hypothesis is that using the Xerces Monitoring protocol, there will be a higher diversity of pollinators present at sites with more diverse floral resources and furthermore that sites with more abundant blooms and diverse soil textures will support more abundant populations of native bees.

\section{Case Study Research Questions}

Question 1: Using the Xerces Monitoring protocol, what insect pollinators can be observed visiting each site?

Question 2: What floral species did the observed insect pollinators visit?

Question 3: Which months have the most observations of bee morphogroups and how does that compare to the number of floral observations per transect?

Question 4: How does soil texture effect the abundance and richness of observed native bees?

Question 5: How does acreage of each site relate to the total numbers of bee observations and to bee species richness?

Sub question: Do collection cups help to inform the diversity of morphogroups present at each site? 
Figure 2.1: Conceptual Model showing the environmental variables potentially impacting the diversity of pollinator morphogroups within the city of Portland

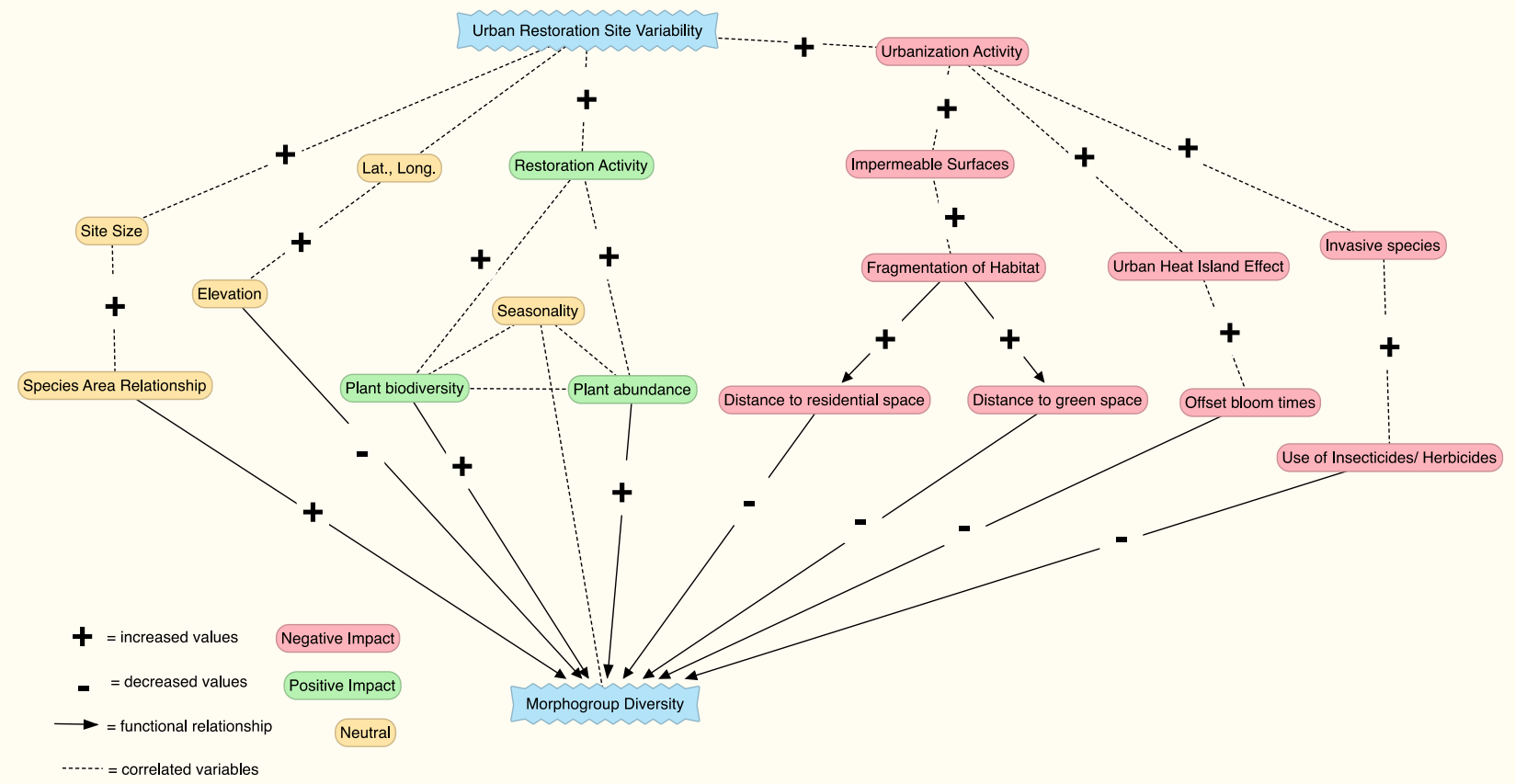

This model shows the relationship between Morphogroup diversity and possible environmental predictors that would indicate pollinator presence at the urban sites monitored. I hypothesize that all of the green impacts will lead to an increase in morphogroup diversity and the red impacts will lead to a decline. Past monitoring studies indicate that available floral resources will improve pollinator diversity at a site while urbanization activities will cause declines (Harrison \& Winfree, 2015). Additionally, I suspect that the yellow impacts will be neutral in their relationship to morphogroup diversity. Since the literature reveals that pollinators are often seen within small city greenspaces, I infer that larger sites will not necessarily contain a greater diversity of morphogroups (Threlfall, 2015).

\section{B. Case Study Methods}

A case study was performed in the summer of 2019 to further investigate these questions and background research. As previously mentioned, there is great potential for pollinator habitat within the city and so this case study is focused on sites that are all within Portland.

\section{Community Partner and Site Selection}

This study was performed in partnership with the Bureau of Environmental Services (BES). BES is dedicated to managing "Portland's wastewater and stormwater infrastructure to protect public health and the environment" (City of Portland, 2020). This cause requires the management of public land for ecological purposes. Strategies for mitigating runoff and chemical leeching in urban spaces requires the planting of native plant species. This has provided 
an opportunity for BES to explore pollinator restoration as many of these sites are open, disturbed habitats.

This study took place at 8 different sites across Portland, Oregon and managed, at least in part, by the City of Portland (Figure 3.1). BES was interested in these sites because there had been casual monitoring of pollinators previously and more data was desired to inform future management decisions. The sites were chosen as areas that had potential to become optimal pollinator habitat. As described below, some of the sites are being actively managed and restored for wildlife benefits and others have been relatively untouched. Figure 2.2 shows the location of all of the sites selected for monitoring.

\section{Figure 2.2: Project site locations}

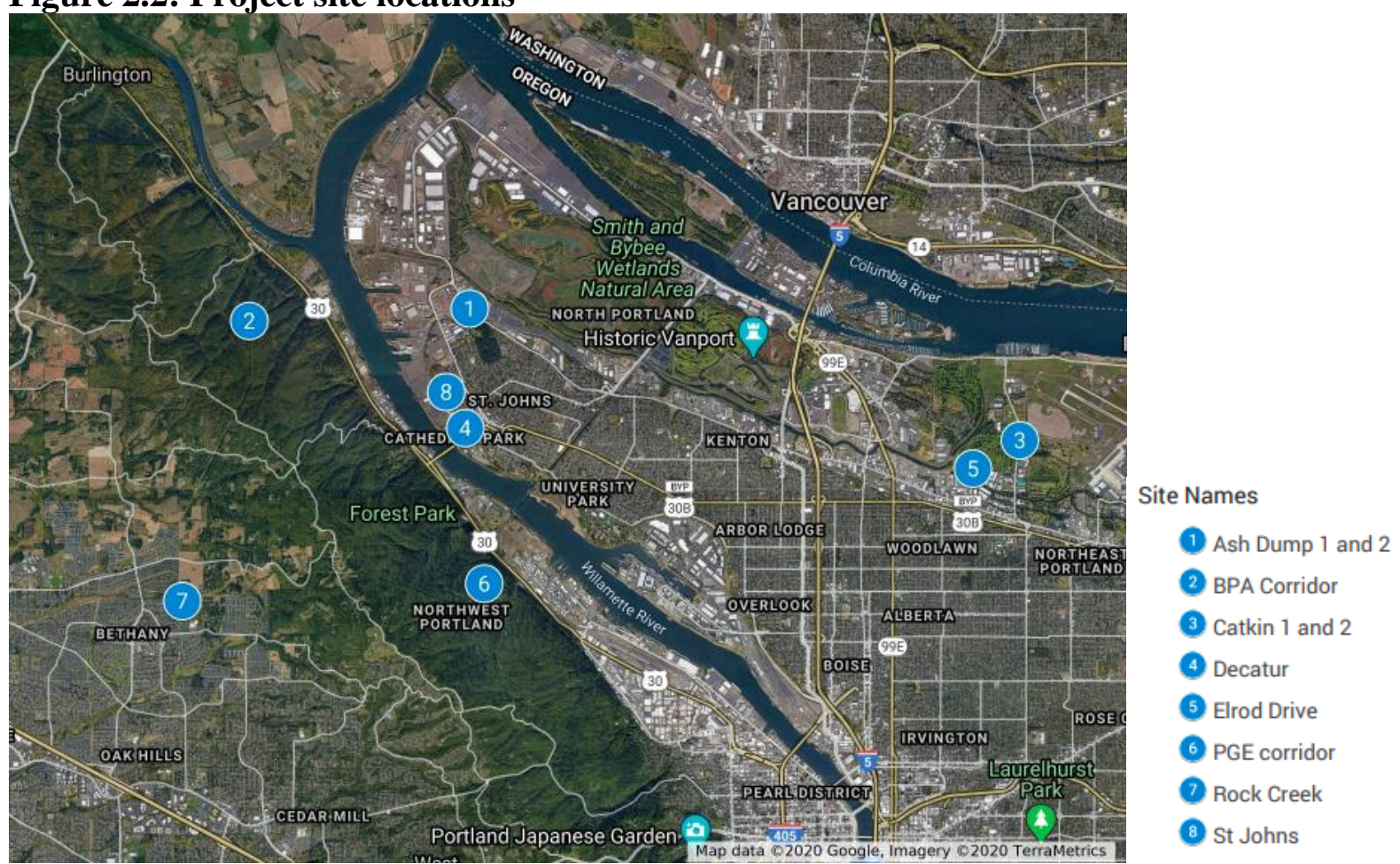

I established one to two linear transects per site, 10 transects in total, for monitoring pollinators and their floral resources. Eight of the transects were 100 meters in length while two transects, Ash Dump 1 and St. Johns Prairie, were 60 meters due to site restraints. Due to the large size of the Ash Dump site and the Catkin site, two transects were established while all other sites had a single transect. GPS coordinates were taken at each site's start and end points and were marked by metal T-posts hammered into the ground. The start and end point of the transects were determined by the site restraints as it bordered impervious surfaces. Additionally, the direction of the transects were determined by the diversity of floral resources, meaning the floral diversity of the site would be adequately represented by the plants on the transect. Each transect was monitored twice per month from May through September 2019. 


\section{Site Descriptions and Timeline}

\section{Figure 2.3: History of ownership and management decisions at BES sites}

\section{SITE MANAGEMENT TIMELINE}

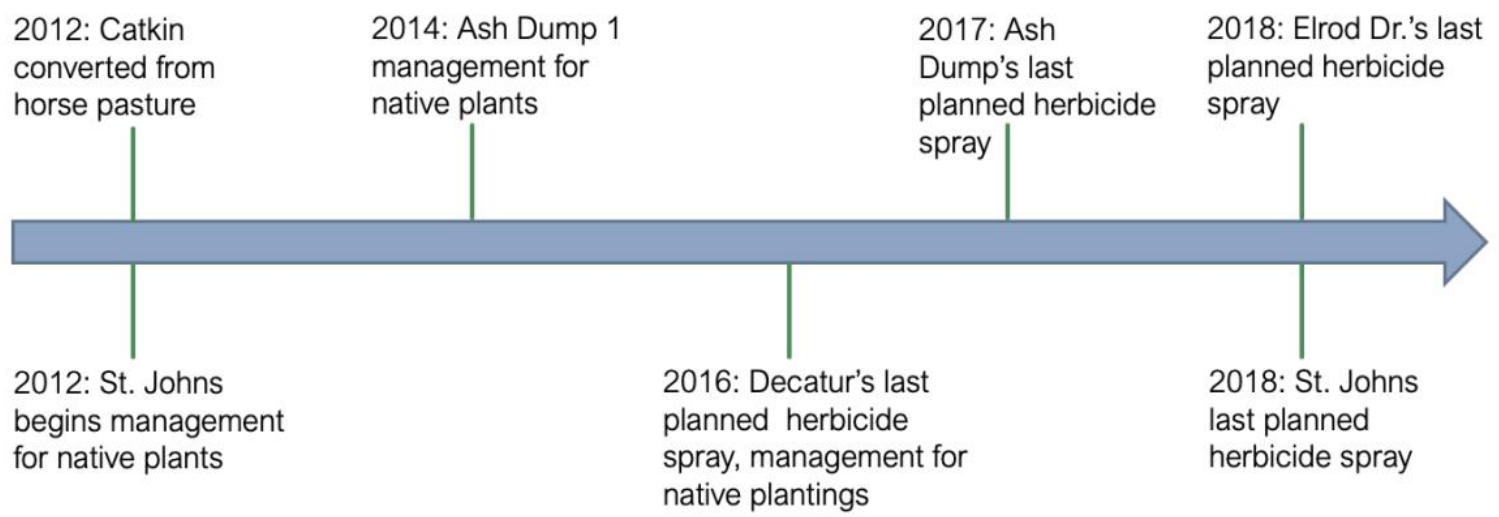

Figure 2.3 details the history of ownership and last herbicide sprays at sites managed by BES. Further known details of all of the sites are as follows. Ash Dump is a converted dump that was filled in from a now nonoperational garbage incinerator, located at the adjacent Chimney Park. It has been managed by BES since 1998. The soil is very compact and rocky, and deep digging will reveal old partly broken-down garbage. The Columbia Slough runs directly northwest of this site. Two transects were established at this site due to the larger size of the site and the varied vegetation present. The first transect has been managed to include some native plant species since 2014. The second transect runs along very poor soil and has not had any native plantings. Neither transect has been sprayed with any herbicide or insecticide since 2017.

The BPA Corridor is located on the northern portion of Forest Park and is managed by the City of Portland's Bureau of Parks and Recreation (PPR). The monitored area is within the Bonneville Power Administration powerline corridor which means it is a clear-cut area within a forest. Monitoring by The Xerces Society has taken place at this site since 2018. Catkin Marsh is a 54-acre property co-owned by PPR and BES. While owned by the city there is no public access. This open site is in the Columbia Slough Watershed and had been horse pasture until 2012. In the past there has been spraying by the city to control introduced plant species. Planting trees in the area has not been successful due to soil conditions and deer and beaver predation.

Decatur is a very small site ( 0.8 acres) located within the Baltimore Woods Natural Area. This site is surrounded by a gravel road and residential houses. This site was last sprayed in 2016 and has had native tree and shrub restoration; however, no management of understory plants has occurred. Elrod Drive is owned by Multnomah County Drainage District and the vegetation is managed by BES. This site runs along an offshoot of the Columbia Slough and is near industrial and residential buildings. It is also near a golf course. This site was sprayed with herbicides in 2013, 2014 and 2018 when a "circle spray" occurred, this is a process of spraying only $2 \mathrm{ft}$ diameter circles around each tree and shrub.

PGE corridor is located on the southern end of Forest Park and is under a cleared area where the Portland General Electric Powerline corridor runs. There have been no active native plantings or seedings. Rock Creek Greenway is located within a suburban residential area in 
Bethany. This site has had some hawthorn removal but very little management since then. There is a paved walking trail near this site but the monitored transect is not open to public access.

St. Johns Prairie is a site owned by BES within 6 acres of natural area and has been managed for native prairie habitat since 2012. Like the Decatur site it is within the Baltimore Woods Natural Area. There are residential houses on one side of the site and industrial activities on the other. Treatment of weeds in the area include a controlled burn and multiple sprays and cuts. The last spray was in 2018 when another agency mistakenly over sprayed and killed most wildflowers.

\section{Pollinator Surveys at Sites}

\section{a. The Xerces Society Protocol}

Monitoring at these sites took place using a protocol developed by the Xerces Society for Invertebrate Conservation which groups pollinators into morphogroups. The Xerces Society for Invertebrate Conservation is an environmental non-profit organization that specializes in educating the public about the importance of invertebrates and researching strategies to support them despite current climate and land use changes. Xerces developed the monitoring protocol for insect pollinators to allow community scientists and others without an entomology background to effectively observe and analyze the richness of insect pollinators at a particular site.

Consistency of monitoring protocols is important when comparing results from varying sites and is therefore followed in this study. Minor adjustments were made to the Xerxes monitoring worksheet in order to fit the confines of this project. For example, insects that were not bees were grouped into butterfly, fly, wasp and other. Additionally, plant species were written down and insect species tallied as opposed to the opposite order being followed in the original Xerces protocol. This adjustment was made in order to focus on the plant interaction and to easily mark multiple insects on a single plant. However, the overall protocol was followed.

To perform this protocol, I visited each site and walked the length of the linear transect at a slow but steady pace noting all of the pollinators I observed. I visited each site twice a month from June through September, and a few practice runs were performed in May. This protocol recommends monitoring on clear days with low wind speeds and when temperatures are above 60 degrees allowing for the most observation activity. Observations were only counted when insects landed on a flower so that they were actively pollinating. The width of the transect was determined as about 5 meters across, this limited observations to a narrow but highly visible path.

\section{b. Morphogroup Descriptions}

The native bees and other pollinating insects of the Pacific Northwest are highly diverse and identifying these animals to species is time consuming and requires experience with capturing and analyzing these specimens. To streamline and simplify this task, the Xerces Society has developed bee morphogroups, "sets of species that look similar and, in some cases, are closely related" (Minnerath et al., 2016). This also allows for patterns to be observed about the pollinator traits such as generalists versus specialist species. Some morphogroups can be categorized as effective generalists when it comes to floral resources while others will not be as 
prevalent if certain flower types are not present. There are ten categories of bee morphogroups and four categories of non-bee morphogroups as shown in Figure 2.4.

Figure 2.4: Insect Pollinator Morphogroups. Insects are grouped into categories based on their appearance including size, color, shape or hairiness.

\section{Oregon Bee Morphogroups}

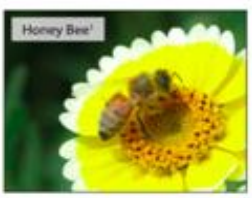

Source: Maritime Northwest Citizen

Science

Monitoring Guide

Native Bees \&

Butterflies, The

Xerces Society
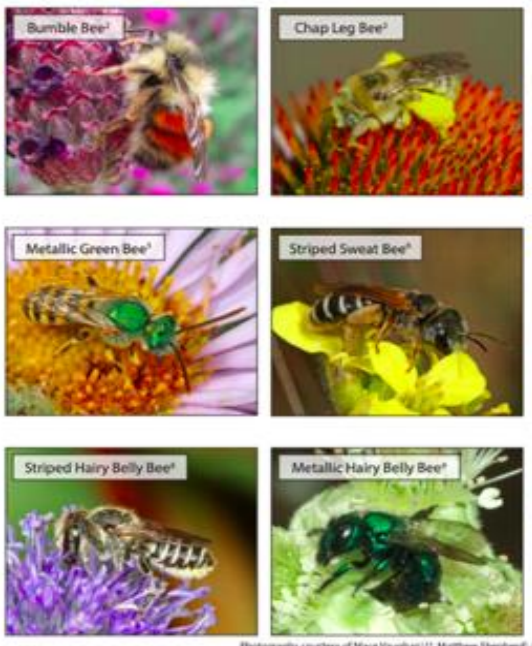

\section{Non-bee Morphogroups}

This includes a fourth group titled "Other" that includes all other insect pollinators (spiders, beetles etc.)
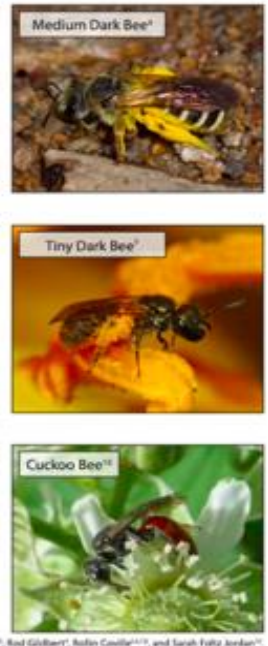
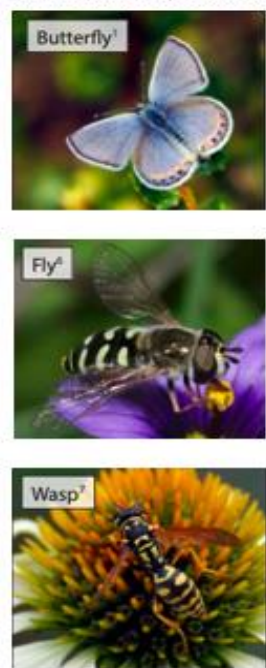

\section{Collection Cups- Pinning and Identification}

The collection of insect specimens for identification should be thought through carefully and the ethical implications should be evaluated before traps are set. While it may seem counterintuitive to kill individual insects in order to further understand and preserve populations of insects, this approach is often used and can advance conservation (Moghaddam et al., 2017). Identification of these small insect pollinators can be very challenging and monitoring of these species in the field will not always provide the most detailed account. Therefore, for this case study insect collection traps were set at BES and Tualatin Hills sites in order to evaluate the effectiveness of using this method as an educational tool and further gauge of morphogroup occurrences. Three collection cups painted blue, white and neon yellow were placed at these sites, filled with soapy water, and left overnight once a month from June through September. Some of these insects were pinned for educational identification purposes while the rest were kept in vials of ethanol to keep the specimens malleable. Due to the scope of this study all pinned insects were only identified to morphogroup. The specimens were grouped by site and month of collection and then placed into their corresponding morphogroup.

\section{Soil Samples}

Out of all bees native to the Pacific Northwest $70 \%$ are ground nesters (Jordan et al., 2019). These bees will spend the majority of their lifespan underground, preparing for the limited amount of time in which they will forage to feed themselves and their young. This means that 
having available nesting sites is an incredibly important factor when considering restoring a site for the benefit of native bees (Danforth et al., 2019). However, the type of soil utilized by ground nesting bees varies greatly by genera and even species (Cane, 1991). Nonetheless, when taking on a restoration project aimed at providing optimal pollinator habitat it is essential to understand the kind of soil present and where it should be left undisturbed or whether new soil should be introduced. Additionally, providing a diverse set of habitat features will increase the probability that bees will nest or overwinter on these urban sites (Jordan et al., 2019). This soil protocol provides a general understanding of the soil type and amount of organic matter on the top layer. There are two components to this protocol:

1. Graduated Cylinder Test for Texture

2. Organic Matter Oven Bake Test

\section{Soil Sampling Protocol}

The optimal number of samples collected for each site to characterize texture and organic matter at a site varies depending on the size, history, and environmental variability of the location. For this study 10 samples were taken at each of the five BES-owned sites. Due to permit restraints the Forest Park and Rock Creek Corridor sites were not evaluated for soil diversity. In order to ensure an unbiased selection of soils collected the 10 samples were randomly selected. Using Google Earth to locate the sites and enabling the plus code grid, the zoom was set to an appropriate level. For these site sizes a code length of 10 digits was established. Each grid square within the project site was assigned a number. Using a randomnumber generator 10 grid squares within the site were selected for soil samples to be collected. The selected squares were stratified so as to encapsulate varying elevation, distance to roads and water bodies.

Once selection sites were determined, soil samples were collected at all five BES sites in the fall of 2019. Each sample consisted of 500 grams of soil, which was collected at surface level. This allowed for extra soil in case of any accident. Samples were placed in gallon sized plastic zip locks that were double bagged to prevent splitting. Each bag was labeled in the field with the site name, date and coordinate code. Each bag was mixed well so as to homogenize the soil sample.

\section{a. Graduated Cylinder Test for Texture}

This test shows the texture of the soil and reveals its dominant type of either sand, silt, clay or organic matter. Using a $100 \mathrm{~mL}$ graduated cylinder I measured out $50 \mathrm{~mL}$ of soil then added water to the $100 \mathrm{~mL}$ line. I allowed any bubbles to settle and filled the cylinder again until it rested evenly at $100 \mathrm{~mL}$. Following this I covered the top of the cylinder with parafilm so that it was airtight. I slowly turned the cylinder upside down for 5 minutes which gave enough time for the soil to mix evenly with the water. Then I let the graduated cylinder rest for at least 24 hours when clear separations appeared. Figure 2.5 shows how the graduated cylinders looked after 24 hours. This data was recorded and then graphed on the soil texture pyramid (USDA Soil Survey Staff, 2014). 


\section{Figure 2.5: Graduated Cylinder test for texture after 24 hours}

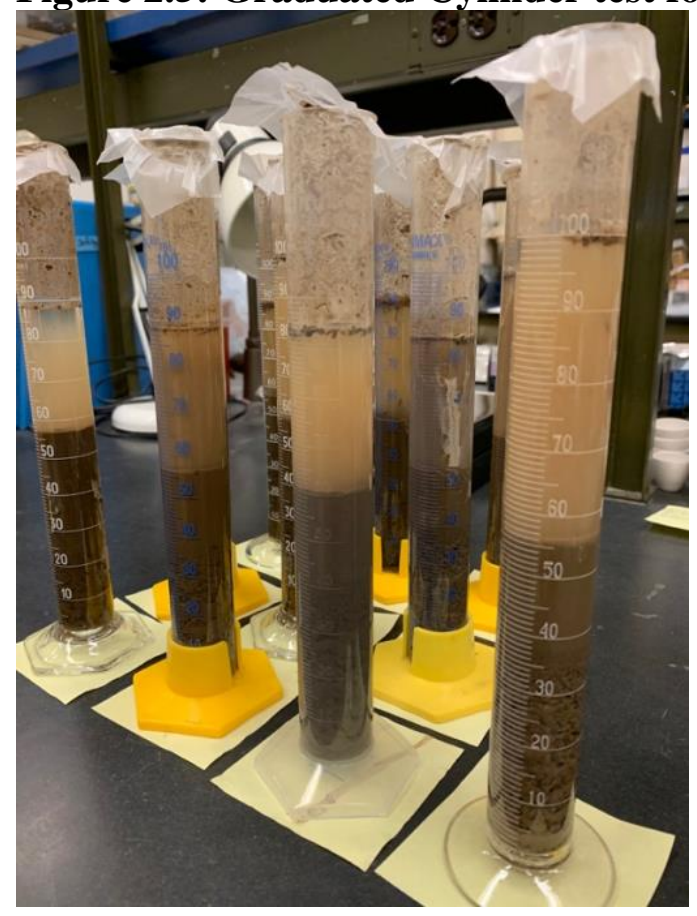

\section{b. Organic Matter Oven Bake Test}

This test gave an accurate measurement of the amount of organic matter present in each soil sample. To perform this test, I measured out 7 grams of soil into individual crucibles meant to withstand the heat of a muffle furnace. These samples first were placed in a drying oven for 24 hours to remove all moisture from the soil. Following this the samples were placed in a muffle furnace for 16 hours to remove any remaining moisture. The weight of these samples was then measured to reveal the organic matter present in the soil. (USDA Soil Survey Staff, 2014).

\section{Determining acreage of Sites for Morphogroup Monitoring-Area Relationship}

In order to observe whether the size of the habitat may have an impact on the amount of morphogroup observations, the area of the site was calculated using an Area of Interest tool on Web Soil Survey. Sites were delineated using their surrounding barriers. I determined a barrier as any urban boundary (asphalt, concrete sidewalk, building etc.), a body of water greater than 10 meters across or a direct shift in habitat type (such as open meadow to golf course or dense forest). The remaining acreage of the sites were plotted against the number of morphogroup observations per site. While the transects did not cover the entirety of the site they provide a sample of pollinator species that were able to utilize these urban sites and yield information on the importance of habitat size to number of morphogroups.

\section{Taking a Transdisciplinary Approach to Pollinator Habitat Restoration}

The potential for vacant lots to become productive in terms of ecosystem services is dependent on a transdisciplinary approach to reaching management goals (Nassauer, 2014). Landscape managers must work in tandem with city planners, businesses owners, government 
officials and neighborhood organizations in order to have effective, resilient results. This project required a great deal of collaboration with community members, city employees and academic professionals. I found that through this teamwork and collaboration I was able to reach the most people and effectively evaluate these varying sites within Portland. It was due to this transdisciplinary approach that I was able to recruit volunteers for data collection, educate the public on my project through a newspaper article and reach land managers searching for strategies to best support pollinators on land they worked on.

\section{Case Study Results}

Question 1: Using the Xerces Monitoring protocol what insect pollinators can be observed visiting each site?

The results in Table 2.1 show all nine of the bee morphogroups that were observed visiting available floral resources along each of the ten transects, with sightings summed across the ten observation periods of summer 2019, and how they varied between sites. Table 2.2 shows the non-bee morphogroups that were observed visiting floral resources during this field season. Note that Ash Dump 1 and St. Johns Prairie were the 60 meter transects compared to the other 100 meter transects. Bumble bees, medium dark bees, tiny dark bees and flies were observed at all sites throughout the monitoring season. Honeybees were the most abundant pollinator at three of the transects, bumble bees were the most common along five of the transects, and tiny dark bees were the most abundant along two of them. In contrast, chap leg bees, metallic green bees, striped hairy bees, and especially metallic hairy bees, were missing from four to nine of the transects and were rare at the remaining ones (Table 2.1). The most abundant morphogroup per site is shown in bold.

Table 2.1: Count of Observed Bee Morphogroups per site across all Months and site totals

\begin{tabular}{|c|c|c|c|c|c|c|c|c|c|c|}
\hline Site Names & Honeybees & Bumblebees & Chap Leg Bees & Medium Dark Bees & Metallic Green Bees & Striped Sweat Bees & Tiny Dark Bees & Striped Hairy Bees & Metallic Hairy Bees & Site Totals \\
\hline Ash Dump 1 & 24 & 9 & 4 & 1 & 1 & 3 & 5 & 2 & & 49 \\
\hline Ash Dump 2 & 6 & 30 & 5 & 3 & 5 & 10 & 34 & & 1 & 94 \\
\hline BPA Corridor & 6 & 23 & 3 & 4 & 1 & 1 & 17 & 1 & & 56 \\
\hline \begin{tabular}{|l|} 
Catkin 1 \\
\end{tabular} & 57 & 67 & & 5 & & 1 & 40 & & & 170 \\
\hline Catkin 2 & 19 & 66 & & 5 & & 1 & 1 & 1 & & 93 \\
\hline \begin{tabular}{|l} 
Decatur \\
\end{tabular} & 127 & 124 & & 9 & 5 & 3 & 28 & 8 & & 304 \\
\hline Elrod Dr & 55 & 19 & & 2 & & 13 & 65 & 1 & & 155 \\
\hline \begin{tabular}{|l} 
PGE Corridor \\
\end{tabular} & & 47 & & 2 & & & 5 & & & 54 \\
\hline Rock Creek & 3 & 6 & & 2 & & & 5 & & & 16 \\
\hline St Johns & 102 & 58 & 8 & 14 & 8 & 14 & 59 & 6 & & 269 \\
\hline Morpho Totals & 399 & 449 & 20 & 47 & 20 & 46 & 259 & 19 & 1 & 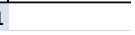 \\
\hline
\end{tabular}

Table 2.2 Observed Non-bee Morphogroups

\begin{tabular}{|l|r|r|l|l|r|}
\hline Site Names & Butterflies & Flies & Wasps & Others & Site Totals \\
\hline Ash Dump 1 & & 11 & $\mathbf{1 5}$ & 6 & $\mathbf{3 2}$ \\
\hline Ash Dump 2 & 1 & 8 & 5 & 6 & $\mathbf{2 0}$ \\
\hline BPA Corridor & 1 & 12 & 6 & 4 & $\mathbf{2 3}$ \\
\hline Catkin 1 & $\mathbf{6}$ & $\mathbf{2 9}$ & 6 & 11 & $\mathbf{5 2}$ \\
\hline Catkin 2 & & 4 & 3 & 2 & $\mathbf{9}$ \\
\hline Decatur & 2 & 8 & 12 & 24 & $\mathbf{4 6}$ \\
\hline Elrod Dr & 1 & 8 & 1 & 3 & $\mathbf{1 3}$ \\
\hline PGE Corridor & & 5 & 4 & 5 & $\mathbf{1 4}$ \\
\hline Rock Creek & & 3 & & 2 & $\mathbf{5}$ \\
\hline St Johns & 2 & 9 & 2 & $\mathbf{3 9}$ & $\mathbf{5 2}$ \\
\hline Morpho Totals & $\mathbf{1 3}$ & $\mathbf{9 7}$ & $\mathbf{5 4}$ & $\mathbf{1 0 2}$ & \\
\hline
\end{tabular}

Table 2.3 shows the morphogroup richness per site, separated out into bee and non-bees. It also presents the number of flowering plants observed along each transect throughout the season as well as the number of different flowering plants. Table 2.4 shows the Shannon Diversity Index (SHDI) for the observed bee morphogroups per site. The SHDI $=-\Sigma(P \times \ln P)$ 
where $\mathrm{P}$ is the ratio of each bee morphogroup's observations to the total. This allows for analysis of the number of morphogroups present at each site: the species richness, as well as the total number of observations: the species abundance. St. Johns Prairie and Ash Dump 2 ranked as the highest bee morphogroup diversity index followed closely by Ash Dump 1 and BPA Corridor, whereas the PGE corridor has the lowest, followed by Catkin 2. Comparing this to table 2.5 which shows the SHDI of plants per transect does not confirm correlation between the two $(\mathrm{r}=$ $0.15, \mathrm{~N}=10, \mathrm{p}=0.673$ ). The sites with the highest SHDI of plants per transect were Elrod Dr., Decatur, Catkin 1 and BPA Corridor. This data shows that the diversity of morphogroups present at a site may be more dependent on abundance of floral resources rather than diversity. During observation periods there was greater activity when there was an abundance of flowers even if there were large patches of the same species. One issue with this, as presented in question 3 , is that when these patches of the same species end their bloom time the pollinators would go with them so likely the diversity of bloom times compared with floral abundance per time is key for sustained pollinator activity.

Table 2.3: Statistics of Morphogroup and plant data

\begin{tabular}{|l|r|r|r|r|r|}
\hline $\begin{array}{l}\text { Site/ Transect } \\
\text { name }\end{array}$ & $\begin{array}{l}\text { Number of Total } \\
\text { Morpho Groups }\end{array}$ & \multicolumn{2}{c|}{$\begin{array}{c}\text { Number of } \\
\text { Bee Morpho }\end{array}$} & $\begin{array}{l}\text { Number of flowering } \\
\text { plants/transect }\end{array}$ & $\begin{array}{l}\text { Number of Plant } \\
\text { Species }\end{array}$ \\
\hline Ash Dump 1 & 11 & 8 & 39 & 14 \\
\hline Ash Dump 2 & 12 & 8 & 48 & 8 \\
\hline BPA Corridor & 11 & 8 & 49 & 15 \\
\hline Catkin 1 & 9 & 5 & 60 & 13 \\
\hline Catkin 2 & 9 & 6 & 42 & 8 \\
\hline Decatur & 11 & 7 & 96 & 15 \\
\hline Elrod Dr & 10 & 6 & 88 & 20 \\
\hline PGE Corridor & 6 & 3 & 28 & 9 \\
\hline Rock Creek & 6 & 4 & 16 & 4 \\
\hline St Johns & 12 & 8 & 89 & 14 \\
\hline
\end{tabular}

Table 2.4: Morphogroup per transect SHDI

\begin{tabular}{|l|r|}
\hline Site Name & Shannon Diversity Index \\
\hline 1. Ash Dump 1 & 1.558701699 \\
\hline 2. Ash Dump 2 & 1.616711771 \\
\hline 3. BPA Corridor & 1.527627317 \\
\hline 4. Catkin 1 & 1.207735522 \\
\hline 5. Catkin 2 & 0.871215158 \\
\hline 6. Decatur & 1.263139608 \\
\hline 7. Elrod Dr & 1.285918831 \\
\hline 8. PGE Corridor & 0.463235506 \\
\hline 9. Rock Creek & 1.305096372 \\
\hline 10. St. Johns & 1.632842021 \\
\hline
\end{tabular}

Table 2.5 Plants per transect SHDI

\begin{tabular}{|l|r|}
\hline Site Name & Shannon Diverstiy Index \\
\hline 1. Ash Dump 1 & 1.974083819 \\
\hline 2. Ash Dump 2 & 1.906316246 \\
\hline 3. BPA Corridor & 2.008138508 \\
\hline 4. Catkin 1 & 2.109073171 \\
\hline 5. Catkin 2 & 1.680538706 \\
\hline 6. Decatur & 2.028236691 \\
\hline 7. Elrod Dr & 2.393136004 \\
\hline 8. PGE Corridor & 1.80571152 \\
\hline 9. Rock Creek & 0.918045918 \\
\hline 10. St. Johns & 1.97867446 \\
\hline
\end{tabular}


Question 2: What floral species did the observed insect pollinators visit?

These Plant-Pollinator Networks provide a visual for the intertwined roles that arise from this mutually beneficial relationship. The width of the arrow describes the number of individuals within the morphogroup that were observed on a specific flower. The width of the box next to the plant species describes the count of floral observations per species per month. More specifically this means the number of times each species was observed in bloom along the transect during monitoring times. All potential pollinator groups, excluding Cuckoo bees since they were never observed, are shown but they only have arrows if they were seen visiting flowers at the site. Any species that is in red is a non-native possibly invasive species, all species or morphogroups in black are native to the Pacific Northwest (MacKinnon et al., 2004).

\section{Figure 2.6: Plant-Pollinator Network Showing the Top 5 most visited plants per month} across all sites by bee morphogroups.

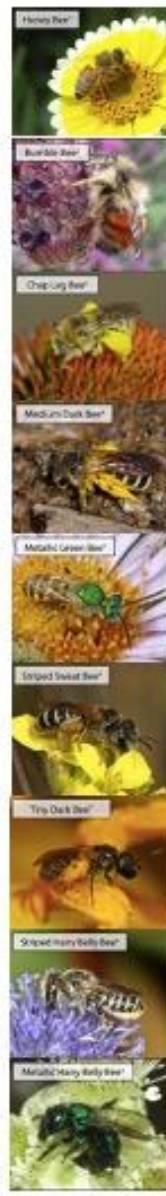

\section{Top five most visited plants across all sites/ per month}

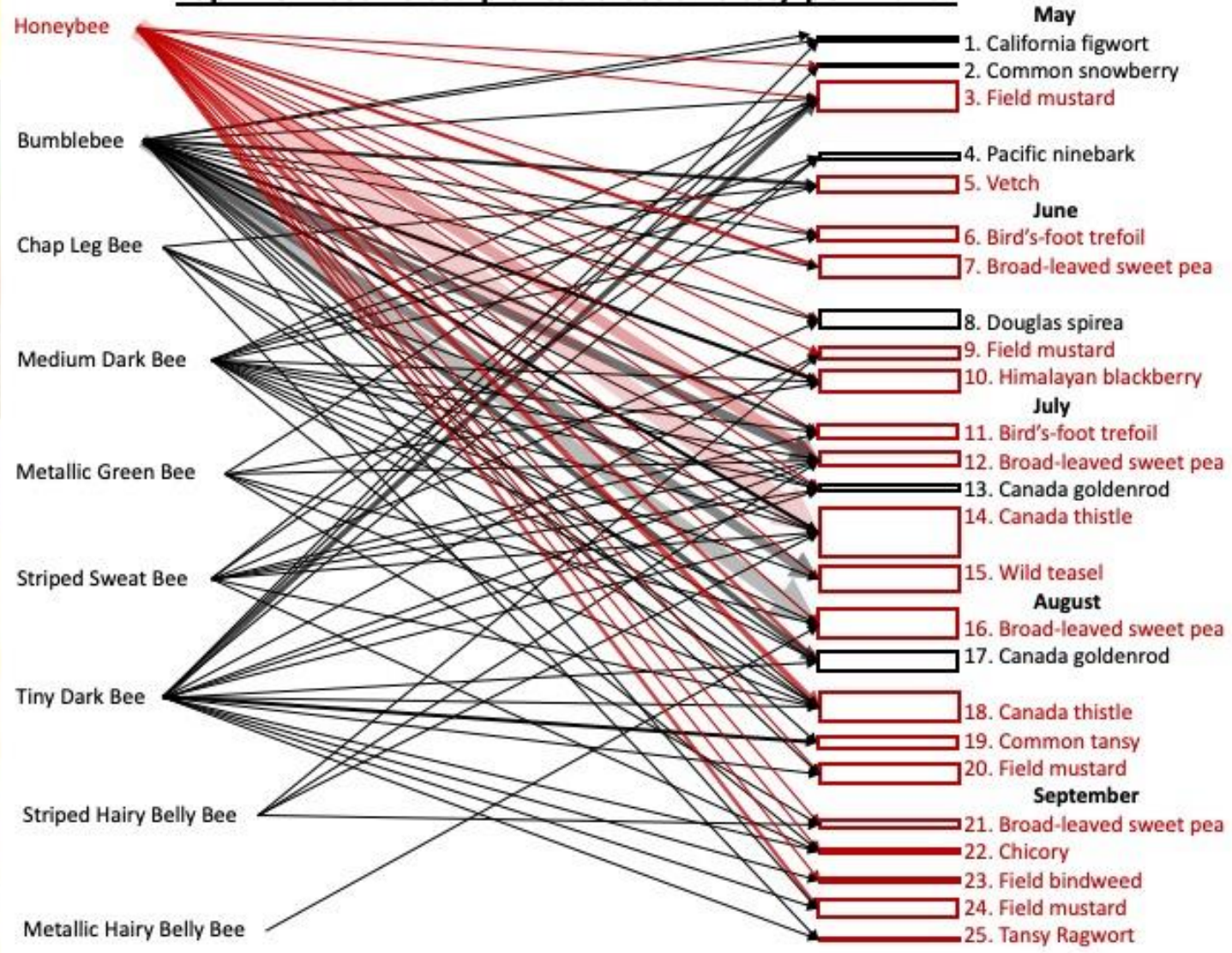


Figure 2.7: Plant-Pollinator Network Showing the Top 5 most visited plants per month across all sites by non-bee morphogroups.

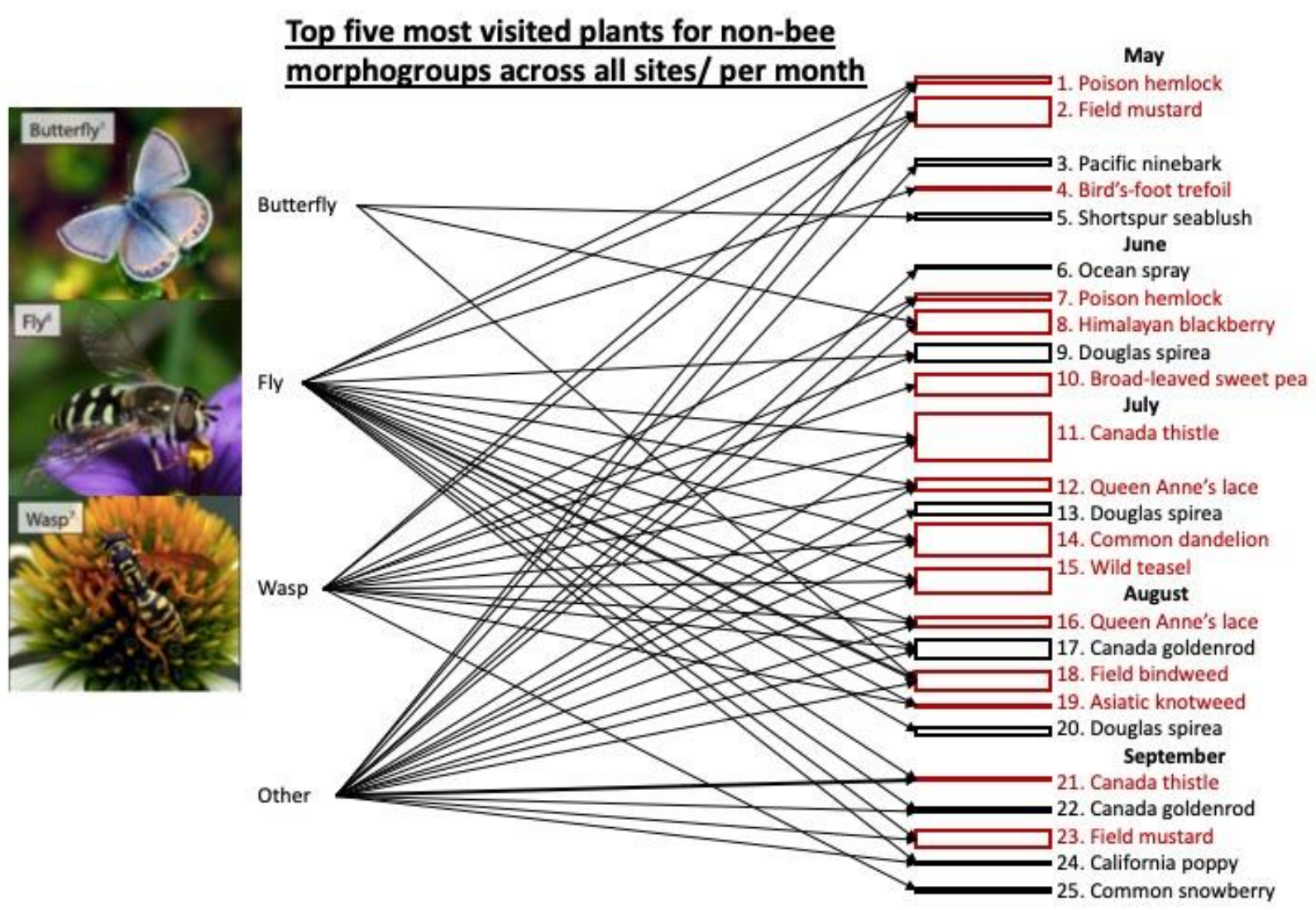

Figures 2.6 and 2.7 show the top five plants per month that had the most visitations by either bees or non-bee morphogroups. It is clear that in both cases pollinators are utilizing a great deal of non-native and often invasive plants. While there are some consistent favorites, the top five plants do differ between bee morphogroups and non-bees. These networks show the incredible interconnectedness between the organisms in these urban ecosystems. 
Figure 2.8: Plant-Pollinator Network of St. Johns Prairie, the site ranked highest in terms of Morphogroup SHDI
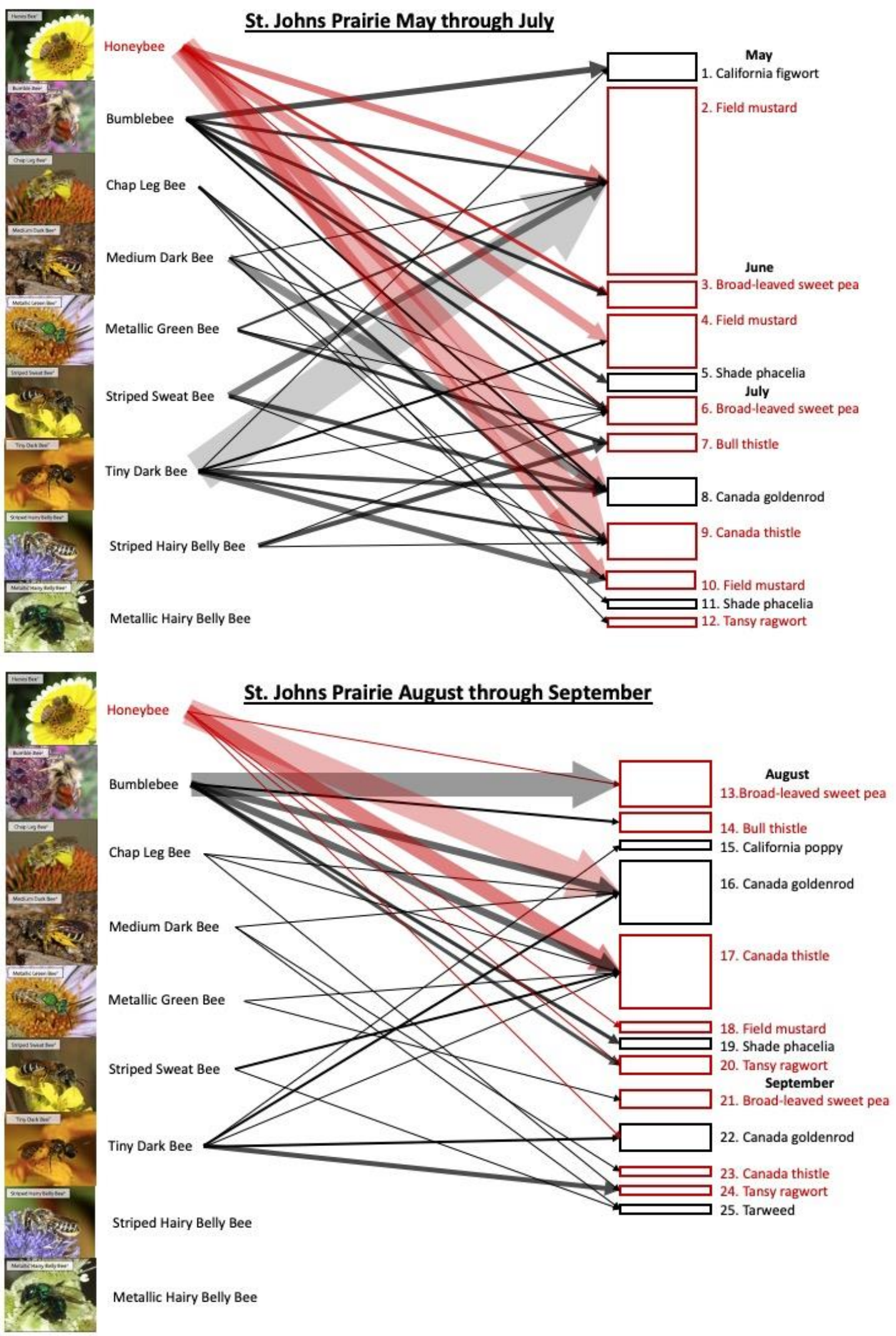

Metallic Hairy Belly Bee 
Figure 2.9: Plant-Pollinator Network of Rock Creek Corridor the site ranked lowest in terms of morphogroup SHDI

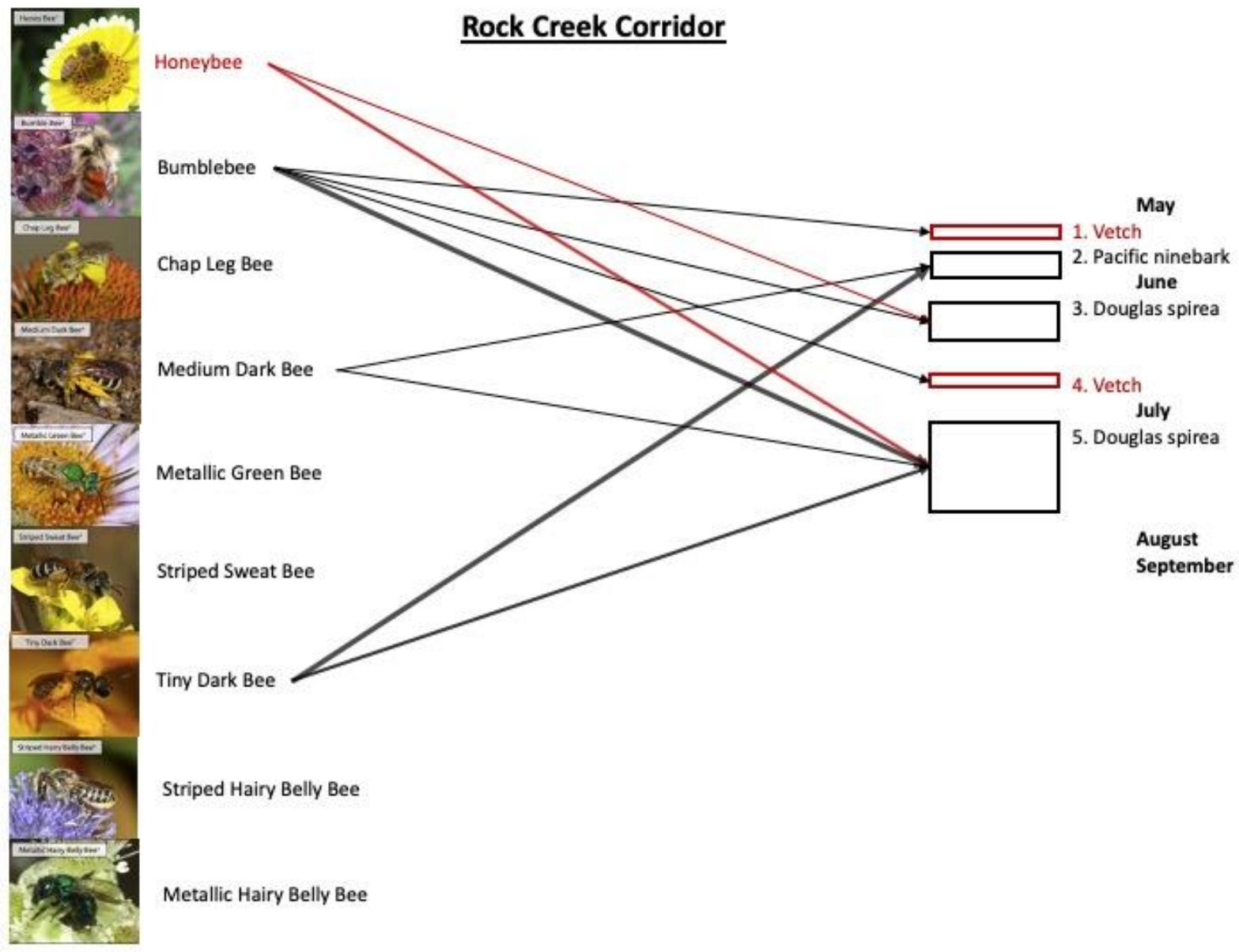

As seen in Figure 2.8, St. Johns Prairie had the highest Shannon Diversity Index value in terms of morphogroup diversity. Conversely, Rock Creek Corridor in Figure 2.9 had the lowest Shannon Diversity Index value. It is for that reason I chose to highlight these two PlantPollinator Networks. The scale on these networks is magnified for closer identification of species patch size, all other rules are the same. These site comparisons show an importance of seasonality in floral resources. While I continued to monitor May through September at both of these sites no bee observations were made at Rock Creek in the later season. It is also clear that lack of diversity and abundance of plant species caused fewer observations of morphogroups within these later months. There may also be an indication that the functional group of the plant has an impact on which pollinators are visiting it. The majority of plant species at the Rock Creek site were woody shrubs, apart from the perennial weed vetch, which may have had an impact on the species visiting it. 
Figure 2.10: Plant-Pollinator Network showing the native bee (meaning all morphogroups apart from honeybee) to native plant species across all sites per month

Native bee to native floral observations

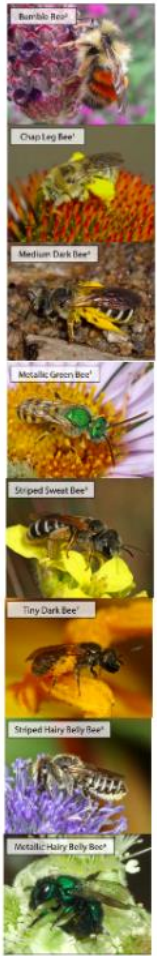

Metallic Hairy Belly Bee

Bumblebee

Medium Dark Bee

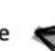

Metallic Green Bee

Striped Sweat Bee

Tiny Dark Bee

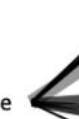

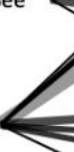

Striped Hairy Belly Bee

\section{May}

1. Blue penstemon

2. California figwort

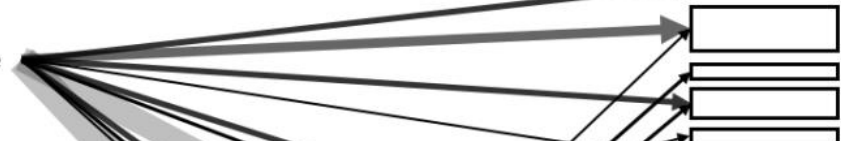

3. California poppy

4. Common snowberry

5. Creeping buttercup

6. Fewflower blue-eyed mary

7. Pacific ninebark

8. Shortspur seablush

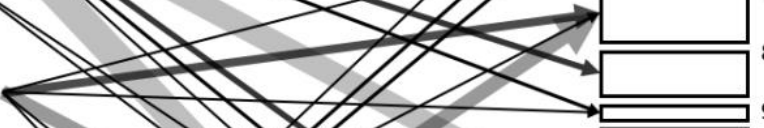

9. Small flower blue-eyed mary June

10. Douglas spirea
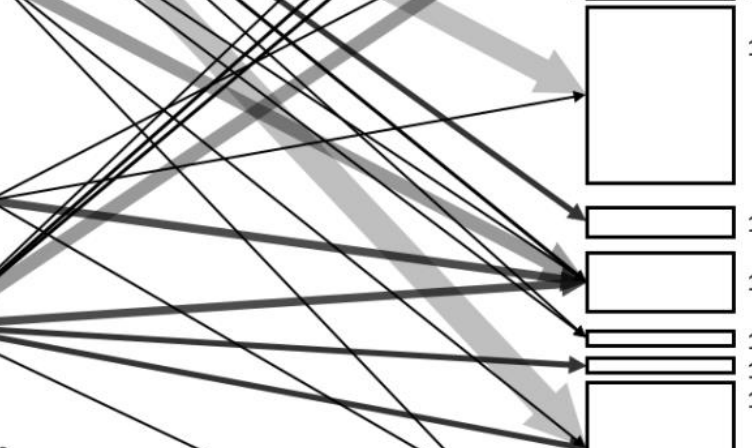

July

12. Canada goldenrod

13. Common snowberry

14. Curlycup gumweed

15. Douglas spirea
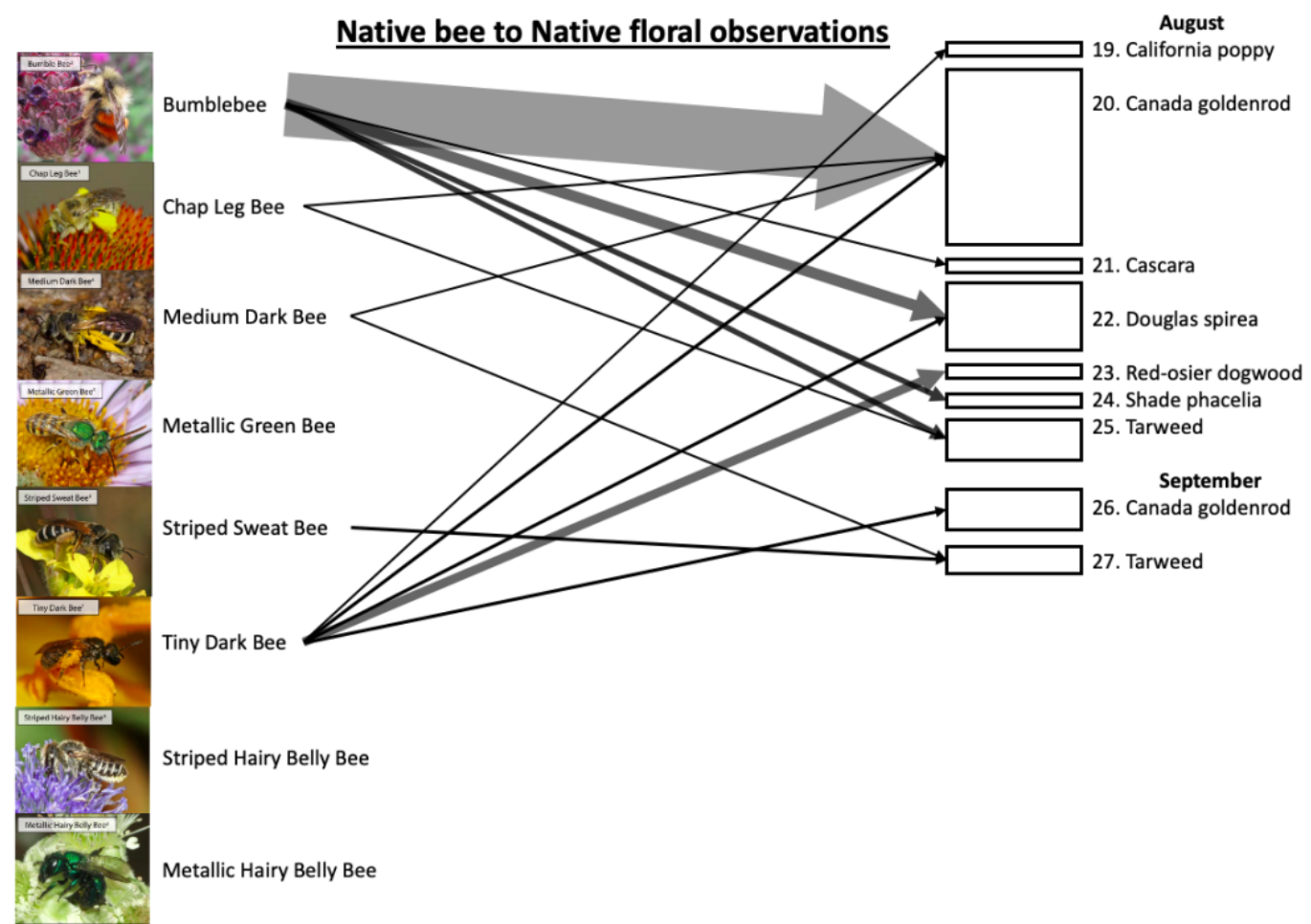

Striped Hairy Belly Bee

Metallic Hairy Belly Bee 
While it is important to realize how these pollinators are utilizing non-native plants, this should not be used to advocate planting them. Rather, land managers should be mindful that they are being used as they strive to better manage the native plants. Figure 2.10 shows the observations of all native morphogroups, honeybees are excluded, to native plant species across all sites per month. This data is important as it shows that native plants were still visited even if they did not have the greatest number of observations. It appears that the abundance of the flowers did have a positive correlation on the number of visitations. All other Plant-Pollinator Networks can be found in the appendix.

Table 2.6: Top Performing Plants in terms of abundance compared to visitation

\begin{tabular}{|c|c|c|c|c|}
\hline Site Name & By Floral Association Abundance & $\%$ & $\begin{array}{c}\text { By Native Morphogroup } \\
\text { Visitation }\end{array}$ & $\%$ \\
\hline Ash Dump 1 & Field Mustard & $41.03 \%$ & Field Mustard & $28.57 \%$ \\
\hline Ash Dump 2 & Chicory & $20.83 \%$ & Field Bindweed & $30.68 \%$ \\
\hline BPA Corridor & Common Dandelion & $46.94 \%$ & Common Dandelion & $48.00 \%$ \\
\hline Catkin 1 & Field Bindweed & $25.00 \%$ & Wild Teasel & $30.97 \%$ \\
\hline Catkin 2 & Birds-Foot Trefoil & $40.48 \%$ & Birds-Foot Trefoil \& Wild Teasel & $32.43 \%$ \\
\hline Decatur & Broad Leaved Sweet Pea & $39.58 \%$ & Broad Leaved Sweet Pea & $68.93 \%$ \\
\hline Elrod & Common Dandelion & $32.95 \%$ & Common Dandelion & $34.00 \%$ \\
\hline PGE Corridor & Himalayan Blackberry & $39.29 \%$ & Canada Golden Rod & $40.74 \%$ \\
\hline Rock Creek & Douglas Spirea & $68.75 \%$ & Douglas Spirea & $53.85 \%$ \\
\hline St Johns & Field Mustard & $33.71 \%$ & Field Mustard & $31.74 \%$ \\
\hline
\end{tabular}

It's important to note how visitation to these flowers ranked in terms of abundance of blooms along the transect. Table 2.6 shows the top performing plants at each site across all months. Only native morphogroups are considered in this analysis, honeybee is removed. The most abundant flower represents the percentage of occurrence against all other floral observations on a transect, for example field mustard was in bloom $41.03 \%$ of the time at Ash 1 but only visited $28.57 \%$ of the time by native bees. The top performer in terms of visitation describes the percentage of visits of all native morphogroups to that flower. At Decatur broad leaved sweet pea was observed in bloom $39.58 \%$ of the time, however, it was visited $68.93 \%$ of the time, basically if sweet pea was in bloom it was visited. There are cases where the plant that had the highest visitation was not the most abundant. This is seen at Ash Dump 2, Catkin 1 and PGE Corridor. 
Figure 2.11 Percentage of Native Morphogroup Visitation to Floral Abundance at Ash Dump and Catkin

Legend: Line graph: Native Morphogroup Visitation

Bar graph: Floral Association Abundance May June July August September Ash Dump 1

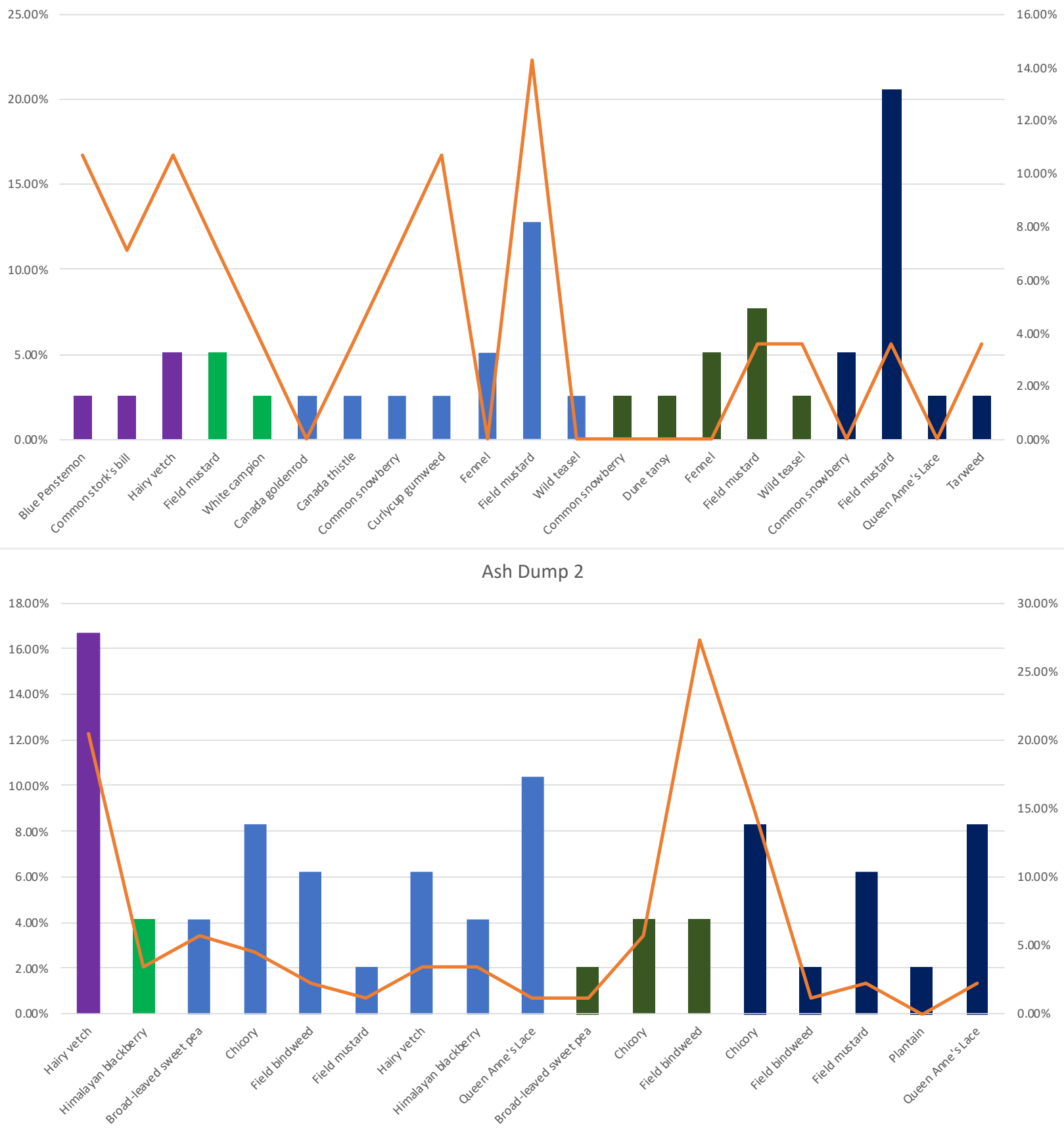



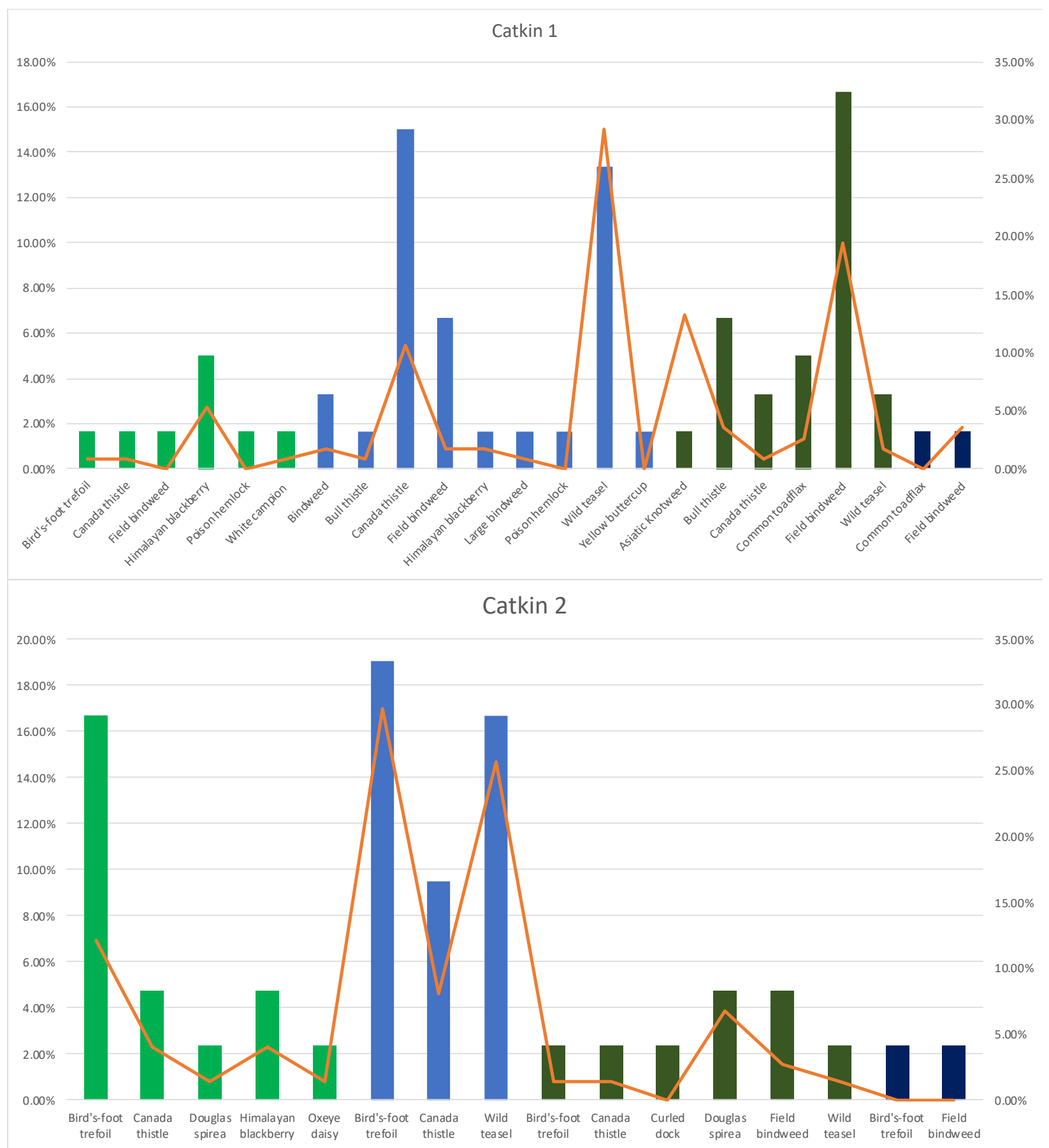

For future management decisions it is imporant to look at site specific data. Ash Dump and Catkin provided an interesting example of abundance to visitation. All other site data can be found in the appendix. In Figure 2.11 the scale bar on the left of these graphs shows the percentage of each flower in terms of its abundance. The scale bar on the right shows the percentage of visitation by native bees to the corresponding flower. There is a clear correlation between abundance and visitation, however, there are distict examples where a flower may have been chosen for reasons other than the fact that it was freqent along a transect. 
Question 3: Which months have the most observations of bee morphogroups and how does that compare to the number of floral observations per transect?

Figure 2.12: Seasonality of Observed Bee Activity

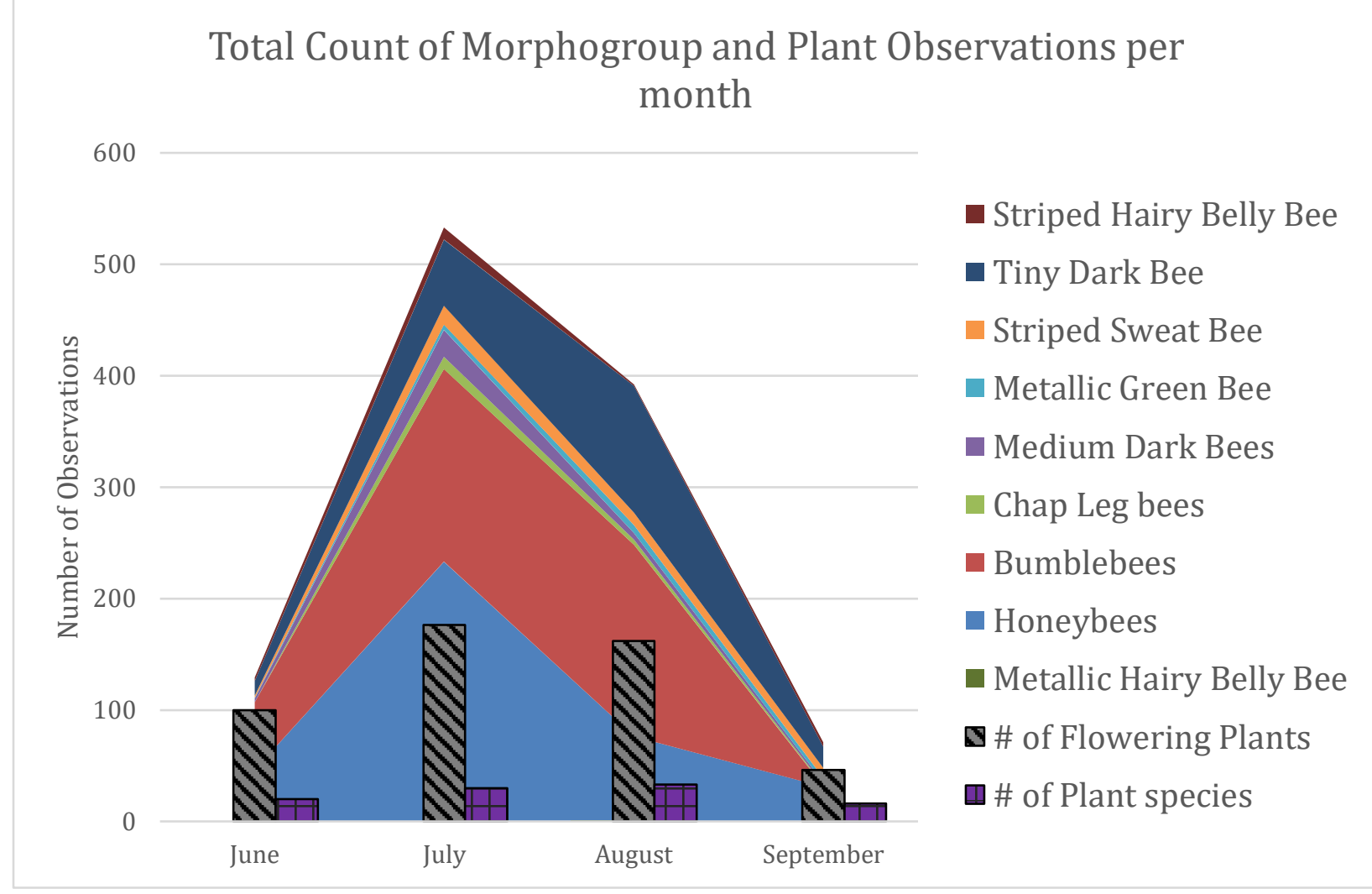

Figure 2.12 shows when the most observations occurred during monitoring months. Since May was not consistently visited across each site it was not included in this analysis. The species richness of flowers was slightly higher in August and the abundance of flowers only dropped a very small degree but the abundance of morphogroups dropped significantly. This may be due to the phenology of the bees; some bees emerge early in the season and will lay eggs and forage early. It is clear that the abundance and richness of flowers is a determining factor in the abundance of morphogroups. Months like September and June had fewer flowers in bloom and therefore fewer pollinator visitors

Question 4: How does soil texture effect the abundance and richness of observed native bees?

Soil texture is an important factor in the type of ground nesting bees that can be supported at a site. Understanding which soil type is most effective for each species is a complex topic that is still very under researched. However, there is still value in evaluating the soil at a site. Figure 2.13 shows how the soils in the five BES sites were similar and all can be described as sandy clay or, for St. Johns, clay. They ranged from 40 to $60 \%$ sand, 38 to 55\% clay, and were all about 5\% (2.5-7\%) silt. St. Johns had the least sand and Catkin and Elrod had the most sand. While it is difficult to tell with just five sites and similar soil types, there was a pattern of fewer ground nesting bee morphogroups in the sandier sites. However, the same pattern does not hold for abundance. 
Figure 2.13: Soil Texture Summary Results (average of 10 samples per site)

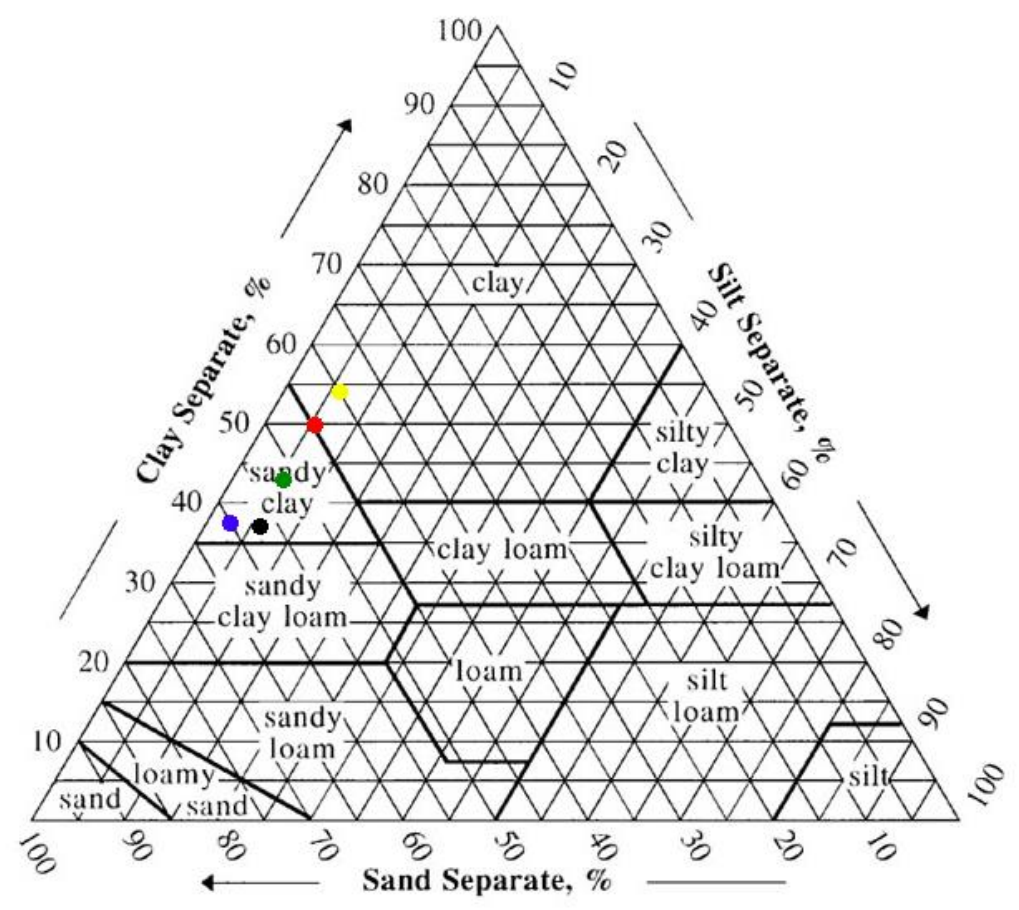
Ash Dump
Catkin
Decatur
Elrod
St. Johns

Figure 2.14: Species abundance and richness of native bees (all morphogroups excluding honeybees) to Percent Clay per site

\section{Percent Clay to Native Bee Diversity}

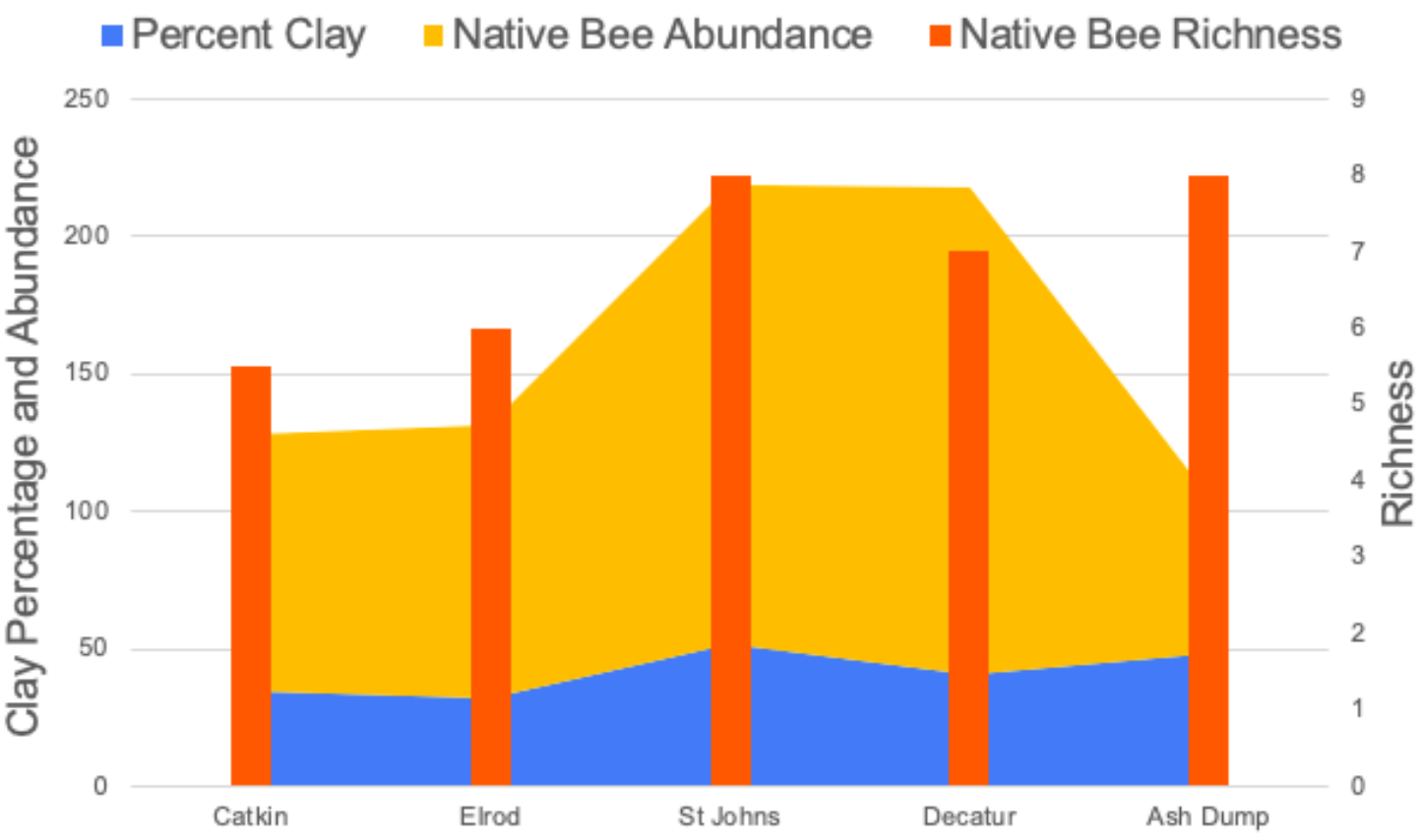


Figure 2.14 shows the percent of clay in the soil against the abundance and richness of native bees (excluding honeybees again). The scale bar on the left shows the percent clay of each site and the abundance of morphogroups. The scale bar on the right shows the richness (number of different morphogroups present regardless of abundance). There appears to be the most diversity of native bees at St. Johns which had the most clay soil. Ash Dump which also had high clay levels had high species richness. This data was all from monitoring so I can't conclusively say whether the soil had any real impact or whether it was just the floral resources, but it was still interesting to see how the soil varied per site and how it may have benefited ground nesting bees.

Question 5: How do the total numbers of bee observations rank in relation to the acreage of each site?

Species Area Relationship (SPAR) describes the number of species present in relation to the size of the habitat they are sharing. While determining the SPAR was outside the scope of this study, I was curious to see how the number of bee observations would look plotted against the acreage of the specific sites. Sites with the smallest amount of acreage ranked highest in terms of number of bee observations. Figure 2.15 shows the number of observations on the $y$ axis against the monitoring site size in acres on the $\mathrm{x}$-axis. This visualizes how the sites rank based off of native bee abundance and honeybee observations. Figure 2.16 shows a closer look at the species richness per site, the number of different morphogroups observed regardless of abundance. Both graphs show that larger sites are not necessary for a diversity of bees. This is encouraging for urban restoration planning; it is clear that even the smallest sites had high visitations. The larger sites actually had fewer observations, however, this is likely due to the fact that the floral resources were more spread out and did not all occur on my transect. This may indicate that having a smaller more isolated site within the city does not necessarily dictate lower observations of bee morphogroups.

There is not an even gradient in the acreage of the sites in that there is one outlier. There is a clear negative trend in the number of observations and the size of the site. This may be due to more fragmentation at the smaller sites allowing for more nesting areas and floral abundance. The sites with more expansive land had less resources per transect which indicates either resources being more spread out or lacking all together. 
Figure 2.15: Morphogroup abundance and richness observations graphed in relation to the acreage of a site

\section{MORPHOGROUP MONITORING-AREA RELATIONSHIP}

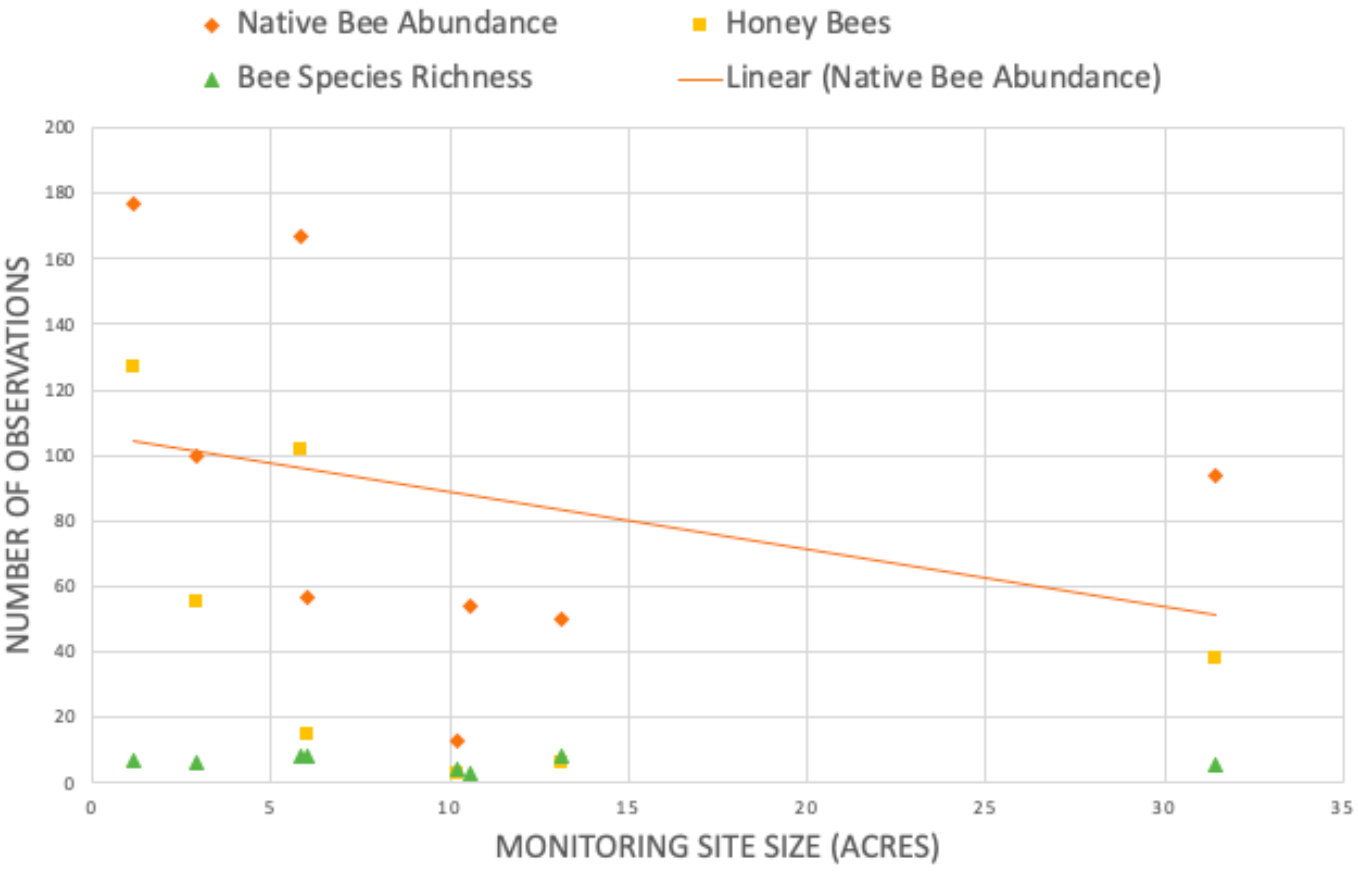

Figure 2.16: Morphogroup Richness observations graphed in relation to the acreage of a site

BEE SPECIES RICHNESS

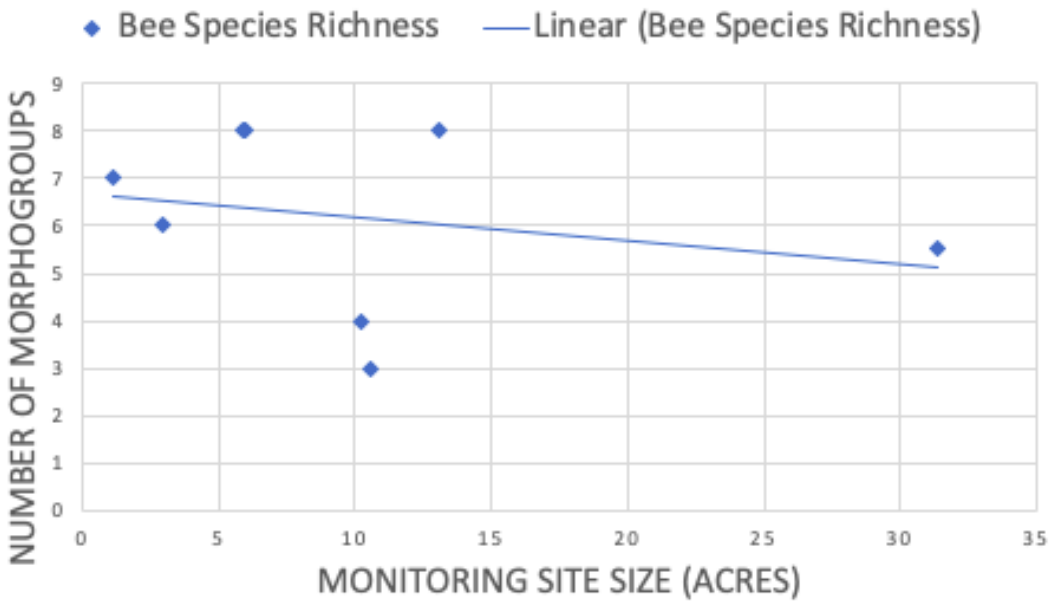

Sub-question: Do collection cups help to inform the diversity of morphogroups present at each site?

This last sub-question was not used much in the majority of my analysis. I found the data from the monitoring protocol more useful and sorting through all of these insect specimens was very time intensive. However, these collection cups were valuable as an educational tool in familiarizing myself and my volunteers with the morphogroups. Furthermore, there were some interesting results from the sorted specimens within their respective morphogroup. It is clear that 
Ash Dump had high abundance and richness of morphogroups especially in September which was interesting as this is when floral observations began to decline. Additionally, it is interesting the to visualize the seasonality trend of diversity. It is almost the opposite of the morphogroup trend, the greatest number of specimens caught were in the early and late months and July had the lowest amount of captures, likely due to floral availability. There were instances where I caught more of a specific morphogroup at a site than I saw while monitoring, this is true of metallic green sweat bees, who were difficult to observe but I did catch them at almost all of the sites I set traps at. Figure 2.17 shows the number of insect specimens captured in collection cups per site and sorted per month. Each specimen was grouped into their corresponding morphogroup.

Figure 2.17: Number of Insect Specimens caught per site and per month Morphogroup Specimens Per Site

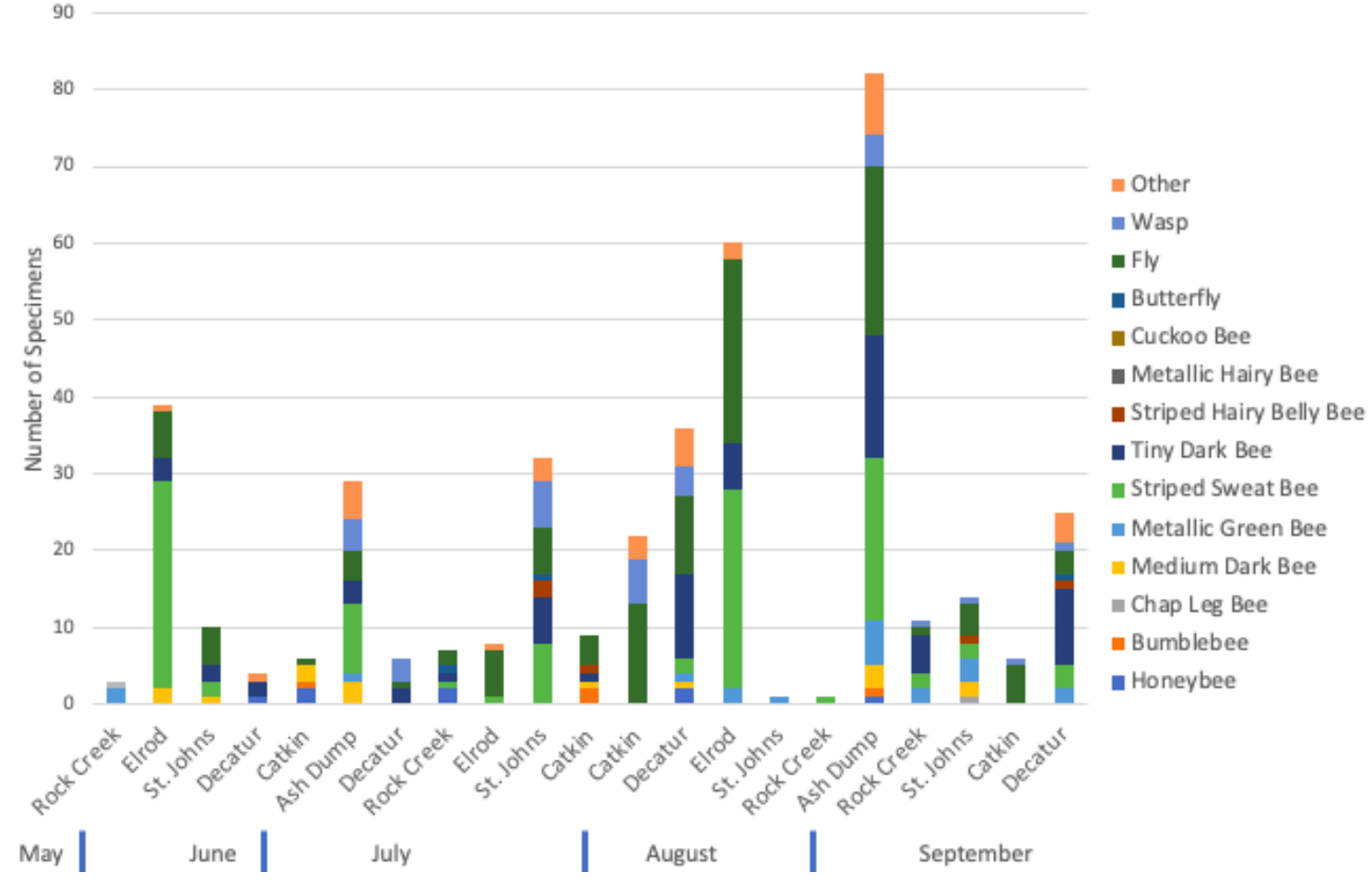

\section{Discussion}

In order to draw strong conclusions about the patterns and preferences of insect pollinators it is essential to monitor for multiple years. There are too many variables involved and preference between insect species is extremely variable. Seasonality plays a distinct role in when pollinators emerge and are the most active. With climate change ever adjusting weather patterns the seasonality of pollinators becomes difficult to predict. Long term monitoring of sites is the best way to assess whether native pollinator populations are declining (Meiners et al., 2019). Site comparisons like this one can provide effective indicators of what factors affect 
pollinators and the data here can serve as a start to long term monitoring that supports more significant conclusions.

Through monitoring in one season I discovered several significant takeaways. Most notably, there are multiple different morphogroups of native bees present at these sites. Many of these native bees as well as flies, wasps and butterflies, are utilizing floral species that are nonnative and often considered invasive; therefore, removal of those species should be weighed against their importance for pollinators. If they are removed, consideration should be given to replacing them with other flowering species that span the times pollinators are active and that are attractive to pollinators. Weather and timing have a major impact on what insects are actively foraging. Honey, bumble and tiny dark bees were observed in all months of this study although sightings of bumble bees diminished in September. Bumble, medium dark and tiny dark bees were observed at all 10 transects at some point in the study season. No cuckoo bees were positively identified in the field. Some pollinators showed an affinity to specific plants if they were available. Canada thistle was overwhelmingly visited by honeybees compared to all other native bee morphogroups. Douglas spirea and teasel were most popular with bumble bees. Queen Anne's lace showed fairly low visitations from bees but was visited by multiple fly and wasp species.

\section{Research Question Analysis}

Question 1: Using Xerces Monitoring protocol what insect pollinators can be observed visiting each site?

This first question sought to evaluate which pollinators may be utilizing these urban sites in order to get an initial grasp on the diversity possible. Monitoring what species are present is an essential first step when performing a restoration project as it will reveal a baseline on which to improve. Table 2.1 revealed the bee morphogroups that were represented at each site. From this initial monitoring year, it is possible to reflect that bumble bees and tiny dark bees may be the most adjusted to urban habitats. This is supported from the number of observations of both of these morphogroups at all sites. Figures 2.8 and 2.9 illustrate the diversity of morphogroups present at a site with a high diversity in bee morphogroups (Fig 2.8) versus a low diversity (Fig 2.9). Hence, in these urban sites three to seven bee morphogroups, representing even more species, were found despite their seeming isolation from other sites and often small size.

Question 2: What floral species did the observed insect pollinators visit?

The pollinator networks reveal a complex set of interactions between insects and the plants they are visiting. Some inferences about pollinator preference can be made from these data although long term monitoring and a controlled preference analysis would be the only way to make conclusive statements about species preference. From this data it is clear that both native and nonnative pollinators are utilizing nonnative and often invasive plant species as well as native ones. Figure 2.7 reveals that the top five most visited plants pooled across all sites per month are overwhelmingly non-native, though of course the non-natives also made up the majority of blooms at the sites. In May two out of the five plants were non-native: field mustard and vetch. These two highly adaptable and widespread plants provided blooms to pollinators while there was little else in full bloom. Early season plants are incredibly important in these urban sites as many species of pollinators will emerge and require sustenance. 
In June, four out of the five most visited plants were non-native: Bird's-foot trefoil, broad-leaved sweet pea, field mustard and Himalayan blackberry. These urbanized sites are highly disturbed and therefore have a high quantity of ruderal plant species. It is clear that insect pollinators in the area have adapted to utilizing these floral resources. In July, again four out of the five most visited plants were non-native. Many of the same species remained including Bird's-foot trefoil and broad-leaved sweet pea, to be joined by Canada thistle and Wild teasel. It is important to note that the non-native honeybees were included in this evaluation. While there were still visitations from native bees to Canada thistle honeybees visited this plant in high numbers. In August, four of the five most visited plants were non-native: Broad-leaved sweet pea, Canada thistle, Common tansy and field mustard. In September, all five of the most observed visitations were on non-native plants: broad-leaved sweet pea, chicory, field bindweed, field mustard and tansy ragwort.

To show the relationship between native pollinators and native plant species only, Figure 2.6 is a network showing monthly activity across all sites. There does seem to be a correlation between the abundance of a plant and the number of bee observations. This correlation was further investigated in Table 2.6. This table which showed the top performing plant in terms of abundance and visitation, helps indicate whether a plant was more valued simply due to the fact that it was so numbered throughout the transect or for some other reason. Plants that were visited more often than with lower abundance may have qualities that deemed them more attractive to native pollinators. In order to confirm these preferences future studies would need to take place in a controlled setting where bees are given choices of blooms.

Question 3: Which months have the most observations of bee morphogroups and how does that compare to the number of floral observations per transect?

This question allowed for an introductory analysis of seasonality of insect pollinator morphogroups. By graphing the number of observations per month against the number of flowering plants per transect it is clear to observe a correlation between these two variables. Pollinator activity is due to both their phenology determining their emergence rates and availability of floral resources. For the summer of 2019, the most observations of morphogroups were recorded in July followed closely by August. June and September saw a distinct drop in observations. May was removed from this analysis as several of the sites were unable to be monitored during that month. As noted above, it is important to have flowers available at each site throughout this timespan and currently early spring and late summer blooms are mostly provided by non-native plants at these sites.

Question 4: How does soil texture effect the abundance and richness of observed native bees?

Testing the soil texture and organic matter content of these sites allowed for a representation of the diversity of soils present. The goal of addressing this question was to provide the basis for analysis of ground nesting bee habitat. As previously mentioned, $70 \%$ of bees native to Oregon nest in the ground (Jordan et al., 2019). However, native bees have adapted to a wide array of soil textures for their nests. By sampling 10 collections of soil for each site and taking the average it is possible to begin to understand the dominant soil type and therefore which bees might be more likely to nest there. Previous research has indicated that a soil substrate is preferred to the majority of bees (Cane, 1991). This means that soil textures that are drastically sand or clay may cater to specialist bees rather than generalists (Danforth et al., 
2019). My results showed an increase in native bee species richness and abundance in soils that were clay and yet still had high percentages of sand. This would support the claim that a balanced soil substrate may foster the most generalist ground nesting bees.

Question 5: How do the total numbers of bee observations rank in relation to the acreage of each site?

The purpose of this question was to begin to evaluate the weight of habitat size on the number of morphogroup observations. Each transect was placed in the middle of a disturbed habitat or on the edge of an urban boundary. By measuring the size of each site and comparing results to the number of observations analysis can begin on morphogroup-area relationship. My results indicated that smaller sites are able to support an abundance and richness of bee morphogroups. This may be due to an edge effect; smaller spaces may have a greater concentration of blooms along their edge versus large spaces that would have spread out resources. A more even gradient of sites in terms of acres would be needed to make definitive conclusions about habitat size to morphogroup diversity. However, the important takeaway here is that small fragmented sites within the city hold value to insect pollinators. They are present in these spaces and foraging on available blooms. This further advocates for urban pollinator enhancement programs.

Sub-question: Do collection cups help to inform the diversity of morphogroups present at each site?

I found the use of The Xerces Society monitoring protocol more beneficial for my data analysis than collection cups. The specimens that I collected were useful and were a great learning opportunity, but the monitoring was the most influential for my analysis and it didn't harm any bees. I found the monitoring more inducive to my results and easier to learn and teach to volunteers. Additionally, it allowed for floral analysis. It is important to note that this protocol is becoming widespread. It is more effective to have a consistent protocol to follow so that we can do this site by site analysis. That is how we will really understand what is going on with these amazing creatures that we are so dependent on and that is how we will find the best strategies to protect them.

\section{E. Conclusions}

Overall, this case study shows the necessity of background research and site monitoring before the implementation of large-scale restoration work on urban pollinator sites. It is important to understand what the diversity of pollinators is and what resources they may be using before management actions are taken. This case study fosters hope for the success of pollinator projects within the city, even on sites that have very little acreage and poor soil conditions. It also presents the land manager with the essential evidence that pollinators may be utilizing floral resources that are non-native and often invasive at a site. This means that removal of these species must be thought through carefully and replacement resources must be researched and planted in a timely fashion. My initial hypothesis was that using the Xerces Monitoring protocol, there will be a higher diversity of pollinators present at sites with more diverse floral resources and furthermore that sites with more abundant blooms and diverse soil textures will support more abundant populations of native bees. This hypothesis was supported by my results. It is evident that urban spaces can provide valuable habitat to insect pollinators that are facing a multitude of threats due to human activity and it is therefore our responsibility to take action with this 
knowledge and implement diligent research, pre- restoration monitoring in order to reach the best strategies for their success in the future.

\section{Acknowledgments}

I would like to thank all of the amazing people that made this project possible. Thank you to my community partner Toby Query at the Bureau of Environmental Services office. He is the one who brought forth this idea for pollinator monitoring and through his dedication to the project I was able to consistently monitor and evaluate pollinators on BES land. Thank you to my advisor Catherine De Rivera for all of her guidance and encouragement. She was consistently supportive of my desire to work with pollinators and always provided the resources and contacts I needed to succeed. Additionally, I would like to thank my additional committee member Susan Masta for sharing her vast knowledge about bees. She helped me with insect identification, resources for pollinator habitat and foraging preferences and gave essential input on the methods for my study.

Additionally, I would like to thank The Xerces Society for Invertebrate Conservation. This non-profit organization has an incredible amount of online resources available to the public. The monitoring protocol that they created was so useful for my project and allowed me to collect a vast amount of information without the painstaking process of identifying insects to species.

Thank you to all of the land managers that I coordinated with at Portland Parks and Recreations and Tualatin Hills Parks and Recreation. A very special thank you to all of my wonderful volunteers who assisted me with data collection. I had such amazing support from both community and Portland State volunteers. Whether they provided help through notetaking, being an extra set of eyes to spot pollinators or just through showing excitement to learn, they all helped me to finish data collection feeling positive and hopeful. Lastly, I want to thank my wonderful friends and family for their constant support and encouragement. I could not have done this without them.

\section{References}

1. Albrecht, M., Schmid, B., Hautier, Y., \& Müller, C. B. (2012). Diverse pollinator communities enhance plant reproductive success. Proceedings of the Royal Society B: Biological Sciences, 279(1748), 4845-4852.

2. Alkassab, A. T., \& Kirchner, W. H. (2017). Sublethal exposure to neonicotinoids and related side effects on insect pollinators: honeybees, bumblebees, and solitary bees. Journal of Plant Diseases and Protection, 124(1), 1-30.

3. Alves, D. A., Imperatriz-Fonseca, V. L., Francoy, T. M., Santos-Filho, P. S., Billen, J., \& Wenseleers, T. (2011). Successful maintenance of a stingless bee population despite a severe genetic bottleneck. Conservation Genetics, 12(3), 647-658.

4. Bartomeus, I., Ascher, J. S., Wagner, D., Danforth, B. N., Colla, S., Kornbluth, S., \& Winfree, R. (2011). Climate-associated phenological advances in bee pollinators and beepollinated plants. Proceedings of the National Academy of Sciences, 108(51), 2064520649. 
5. Bartomeus, I., Park, M. G., Gibbs, J., Danforth, B. N., Lakso, A. N., \& Winfree, R. (2013). Biodiversity ensures plant-pollinator phenological synchrony against climate change. Ecology letters, 16(11), 1331-1338.

6. Bartuszevige, A. M., Kennedy, P. L., \& Taylor, R. V. (2012). Sixty-seven years of landscape change in the last, large remnant of the Pacific Northwest Bunchgrass Prairie. Natural Areas Journal, 32(2), 166-170.

7. Bates, A. J., Sadler, J. P., Fairbrass, A. J., Falk, S. J., Hale, J. D., \& Matthews, T. J. (2011). Changing bee and hoverfly pollinator assemblages along an urban-rural gradient. PloS one, 6(8).

8. Blair, R. B. (1999). Birds and butterflies along an urban gradient: surrogate taxa for assessing biodiversity?. Ecological applications, 9(1), 164-170.

9. Biocca, M., Fanigliulo, R., Gallo, P., Pulcini, P., Perrino, C., \& Pochi, D. (2014). Assessing dust drift from dressed seeds by air sampling. Aspects of Applied Biology, 122, 103-111.

10. Bolund, P., \& Hunhammar, S. (1999). Ecosystem services in urban areas. Ecological economics, 29(2), 293-301.

11. Camerson, S. A., Lozier, J. D., Strange, J. P., Koch, J. B., Cordes, N., Solter, L. F., \& Griswold, T. L. (2011). Patterns of widespread decline in North American bumble bees. Proceedings of the National Academy of Sciences, 108, 662-627.

12. Cane, J. H. (1991). Soils of ground-nesting bees (Hymenoptera: Apoidea): texture, moisture, cell depth and climate. Journal of the Kansas Entomological Society, 406-413.

13. Colla, S. R., \& MacIvor, J. S. (2017). Questioning public perception, conservation policy, and recovery actions for honeybees in North America. Conservation Biology, 31(5), 1202-1204.

14. Corrigan, M. P. (2011). Growing what you eat: Developing community gardens in Baltimore, Maryland. Applied Geography, 31(4), 1232-1241.

15. Cotrufo, M. F., Ranalli, M. G., Haddix, M. L., Six, J., \& Lugato, E. (2019). Soil carbon storage informed by particulate and mineral-associated organic matter. Nature Geoscience, 12(12), 989-994. doi:http://dx.doi.org.proxy.lib.pdx.edu/10.1038/s41561019-0484-6

16. Danforth, B., Minckley, R., Neff, J., (2019). The Solitary Bees: Biology, Evolution, Conservation. Princeton University Press. 
17. De Perre, C., Murphy, T. M., \& Lydy, M. J. (2015). Fate and effects of clothianidin in fields using conservation practices. Environmental toxicology and chemistry, 34(2), 258265.

18. Di Prisco, G., Cavaliere, V., Annoscia, D., Varricchio, P., Caprio, E., Nazzi, F., ... \& Pennacchio, F. (2013). Neonicotinoid clothianidin adversely affects insect immunity and promotes replication of a viral pathogen in honey bees. Proceedings of the National Academy of Sciences, 110(46), 18466-18471.

19. Egli, V., Oliver, M., \& Tautolo, E. S. (2016). The development of a model of community garden benefits to wellbeing. Preventive medicine reports, 3, 348-352.

20. Ellis, H. (2010). Sweetness and light: the mysterious history of the honeybee. Crown.

21. Faegri, K., \& Van Der Pijl, L. (2013). Principles of pollination ecology. Elsevier.

22. Fishel, F. M. (2005). Pesticide toxicity profile: neonicotinoid pesticides. University of Florida, IFAS.

23. Firth, C., Maye, D., \& Pearson, D. (2011). Developing “community" in community gardens. Local Environment, 16(6), 555-568.

24. Francis, R. A., \& Chadwick, M. A. (2015). Urban invasions: non-native and invasive species in cities. Geography, 100, 144.

25. Georgiadis, P. T., Pistorius, J., Heimbach, U., Stähler, M., \& Schwabe, K. (2012). Dust drift during sowing of maize-effects on honey bees. Julius-Kühn-Archiv, (437), 134.

26. Goulson, D., Stout, J. C., \& Kells, A. R. (2002). Do exotic bumblebees and honeybees compete with native flower-visiting insects in Tasmania?. Journal of Insect Conservation, 6(3), 179-189.

27. Graystock, P., Yates, K., Evison, S. E., Darvill, B., Goulson, D., \& Hughes, W. O. (2013). The Trojan hives: pollinator pathogens, imported and distributed in bumblebee colonies. Journal of Applied Ecology, 50(5), 1207-1215.

28. Graystock, P., Blane, E. J., McFrederick, Q. S., Goulson, D., \& Hughes, W. O. (2016). Do managed bees drive parasite spread and emergence in wild bees?. International Journal for Parasitology: Parasites and Wildlife, 5(1), 64-75.

29. Hadley, A. S., \& Betts, M. G. (2012). The effects of landscape fragmentation on pollination dynamics: absence of evidence not evidence of absence. Biological Reviews, 87(3), 526-544. 
30. Hatfield, R., Jepsen, S., Mader, E., Hoffman Black, S., Shepherd, M. (2012). Conserving Bumble Bees: Guidelines for Creating and Managing Habitat for America's Declining Pollinators. The Xerces Society for Invertebrate Conservation.

31. Harrison, T., \& Winfree, R. (2015). Urban drivers of plant-pollinator interactions. Functional Ecology, 29(7), 879-888.

32. Havens, K., \& Vitt, P. (2016). The importance of phenological diversity in seed mixes for pollinator restoration. Natural Areas Journal, 36(4), 531-537.

33. Heinrich, B. (1975). Bee flowers: a hypothesis on flower variety and blooming times. Evolution, 29(2), 325-334.

34. Hernandez, J. L., Frankie, G. W., \& Thorp, R. W. (2009). Ecology of urban bees: a review of current knowledge and directions for future study. Cities and the Environment (CATE), 2(1), 3 .

35. Hu, S., Dilcher, D. L., Jarzen, D. M., \& Taylor, D. W. (2008). Early steps of angiospermpollinator coevolution. Proceedings of the National Academy of Sciences, 105(1), 240245.

36. Iwasa, T., Motoyama, N., Ambrose, J. T., \& Roe, R. M. (2004). Mechanism for the differential toxicity of neonicotinoid insecticides in the honey bee, Apis mellifera. Crop protection, 23(5), 371-378.

37. Jackson, A. (2019). The Bees of the Willamette Valley: A Comprehensive Guide to Genera.

38. Jordan, S., Hopwood, J., Evans, E., Gill, K., Code, A., Frischie, S., Stiles, P. (2019). Habitat Assessment Guide for Pollinators in Yards, Gardens, and Parks. The Xerces Society for Invertebrate Conservation.

39. Kimoto, C., DeBano, S. J., Thorp, R. W., Rao, S., \& Stephen, W. P. (2012). Investigating temporal patterns of a native bee community in a remnant North American bunchgrass prairie using blue vane traps. Journal of Insect Science, 12(1), 108.

40. Kluser, S., Neumann, P., Chauzat, M. P., Pettis, J. S., Peduzzi, P., Witt, R., ... \& Theuri, M. (2010). Global honey bee colony disorders and other threats to insect pollinators.

41. Knauer, A. C., \& Schiestl, F. P. (2015). Bees use honest floral signals as indicators of reward when visiting flowers. Ecology letters, 18(2), 135-143.

42. Kremen, C., Williams, N. M., \& Thorp, R. W. (2002). Crop pollination from native bees at risk from agricultural intensification. Proceedings of the National Academy of Sciences, 99(26), 16812-16816. 
43. Lawrence, T. J., Culbert, E. M., Felsot, A. S., Hebert, V. R., \& Sheppard, W. S. (2016). Survey and risk assessment of Apis mellifera (Hymenoptera: Apidae) exposure to neonicotinoid pesticides in urban, rural, and agricultural settings. Journal of economic entomology, 109(2), 520-528.

44. MacKinnon, A., Pojar, J., \& Alaback, P. B. (2004). Plants of the Pacific Northwest coast. Lone Pine Pub.

45. Mader, E., Shepherd, M., Vaughan, M., Hoffman Black, S., LeBuhn, G. (2011). The Xerces Society Guide: Attracting Native Pollinators: Protecting North America's Bees and Butterflies. Storey Publishing.

46. Martin, C. A., \& Stabler, L. B. (2002, August). Urban horticultural ecology: interactions between plants, people and the physical environment. In XXVI International

Horticultural Congress: Expanding Roles for Horticulture in Improving Human WellBeing and Life Quality 639 (pp. 97-101).

47. Matteson, K. C., \& Langellotto, G. A. (2011). Small scale additions of native plants fail to increase beneficial insect richness in urban gardens. Insect Conservation and Diversity, 4(2), 89-98.

48. McMahon, D. P., Fürst, M. A., Caspar, J., Theodorou, P., Brown, M. J., \& Paxton, R. J. (2015). A sting in the spit: widespread cross-infection of multiple RNA viruses across wild and managed bees. Journal of Animal Ecology, 84(3), 615-624.

49. Meiners, J. M., Griswold, T. L., \& Carril, O. M. (2019). Decades of native bee biodiversity surveys at Pinnacles National Park highlight the importance of monitoring natural areas over time. PloS one, 14(1), e0207566.

50. Miller, J. C. (1993). Insect natural history, multi-species interactions and biodiversity in ecosystems. Biodiversity \& Conservation, 2(3), 233-241.

51. Minnerath, A., Vaughan, M., Lee-Mader, E. (2016). Maritime Northwest Citizen Science Monitoring Guide Native Bees and Butterflies. The Xerces Society.

52. Minnesota Department of Health. (2016). Clothianidin and Drinking Water. Health Risk Assessment Unit.

53. Moghaddam, M. H. G., Moghaddam, M. G., Rakhshani, E., \& Mokhtari, A. (2017). An upgrade pinning block: a mechanical practical aid for fast labelling of the insect specimens. Biodiversity data journal, (5).

54. Nassauer, J. I., \& Raskin, J. (2014). Urban vacancy and land use legacies: A frontier for urban ecological research, design, and planning. Landscape and Urban Planning, 125, $245-253$. 
55. Nieto, A., Roberts, S. P., Kemp, J., Rasmont, P., Kuhlmann, M., Criado, M. G., ... \& De Meulemeester, T. (2017). European red list of bees.

56. Noland, S., \& Carver L. (2011). Prairie Landowner Guide for Western Washington. U.S. Fish and Wildlife Service.

57. O'Connor, R. S., Kunin, W. E., Garratt, M. P., Potts, S. G., Roy, H. E., Andrews, C., ... \& Morris, R. K. (2019). Monitoring insect pollinators and flower visitation: the effectiveness and feasibility of different survey methods. Methods in Ecology and Evolution, 10(12), 2129-2140.

58. Ollerton, J., Winfree, R., \& Tarrant, S. (2011). How many flowering plants are pollinated by animals?. Oikos, 120(3), 321-326.

59. Ollerton, J. (2017). Pollinator diversity: distribution, ecological function, and conservation. Annual Review of Ecology, Evolution, and Systematics, 48, 353-376.

60. Pecenka, J. R., \& Lundgren, J. G. (2015). Non-target effects of clothianidin on monarch butterflies. The Science of Nature, 102(3-4), 19.

61. Plascencia, M., \& Philpott, S. M. (2017). Floral abundance, richness, and spatial distribution drive urban garden bee communities. Bulletin of Entomological Research, 107(5), 658-667.

62. Rudall, P. J. (2020). Colourful cones: how did flower colour first evolve?

63. Shavit, O., Dafni, A., \& Ne'eman, G. (2009). Competition between honeybees (Apis mellifera) and native solitary bees in the Mediterranean region of Israel-Implications for conservation. Israel Journal of Plant Sciences, 57(3), 171-183.

64. Stanley, A. G., Dunwiddie, P. W., \& Kaye, T. N. (2011). Restoring invaded Pacific Northwest prairies: management recommendations from a region-wide experiment. Northwest Science, 85(2), 233-246.

65. Steffan-Dewenter, I., \& Westphal, C. (2008). The interplay of pollinator diversity, pollination services and landscape change. Journal of Applied Ecology, 45(3), 737-741.

66. Tepedino, V. J., Bradley, B. A., \& Griswold, T. L. (2008). Might flowers of invasive plants increase native bee carrying capacity? Intimations from Capitol Reef National Park, Utah. Natural Areas Journal, 28(1), 44-50.

67. Thien, L. B., Azuma, H., \& Kawano, S. (2000). New perspectives on the pollination biology of basal angiosperms. International Journal of Plant Sciences, 161(S6), S225S235. 
68. Threlfall, C. G., Walker, K., Williams, N. S., Hahs, A. K., Mata, L., Stork, N., \& Livesley, S. J. (2015). The conservation value of urban green space habitats for Australian native bee communities. Biological Conservation, 187, 240-248.

69. Soil Survey Staff. 2014. Soil Survey Field and Laboratory Methods Manual. Soil Survey Investigations Report No. 51, Version 2.0. R. Burt and Soil Survey Staff (ed.). U.S. Department of Agriculture, Natural Resources Conservation Service

70. Van Kleunen, M., Weber, E., \& Fischer, M. (2010). A meta-analysis of trait differences between invasive and non-invasive plant species. Ecology letters, 13(2), 235-245.

71. Vanbergen, A. J., \& Initiative, T. I. P. (2013). Threats to an ecosystem service: pressures on pollinators. Frontiers in Ecology and the Environment, 11(5), 251-259.

72. Wcislo, W. T., \& Cane, J. H. (1996). Floral resource utilization by solitary bees (Hymenoptera: Apoidea) and exploitation of their stored foods by natural enemies. Annual review of entomology, 41(1), 257-286.

73. Williams, N. M., Mola, J. M., Stuligross, C., Harrison, T., Page, M. L., Brennan, R. M., ... \& Rundlöf, M. (2019). Fantastic bees and where to find them: locating the cryptic overwintering queens of a western bumble bee. Ecosphere, 10(11), e02949.

74. Wilson, J. S., \& Carril, O. J. M. (2015). The bees in your backyard: a guide to North America's bees. Princeton University Press.

\section{Appendices}

\section{Useful contacts and trainings}

The Xerces Society: https://www.xerces.org/

Monitoring guides:

https://xerces.org/publications/id-monitoring/maritime-northwest-citizen-science-monitoring https://xerces.org/publications/id-monitoring USDA Soil Survey Manual:

https://www.nrcs.usda.gov/Internet/FSE_DOCUMENTS/stelprdb1244466.pdf

\section{Useful plant and pollinator ID guides}

Oregon Bee Project: https://www.oregonbeeproject.org/

PNW Bumble Bee Atlas: https://www.pnwbumblebeeatlas.org/

Bumble Bee Watch: https://www.bumblebeewatch.org/

iNaturalist: https://www.inaturalist.org/ 


\section{Plant-Pollinator Networks}

\section{Additional Tables and Figures}

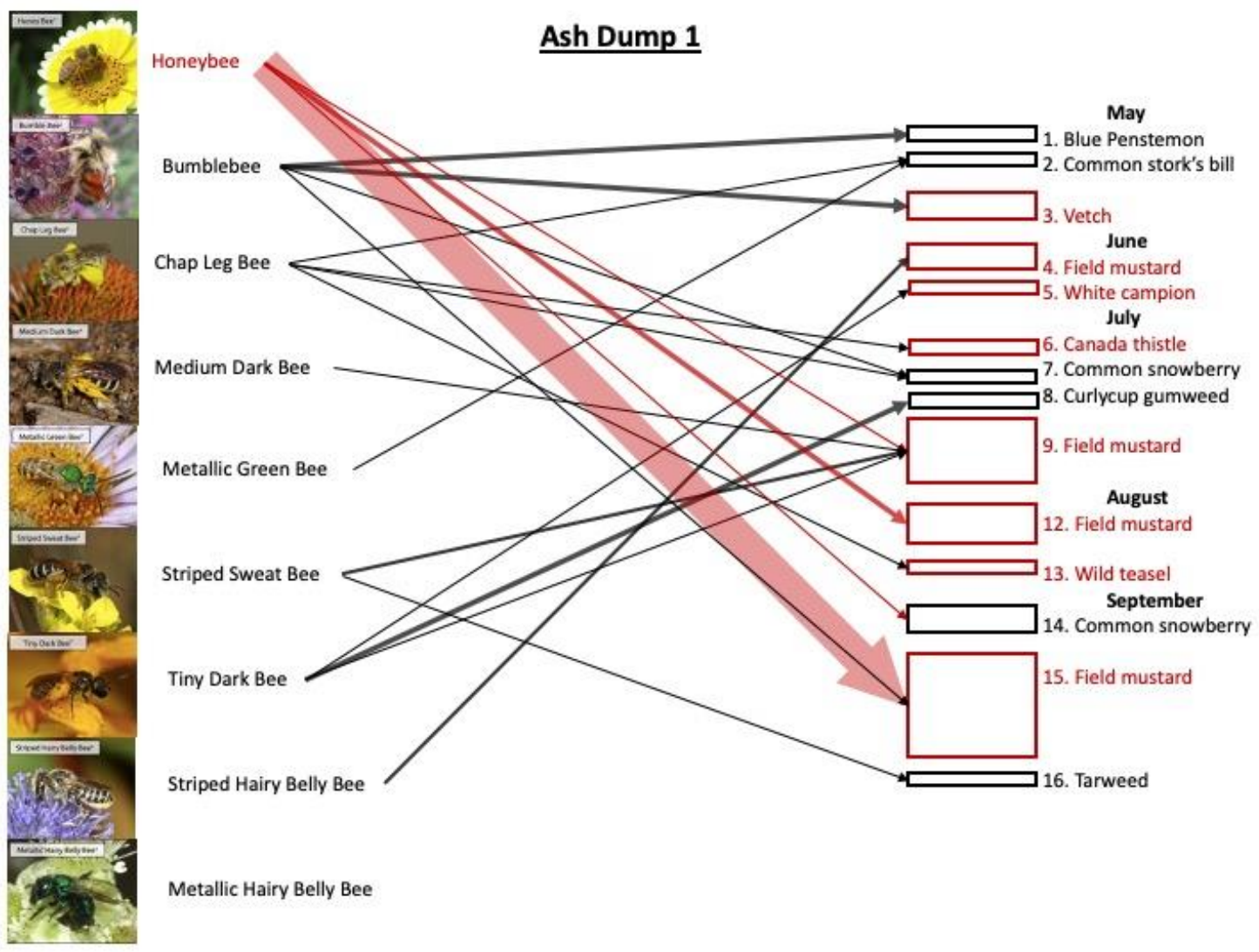



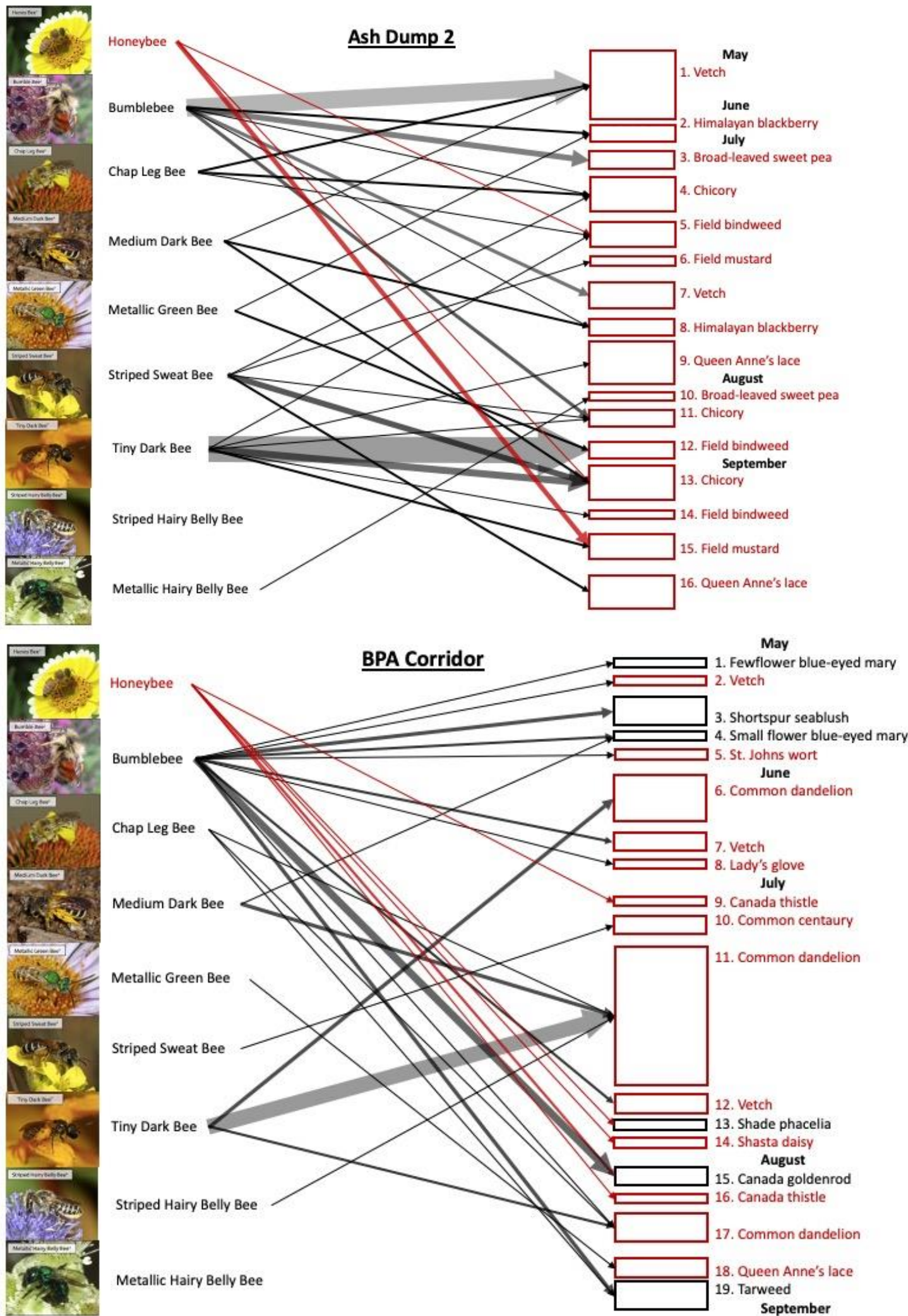

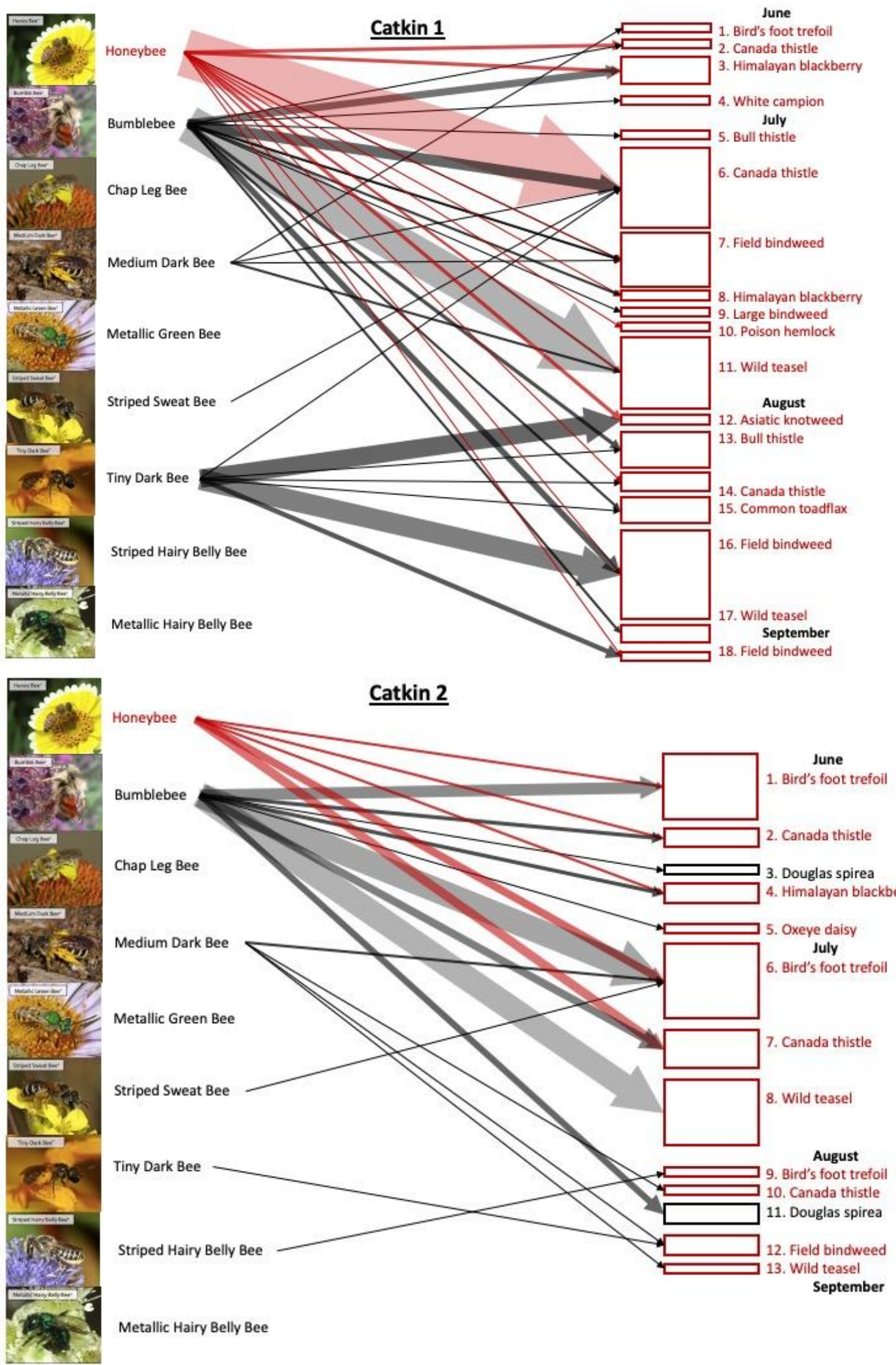

Metallic Hairy Belly Bee 

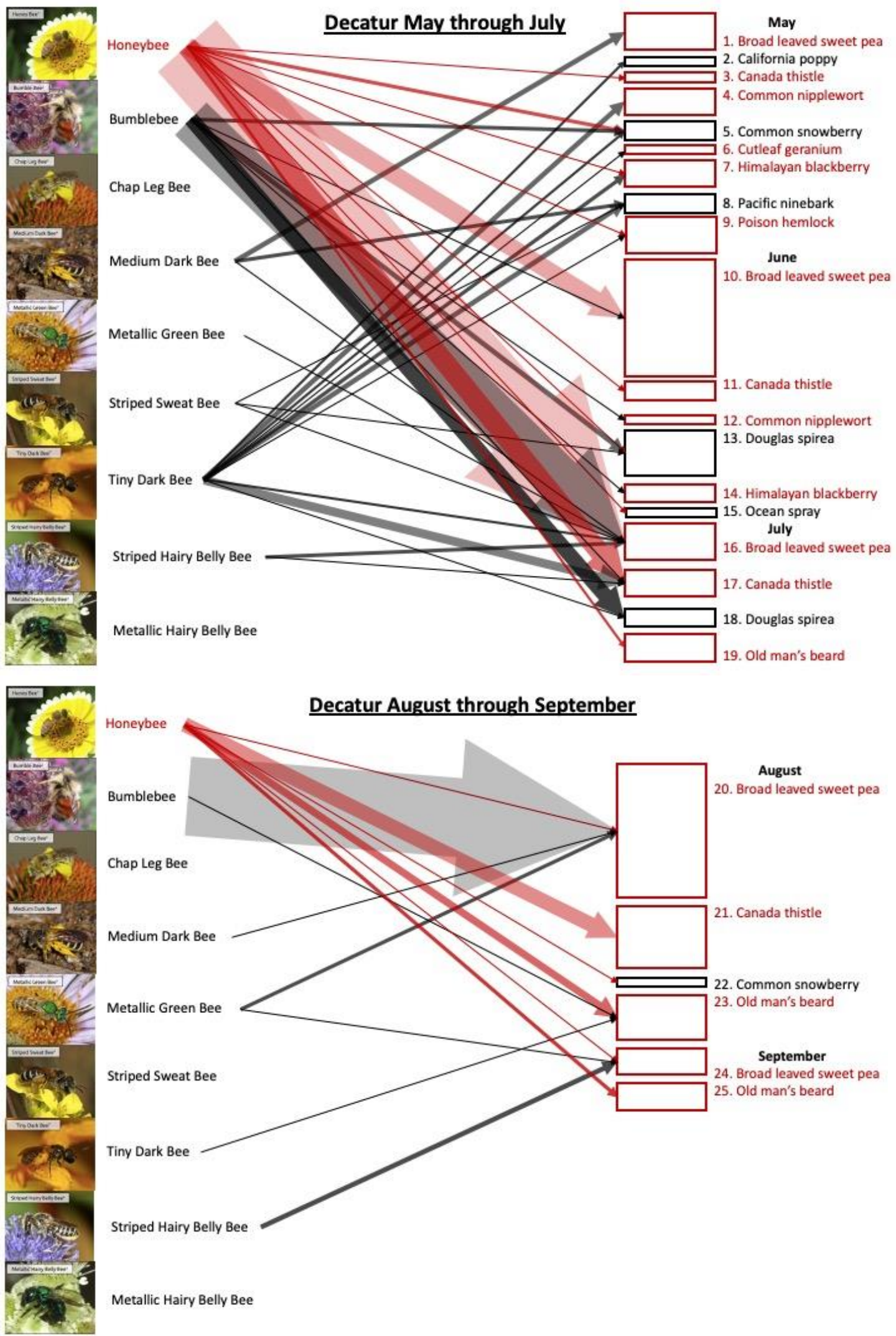

Metallic Hairy Belly Bee 

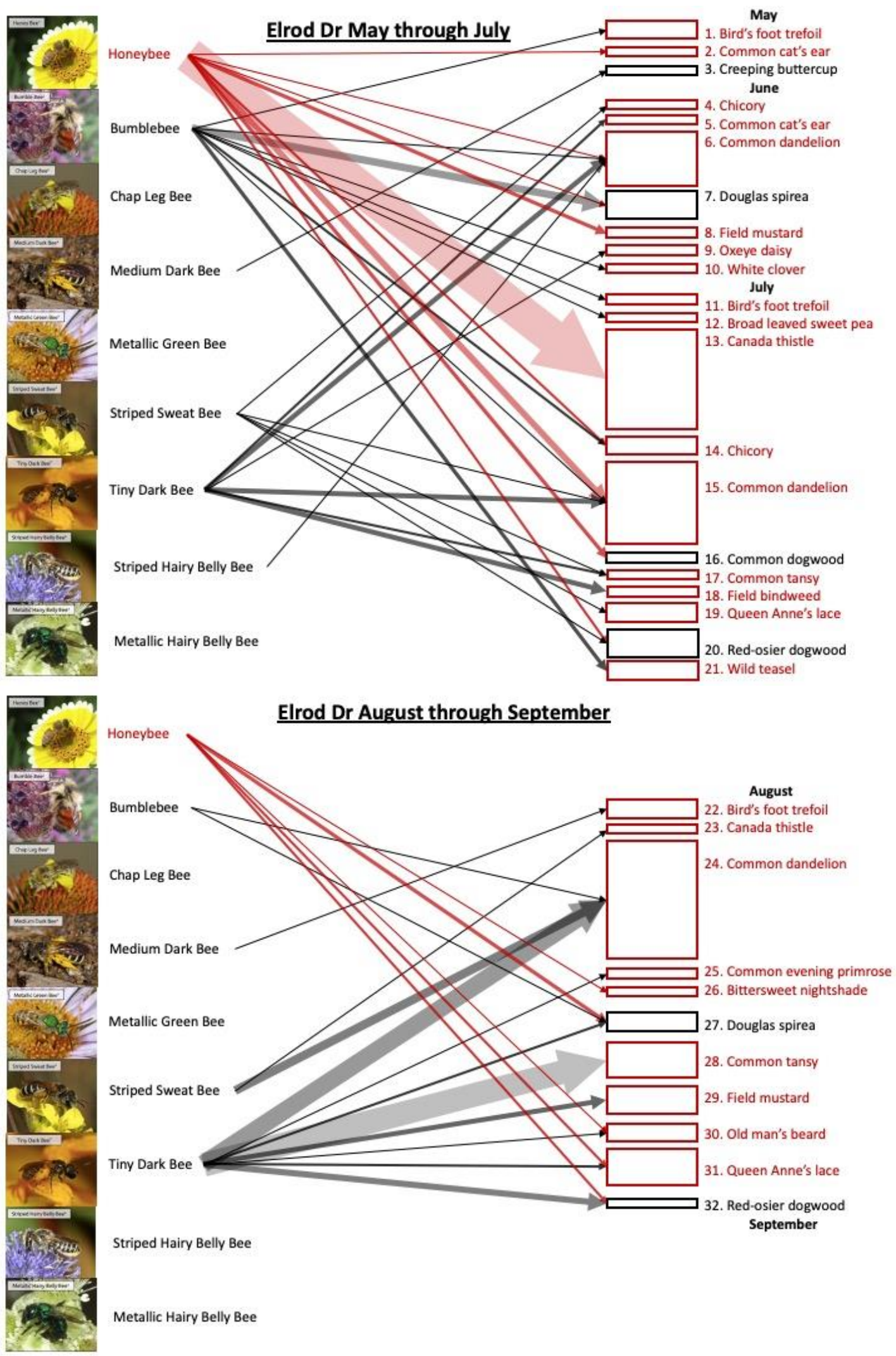

Striped Hairy Belly Bee

September

Metallic Hairy Belly Bee 

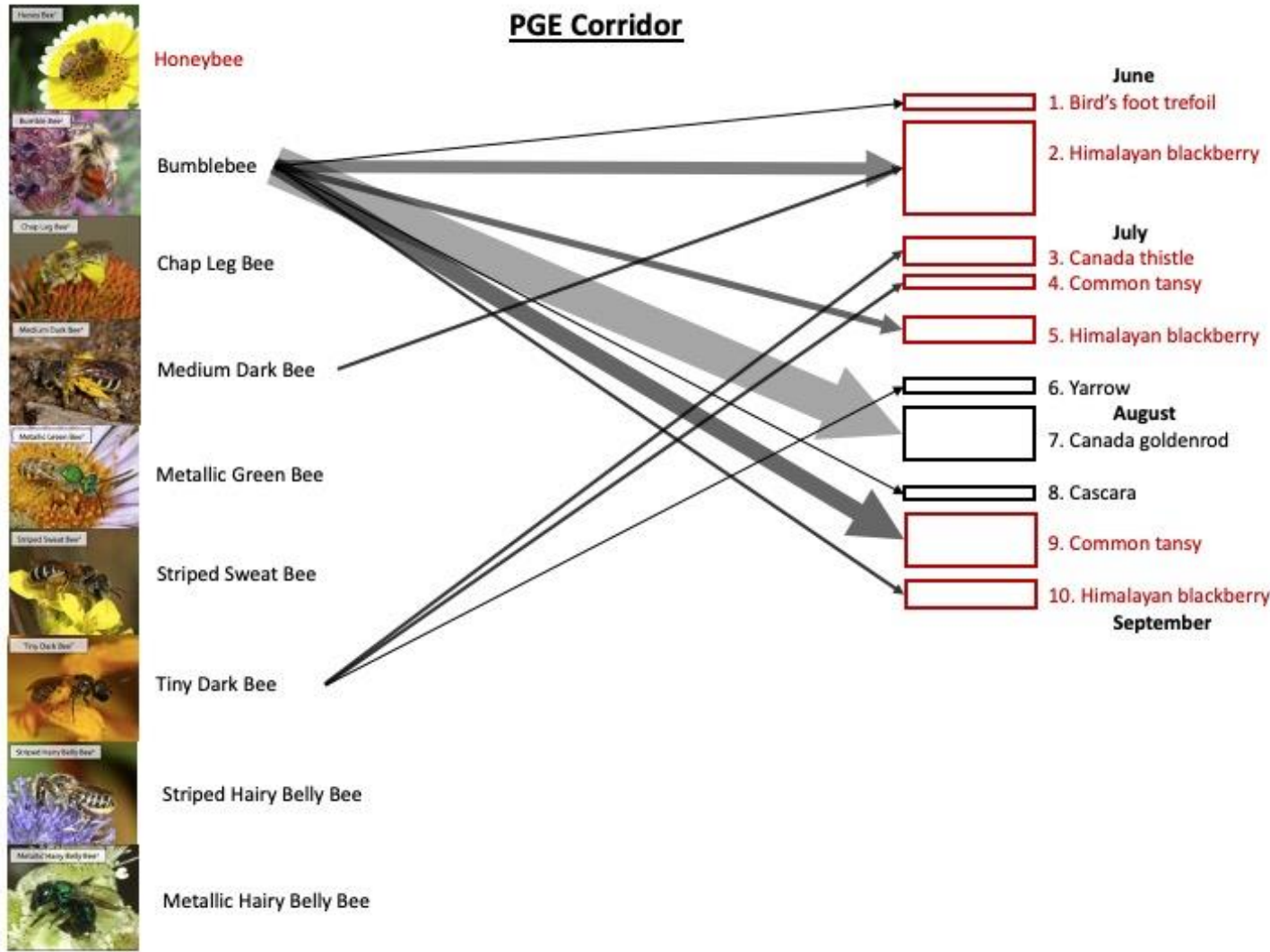

Tiny Dark Bee

Striped Hairy Belly Bee

Metallic Hairy Belly Bee

\section{Native bee to nonnative floral observations May}

Bumblebee

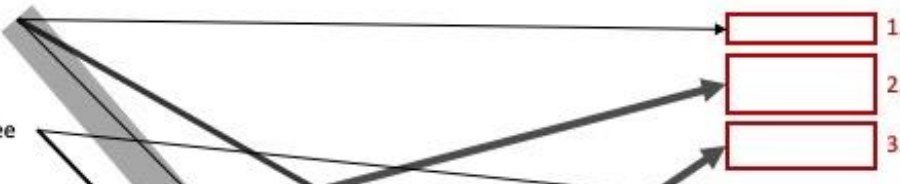

May

1. Birds-foot trefoil

2. Broad-leaved sweet pea

Chap Leg Bee

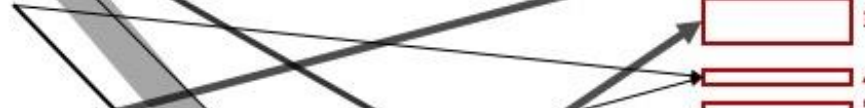

3. Common nipplewort

Medium Dark Bee

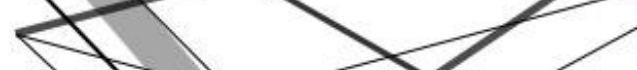

5. Cutleaf geranium
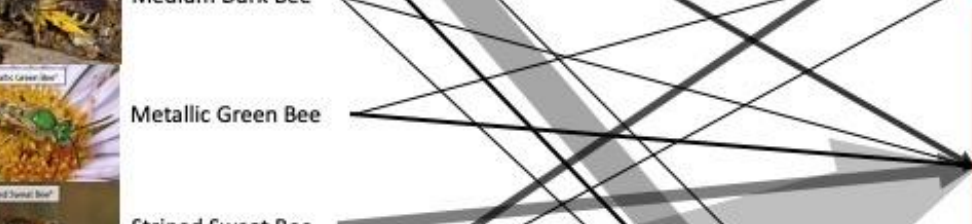

Metallic Green Be

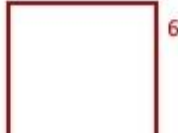

6. Field mustard

Tiny Dark Bee

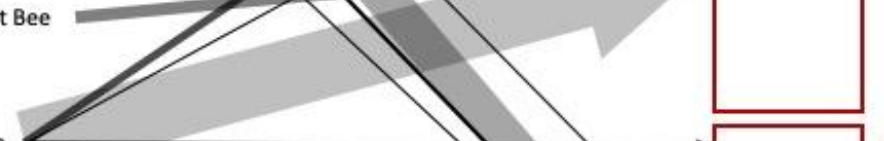

Ti

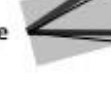

Striped Hairy Belly Bee

Metallic Hairy Belly Bee

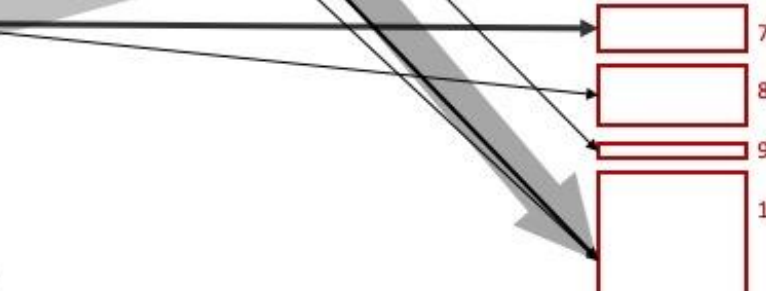

7. Himalayan blackberry

8. Poison hemlock

9. St. Johns wort

10. Vetch 


\section{Native bee to nonnative floral observations June Part 1}
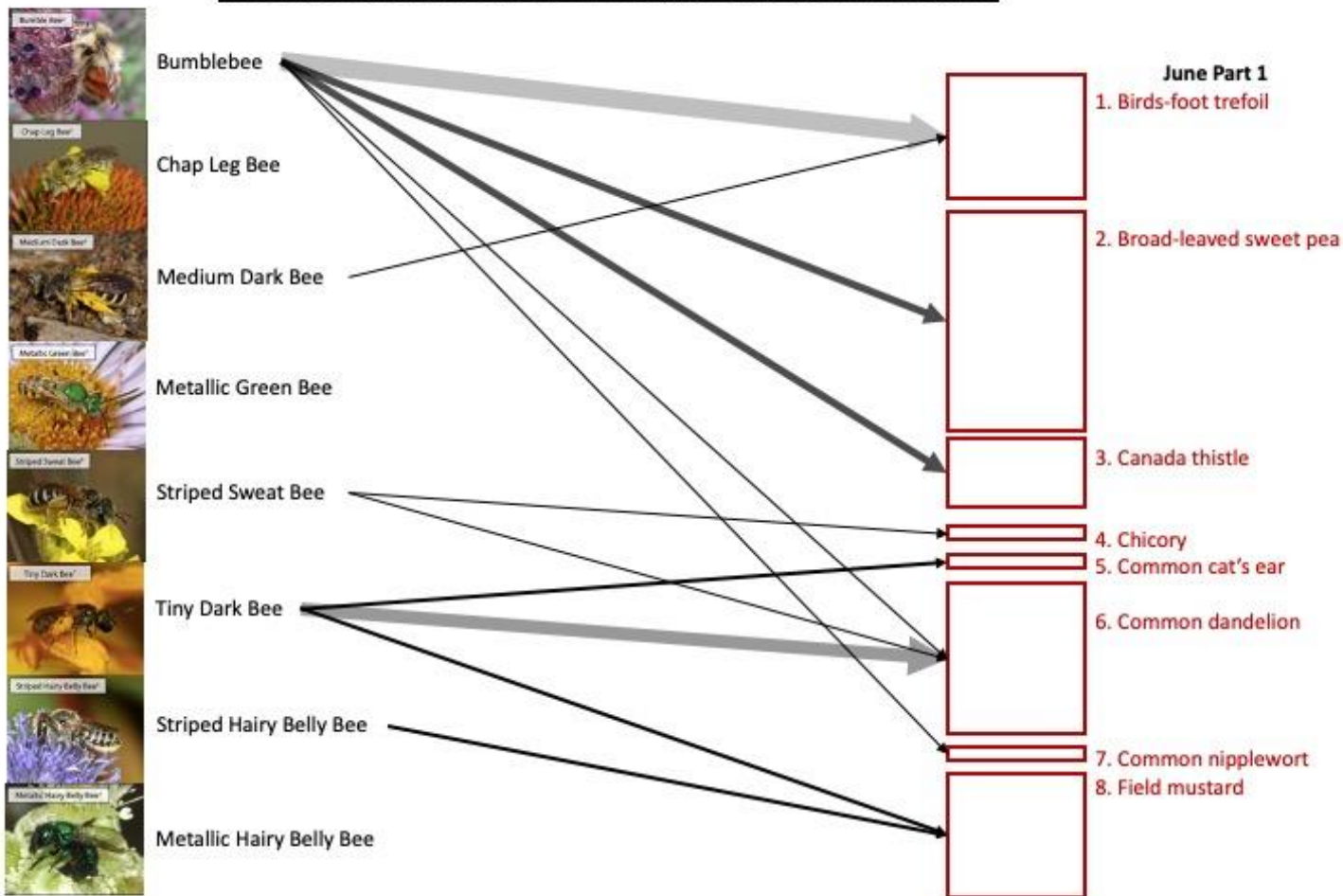

Native bee to nonnative floral observations June Part 2

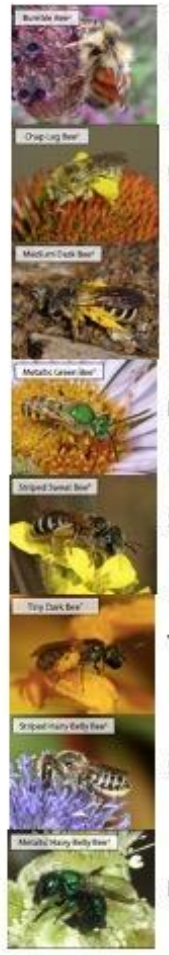

Bumblebee

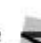

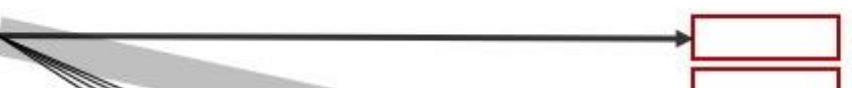

June Part 2

9. Vetch

Chap Leg Bee

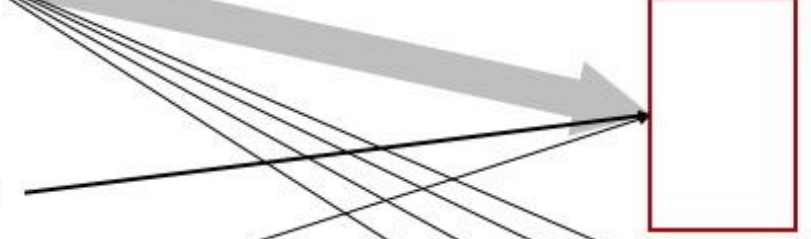

10. Himalayan blackberry

Medium Dark Bee

Metallic Green Bee

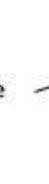

Striped Sweat Bee

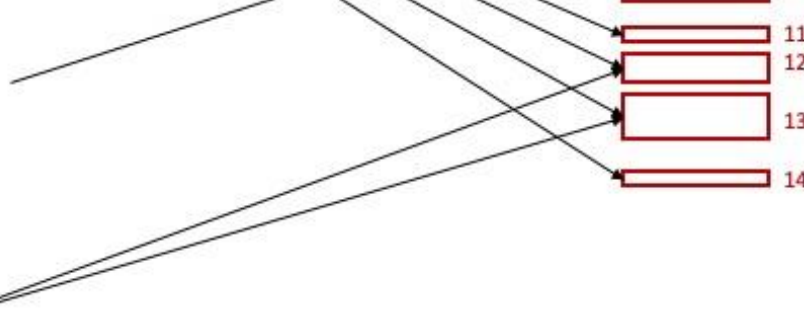

11. Lady's glove

12. Oxeye daisy

13. White campion

Tiny Dark Bee

Striped Hairy Belly Bee

Metallic Hairy Belly Bee 


\section{Native bee to nonnative floral observations July Part 1}
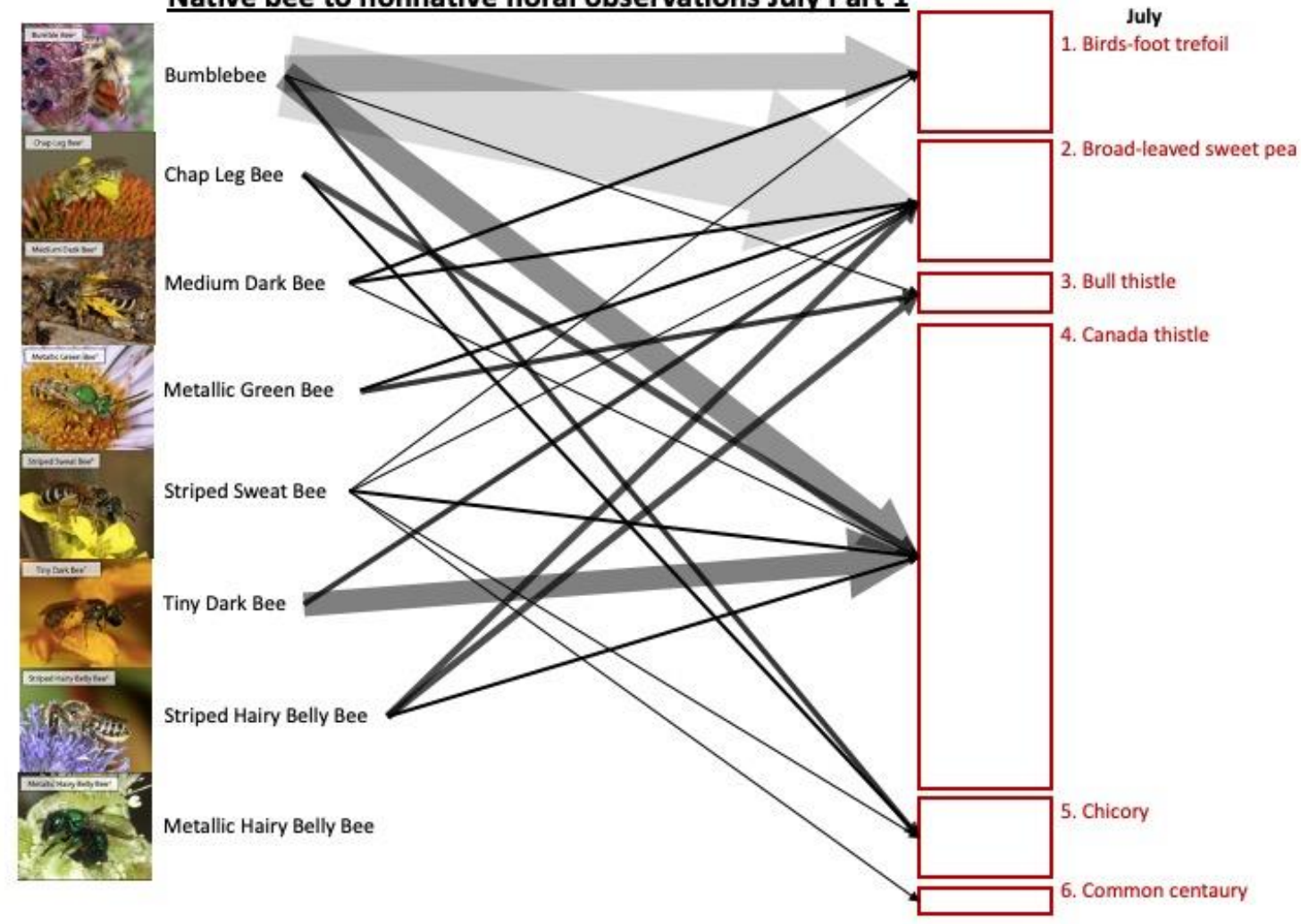

Native bee to nonnative floral observations July Part 2
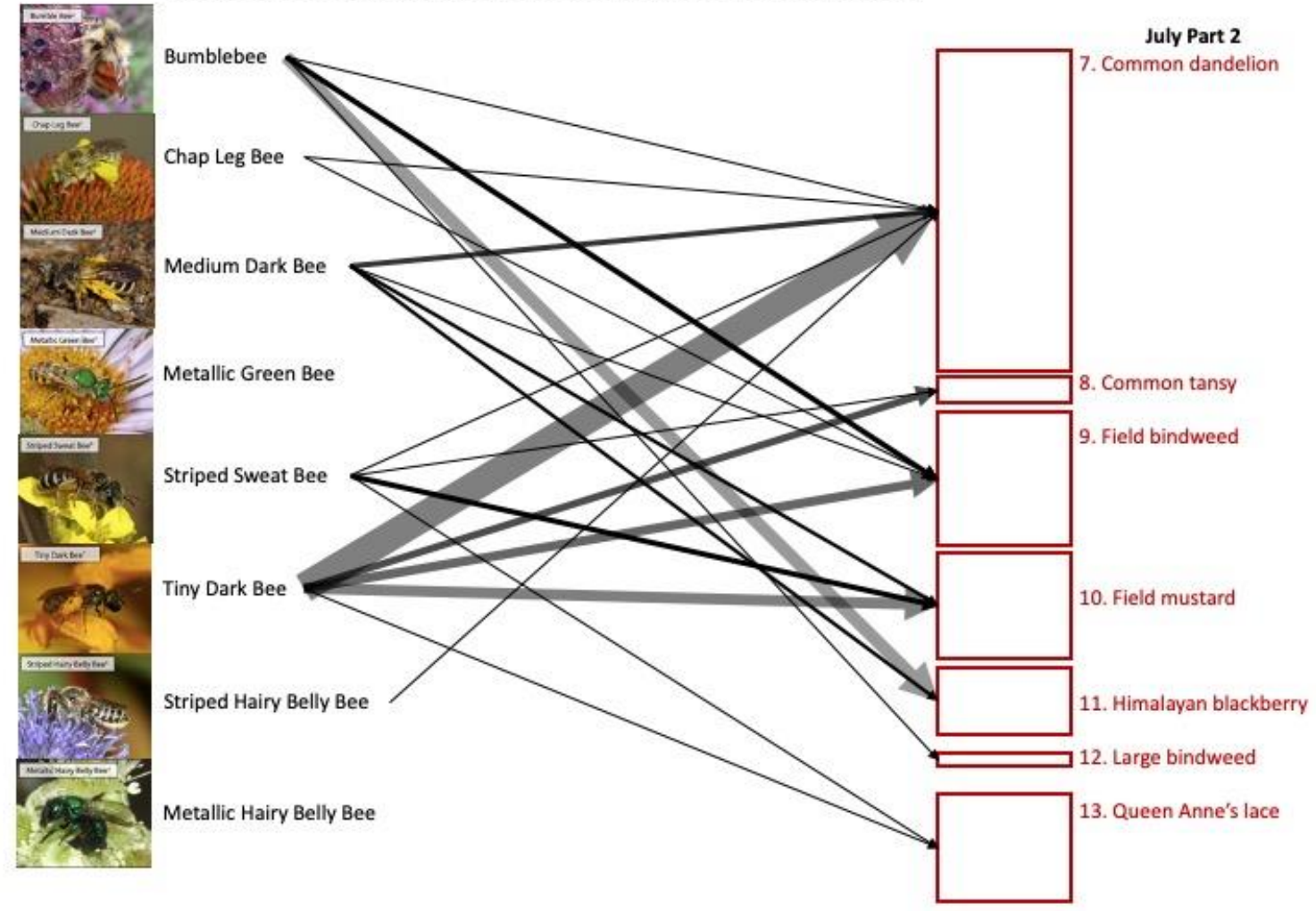


\section{Native bee to nonnative floral observations July Part 3}
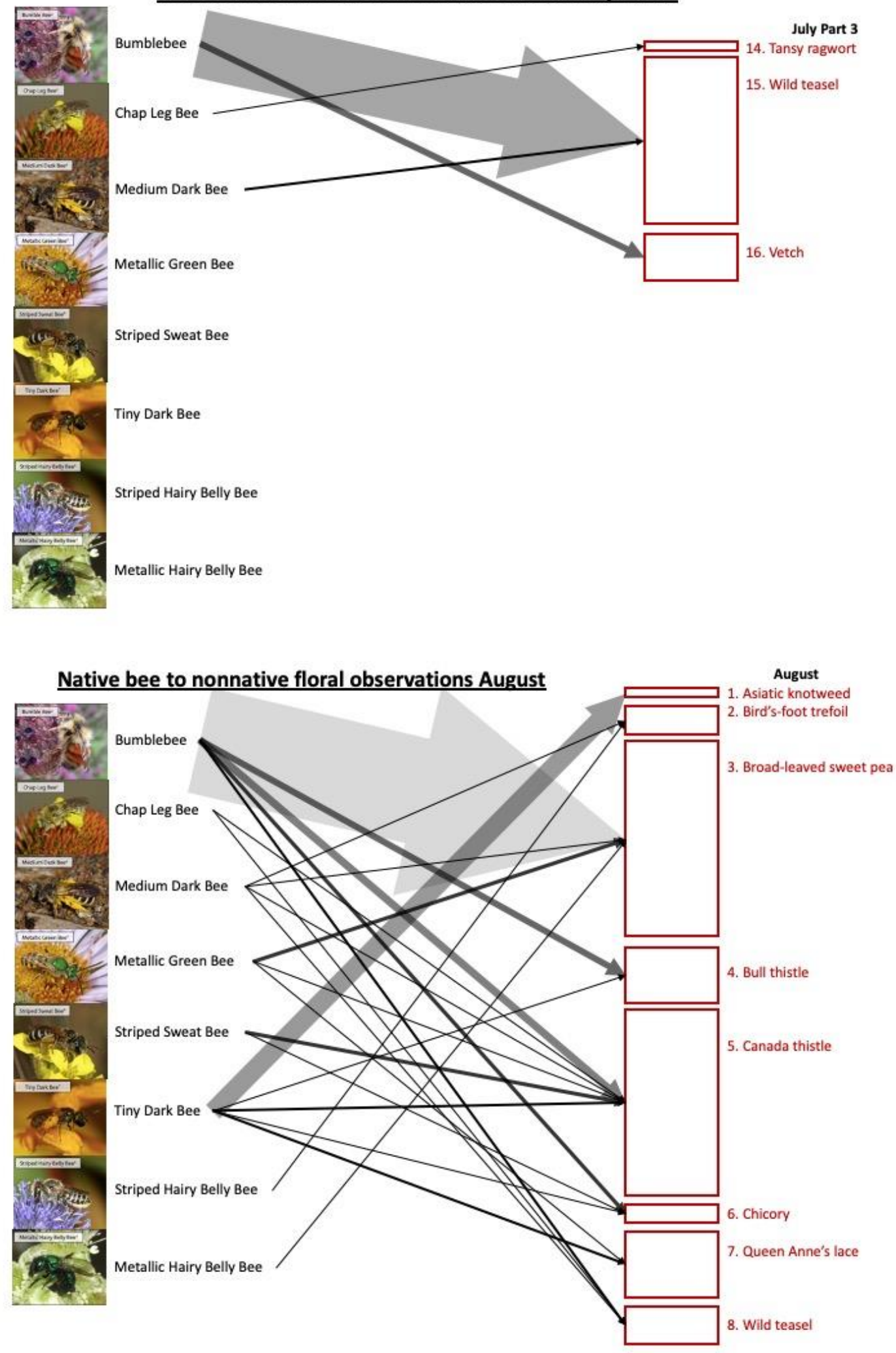


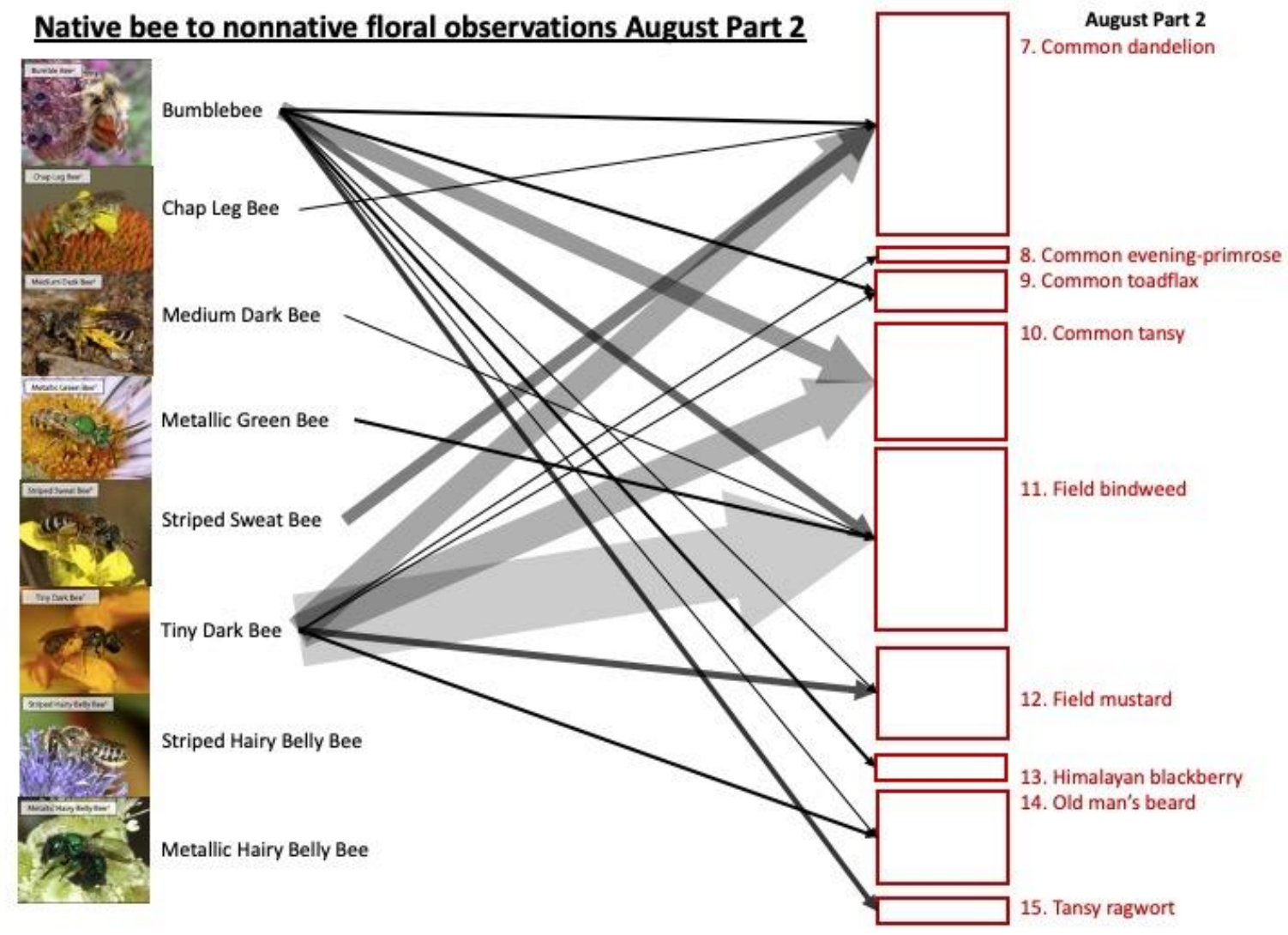

Native bee to nonnative floral observations September
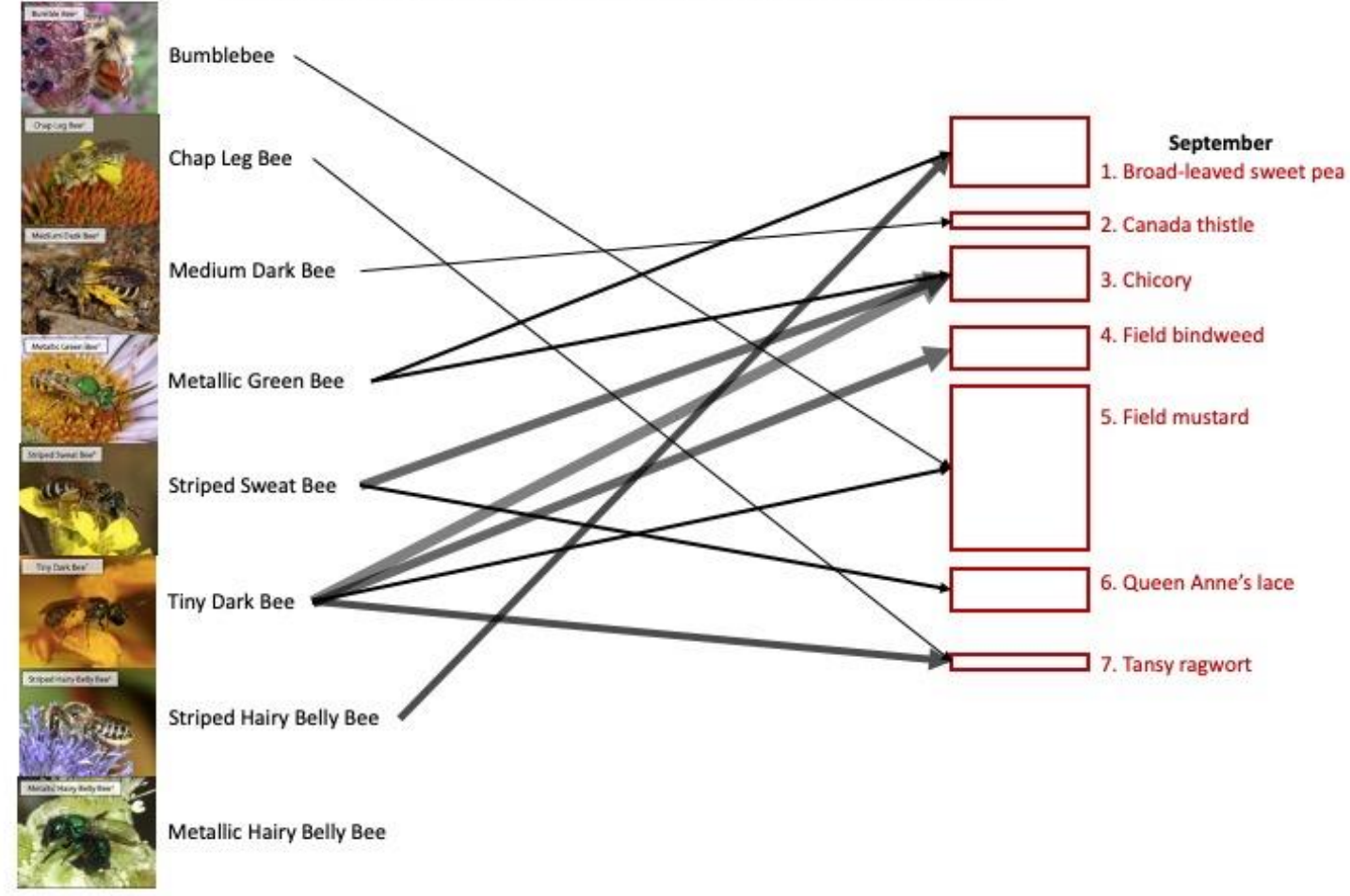

Metallic Hairy Belly Bee 
Table A1: Percentage of Floral Association and Morphogroup Visitations

\begin{tabular}{|c|c|c|c|c|c|c|c|c|}
\hline Row Labels & $\begin{array}{l}\text { \# of Floral } \\
\text { Association } \\
\text { Common }\end{array}$ & & $\begin{array}{l}\text { \% of Floral } \\
\text { Association } \\
\text { Common }\end{array}$ & $\begin{array}{l}\text { Sum } \\
\text { Morpho }\end{array}$ & $\begin{array}{l}\text { Sum No } \\
\text { Honey }\end{array}$ & & $\begin{array}{l}\% \\
\text { Morph } \\
\text { o }\end{array}$ & $\begin{array}{l}\text { \% Morpho No } \\
\text { Honey }\end{array}$ \\
\hline Ash Dump 1 & & 39 & & & 52 & 28 & & - \\
\hline May & & 4 & $10.26 \%$ & & & & & \\
\hline Blue Penstemon & & 1 & $2.56 \%$ & & 3 & 3 & $5.77 \%$ & $10.71 \%$ \\
\hline Common stork's bill & & 1 & $2.56 \%$ & & 2 & 2 & $3.85 \%$ & $7.14 \%$ \\
\hline Hairy vetch & & 2 & $5.13 \%$ & & 3 & 3 & $5.77 \%$ & $10.71 \%$ \\
\hline Jun & & 3 & $7.69 \%$ & & 3 & 3 & & \\
\hline Field mustard & & 2 & $5.13 \%$ & & 2 & 2 & $3.85 \%$ & $7.14 \%$ \\
\hline White campion & & 1 & $2.56 \%$ & & 1 & 1 & $1.92 \%$ & $3.57 \%$ \\
\hline Jul & & 12 & $30.77 \%$ & & & & & \\
\hline Canada goldenrod & & 1 & $2.56 \%$ & & 0 & 0 & $0.00 \%$ & $0.00 \%$ \\
\hline Canada thistle & & 1 & $2.56 \%$ & & 1 & 1 & $1.92 \%$ & $3.57 \%$ \\
\hline Common snowberry & & 1 & $2.56 \%$ & & 2 & 2 & $3.85 \%$ & $7.14 \%$ \\
\hline Curlycup gumweed & & 1 & $2.56 \%$ & & 3 & 3 & $5.77 \%$ & $10.71 \%$ \\
\hline Fennel & & 2 & $5.13 \%$ & & 0 & 0 & $0.00 \%$ & $0.00 \%$ \\
\hline Field mustard & & 5 & $12.82 \%$ & & 5 & 4 & $9.62 \%$ & $14.29 \%$ \\
\hline Wild teasel & & 1 & $2.56 \%$ & & 0 & 0 & $0.00 \%$ & $0.00 \%$ \\
\hline Aug & & 8 & $20.51 \%$ & & & & & \\
\hline Common snowberry & & 1 & $2.56 \%$ & & 0 & 0 & $0.00 \%$ & $0.00 \%$ \\
\hline Dune tansy & & 1 & $2.56 \%$ & & 0 & 0 & $0.00 \%$ & $0.00 \%$ \\
\hline Fennel & & 2 & $5.13 \%$ & & 0 & 0 & $0.00 \%$ & $0.00 \%$ \\
\hline Field mustard & & 3 & $7.69 \%$ & & 4 & 1 & $7.69 \%$ & $3.57 \%$ \\
\hline Wild teasel & & 1 & $2.56 \%$ & & 1 & 1 & $1.92 \%$ & $3.57 \%$ \\
\hline Sep & & 12 & $30.77 \%$ & & & & & \\
\hline Common snowberry & & 2 & $5.13 \%$ & & 1 & 0 & $1.92 \%$ & $0.00 \%$ \\
\hline Field mustard & & 8 & $20.51 \%$ & & 20 & 1 & $38.46 \%$ & $3.57 \%$ \\
\hline Queen Anne's Lace & & 1 & $2.56 \%$ & & 0 & 0 & $0.00 \%$ & $0.00 \%$ \\
\hline Tarweed & & 1 & $2.56 \%$ & & 1 & 1 & $1.92 \%$ & $3.57 \%$ \\
\hline Ash Dump 2 & & 48 & & & 94 & 88 & & \\
\hline May & & 8 & $16.67 \%$ & & & & & \\
\hline Hairy vetch & & 8 & $16.67 \%$ & & 18 & 18 & $19.15 \%$ & $20.45 \%$ \\
\hline Jun & & 2 & $4.17 \%$ & & & & & \\
\hline Himalayan blackberry & & 2 & $4.17 \%$ & & 3 & 3 & $3.19 \%$ & $3.41 \%$ \\
\hline \multirow{2}{*}{\multicolumn{9}{|c|}{ Broad-leaved sweet }} \\
\hline & & & & & & & & \\
\hline pea & & 2 & $4.17 \%$ & & 5 & 5 & $5.32 \%$ & $5.68 \%$ \\
\hline Chicory & & 4 & $8.33 \%$ & & 4 & 4 & $4.26 \%$ & $4.55 \%$ \\
\hline Field bindweed & & 3 & $6.25 \%$ & & 3 & 2 & $3.19 \%$ & $2.27 \%$ \\
\hline Field mustard & & 1 & $2.08 \%$ & & 1 & 1 & $1.06 \%$ & $1.14 \%$ \\
\hline
\end{tabular}




\begin{tabular}{|c|c|c|c|c|c|c|}
\hline Hairy vetch & 3 & $6.25 \%$ & 3 & 3 & $3.19 \%$ & $3.41 \%$ \\
\hline Himalayan blackberry & 2 & $4.17 \%$ & 3 & 3 & $3.19 \%$ & $3.41 \%$ \\
\hline Queen Anne's Lace & 5 & $10.42 \%$ & 1 & 1 & $1.06 \%$ & $1.14 \%$ \\
\hline Aug & 5 & $10.42 \%$ & & & & \\
\hline \multicolumn{7}{|l|}{ Broad-leaved sweet } \\
\hline pea & 1 & $2.08 \%$ & 1 & 1 & $1.06 \%$ & $1.14 \%$ \\
\hline Chicory & 2 & $4.17 \%$ & 5 & 5 & $5.32 \%$ & $5.68 \%$ \\
\hline Field bindweed & 2 & $4.17 \%$ & 24 & 24 & $25.53 \%$ & $27.27 \%$ \\
\hline Sep & 13 & $27.08 \%$ & & & & \\
\hline Chicory & 4 & $8.33 \%$ & 14 & 13 & $14.89 \%$ & $14.77 \%$ \\
\hline Field bindweed & 1 & $2.08 \%$ & 1 & 1 & $1.06 \%$ & $1.14 \%$ \\
\hline Field mustard & 3 & $6.25 \%$ & 6 & 2 & $6.38 \%$ & $2.27 \%$ \\
\hline Plantain & 1 & $2.08 \%$ & 0 & 0 & $0.00 \%$ & $0.00 \%$ \\
\hline Queen Anne's Lace & 4 & $8.33 \%$ & 2 & 2 & $2.13 \%$ & $2.27 \%$ \\
\hline BPA Corridor & 49 & & 56 & 50 & & \\
\hline May & 7 & $14.29 \%$ & & & & \\
\hline \multicolumn{7}{|l|}{ Fewflower blue-eyed } \\
\hline Hairy vetch & 1 & $2.04 \%$ & 1 & 1 & $1.79 \%$ & $2.00 \%$ \\
\hline Shortspur seablush & 3 & $6.12 \%$ & 3 & 3 & $5.36 \%$ & $6.00 \%$ \\
\hline \multicolumn{7}{|l|}{ Small flowered blue- } \\
\hline St John's wort & 1 & $2.04 \%$ & 1 & 1 & $1.79 \%$ & $2.00 \%$ \\
\hline Jun & 9 & $18.37 \%$ & & & & \\
\hline Common dandelion & 5 & $10.20 \%$ & 3 & 3 & $5.36 \%$ & $6.00 \%$ \\
\hline Hairy vetch & 2 & $4.08 \%$ & 2 & 2 & $3.57 \%$ & $4.00 \%$ \\
\hline Lady's glove & 1 & $2.04 \%$ & 1 & 1 & $1.79 \%$ & $2.00 \%$ \\
\hline Red columbine & 1 & $2.04 \%$ & 0 & 0 & $0.00 \%$ & $0.00 \%$ \\
\hline Jul & 22 & $44.90 \%$ & & & & \\
\hline Canada thistle & 1 & $2.04 \%$ & 1 & 0 & $1.79 \%$ & $0.00 \%$ \\
\hline Common centaury & 2 & $4.08 \%$ & 1 & 1 & $1.79 \%$ & $2.00 \%$ \\
\hline Common dandelion & 15 & $30.61 \%$ & 17 & 17 & $30.36 \%$ & $34.00 \%$ \\
\hline Hairy vetch & 2 & $4.08 \%$ & 2 & 2 & $3.57 \%$ & $4.00 \%$ \\
\hline Shade phacelia & 1 & $2.04 \%$ & 1 & 0 & $1.79 \%$ & $0.00 \%$ \\
\hline Shasta daisy & 1 & $2.04 \%$ & 1 & 0 & $1.79 \%$ & $0.00 \%$ \\
\hline Aug & 11 & $22.45 \%$ & & & & \\
\hline Canada goldenrod & 2 & $4.08 \%$ & 8 & 6 & $14.29 \%$ & $12.00 \%$ \\
\hline Canada thistle & 1 & $2.04 \%$ & 1 & 0 & $1.79 \%$ & $0.00 \%$ \\
\hline Common dandelion & 3 & $6.12 \%$ & 4 & 4 & $7.14 \%$ & $8.00 \%$ \\
\hline Queen Anne's Lace & 2 & $4.08 \%$ & 1 & 1 & $1.79 \%$ & $2.00 \%$ \\
\hline Tarweed & 3 & $6.12 \%$ & 4 & 4 & $7.14 \%$ & $8.00 \%$ \\
\hline Catkin 1 & 60 & & 170 & 113 & & \\
\hline Jun & 8 & $13.33 \%$ & & & & \\
\hline
\end{tabular}




\begin{tabular}{|c|c|c|c|c|c|c|}
\hline Bird's-foot trefoil & 1 & $1.67 \%$ & 1 & 1 & $0.59 \%$ & $0.88 \%$ \\
\hline Canada thistle & 1 & $1.67 \%$ & 4 & 1 & $2.35 \%$ & $0.88 \%$ \\
\hline Field bindweed & 1 & $1.67 \%$ & 0 & 0 & $0.00 \%$ & $0.00 \%$ \\
\hline Himalayan blackberry & 3 & $5.00 \%$ & 9 & 6 & $5.29 \%$ & $5.31 \%$ \\
\hline Poison hemlock & 1 & $1.67 \%$ & 0 & 0 & $0.00 \%$ & $0.00 \%$ \\
\hline White campion & 1 & $1.67 \%$ & 1 & 1 & $0.59 \%$ & $0.88 \%$ \\
\hline Jul & 28 & $46.67 \%$ & & & & \\
\hline Bindweed & 2 & $3.33 \%$ & 3 & 2 & $1.76 \%$ & $1.77 \%$ \\
\hline Bull thistle & 1 & $1.67 \%$ & 1 & 1 & $0.59 \%$ & $0.88 \%$ \\
\hline Canada thistle & 9 & $15.00 \%$ & 51 & 12 & $30.00 \%$ & $10.62 \%$ \\
\hline Field bindweed & 4 & $6.67 \%$ & 3 & 2 & $1.76 \%$ & $1.77 \%$ \\
\hline Himalayan blackberry & 1 & $1.67 \%$ & 3 & 2 & $1.76 \%$ & $1.77 \%$ \\
\hline Large bindweed & 1 & $1.67 \%$ & 1 & 1 & $0.59 \%$ & $0.88 \%$ \\
\hline Poison hemlock & 1 & $1.67 \%$ & 1 & 0 & $0.59 \%$ & $0.00 \%$ \\
\hline Wild teasel & 8 & $13.33 \%$ & 35 & 33 & $20.59 \%$ & $29.20 \%$ \\
\hline Yellow buttercup & 1 & $1.67 \%$ & 0 & 0 & $0.00 \%$ & $0.00 \%$ \\
\hline Aug & 22 & $36.67 \%$ & & & & \\
\hline Asiatic Knotweed & 1 & $1.67 \%$ & 18 & 15 & $10.59 \%$ & $13.27 \%$ \\
\hline Bull thistle & 4 & $6.67 \%$ & 4 & 4 & $2.35 \%$ & $3.54 \%$ \\
\hline Canada thistle & 2 & $3.33 \%$ & 2 & 1 & $1.18 \%$ & $0.88 \%$ \\
\hline Common toadflax & 3 & $5.00 \%$ & 3 & 3 & $1.76 \%$ & $2.65 \%$ \\
\hline Field bindweed & 10 & $16.67 \%$ & 23 & 22 & $13.53 \%$ & $19.47 \%$ \\
\hline Wild teasel & 2 & $3.33 \%$ & 2 & 2 & $1.18 \%$ & $1.77 \%$ \\
\hline Sep & 2 & $3.33 \%$ & & & & \\
\hline Common toadflax & 1 & $1.67 \%$ & 0 & 0 & $0.00 \%$ & $0.00 \%$ \\
\hline Field bindweed & 1 & $1.67 \%$ & 5 & 4 & $2.94 \%$ & $3.54 \%$ \\
\hline Catkin 2 & 42 & & 93 & 74 & & \\
\hline Jun & 13 & $30.95 \%$ & & & & \\
\hline Bird's-foot trefoil & 7 & $16.67 \%$ & 11 & 9 & $11.83 \%$ & $12.16 \%$ \\
\hline Canada thistle & 2 & $4.76 \%$ & 5 & 3 & $5.38 \%$ & $4.05 \%$ \\
\hline Douglas spirea & 1 & $2.38 \%$ & 1 & 1 & $1.08 \%$ & $1.35 \%$ \\
\hline Himalayan blackberry & 2 & $4.76 \%$ & 5 & 3 & $5.38 \%$ & $4.05 \%$ \\
\hline Oxeye daisy & 1 & $2.38 \%$ & 1 & 1 & $1.08 \%$ & $1.35 \%$ \\
\hline Jul & 19 & $45.24 \%$ & & & & \\
\hline Bird's-foot trefoil & 8 & $19.05 \%$ & 28 & 22 & $30.11 \%$ & $29.73 \%$ \\
\hline Canada thistle & 4 & $9.52 \%$ & 13 & 6 & $13.98 \%$ & $8.11 \%$ \\
\hline Wild teasel & 7 & $16.67 \%$ & 19 & 19 & $20.43 \%$ & $25.68 \%$ \\
\hline Aug & 8 & $19.05 \%$ & & & & \\
\hline Bird's-foot trefoil & 1 & $2.38 \%$ & 1 & 1 & $1.08 \%$ & $1.35 \%$ \\
\hline Canada thistle & 1 & $2.38 \%$ & 1 & 1 & $1.08 \%$ & $1.35 \%$ \\
\hline Curled dock & 1 & $2.38 \%$ & 0 & 0 & $0.00 \%$ & $0.00 \%$ \\
\hline Douglas spirea & 2 & $4.76 \%$ & 5 & 5 & $5.38 \%$ & $6.76 \%$ \\
\hline Field bindweed & 2 & $4.76 \%$ & 2 & 2 & $2.15 \%$ & $2.70 \%$ \\
\hline
\end{tabular}




\begin{tabular}{|c|c|c|c|c|c|c|}
\hline Wild teasel & 1 & $2.38 \%$ & 1 & 1 & $1.08 \%$ & $1.35 \%$ \\
\hline Sep & 2 & $4.76 \%$ & & & & \\
\hline Bird's-foot trefoil & 1 & $2.38 \%$ & 0 & 0 & $0.00 \%$ & $0.00 \%$ \\
\hline Field bindweed & 1 & $2.38 \%$ & 0 & 0 & $0.00 \%$ & $0.00 \%$ \\
\hline Decatur & 96 & & 304 & 177 & & \\
\hline May & 21 & $21.88 \%$ & & & & \\
\hline \multicolumn{7}{|l|}{ Broad-leaved sweet } \\
\hline pea & 4 & $4.17 \%$ & 4 & 4 & $1.32 \%$ & $2.26 \%$ \\
\hline California poppy & 1 & $1.04 \%$ & 2 & 2 & $0.66 \%$ & $1.13 \%$ \\
\hline Canada thistle & 1 & $1.04 \%$ & 1 & 0 & $0.33 \%$ & $0.00 \%$ \\
\hline Common nipplewort & 3 & $3.13 \%$ & 4 & 4 & $1.32 \%$ & $2.26 \%$ \\
\hline Common snowberry & 2 & $2.08 \%$ & 8 & 5 & $2.63 \%$ & $2.82 \%$ \\
\hline Cutleaf geranium & 1 & $1.04 \%$ & 1 & 1 & $0.33 \%$ & $0.56 \%$ \\
\hline Himalayan blackberry & 3 & $3.13 \%$ & 4 & 3 & $1.32 \%$ & $1.69 \%$ \\
\hline Pacific ninebark & 2 & $2.08 \%$ & 8 & 8 & $2.63 \%$ & $4.52 \%$ \\
\hline Poison hemlock & 4 & $4.17 \%$ & 2 & 1 & $0.66 \%$ & $0.56 \%$ \\
\hline Jun & 27 & $28.13 \%$ & & & & \\
\hline \multicolumn{7}{|l|}{ Broad-leaved sweet } \\
\hline pea & 13 & $13.54 \%$ & 15 & 1 & $4.93 \%$ & $0.56 \%$ \\
\hline Canada thistle & 2 & $2.08 \%$ & 1 & 0 & $0.33 \%$ & $0.00 \%$ \\
\hline Common nipplewort & 1 & $1.04 \%$ & 1 & 1 & $0.33 \%$ & $0.56 \%$ \\
\hline Douglas spirea & 5 & $5.21 \%$ & 6 & 5 & $1.97 \%$ & $2.82 \%$ \\
\hline Himalayan blackberry & 2 & $2.08 \%$ & 1 & 1 & $0.33 \%$ & $0.56 \%$ \\
\hline Ocean spray & 1 & $1.04 \%$ & 1 & 0 & $0.33 \%$ & $0.00 \%$ \\
\hline Poison hemlock & 3 & $3.13 \%$ & 0 & 0 & $0.00 \%$ & $0.00 \%$ \\
\hline Jul & 12 & $12.50 \%$ & & & & \\
\hline \multicolumn{7}{|l|}{ Broad-leaved sweet } \\
\hline pea & 3 & $3.13 \%$ & 106 & 44 & $34.87 \%$ & $24.86 \%$ \\
\hline Canada thistle & 3 & $3.13 \%$ & 25 & 9 & $8.22 \%$ & $5.08 \%$ \\
\hline Douglas spirea & 2 & $2.08 \%$ & 13 & 13 & $4.28 \%$ & $7.34 \%$ \\
\hline Old man's beard & 3 & $3.13 \%$ & 2 & 0 & $0.66 \%$ & $0.00 \%$ \\
\hline Queen Anne's Lace & 1 & $1.04 \%$ & 0 & 0 & $0.00 \%$ & $0.00 \%$ \\
\hline Aug & 30 & $31.25 \%$ & & & & \\
\hline \multicolumn{7}{|l|}{ Broad-leaved sweet } \\
\hline pea & 15 & $15.63 \%$ & 69 & 68 & $22.70 \%$ & $38.42 \%$ \\
\hline Canada thistle & 7 & $7.29 \%$ & 12 & 0 & $3.95 \%$ & $0.00 \%$ \\
\hline Common snowberry & 1 & $1.04 \%$ & 1 & 0 & $0.33 \%$ & $0.00 \%$ \\
\hline Old man's beard & 5 & $5.21 \%$ & 8 & 2 & $2.63 \%$ & $1.13 \%$ \\
\hline Prickly lettuce & 1 & $1.04 \%$ & 0 & 0 & $0.00 \%$ & $0.00 \%$ \\
\hline Wild lettuce & 1 & $1.04 \%$ & 0 & 0 & $0.00 \%$ & $0.00 \%$ \\
\hline Sep & 6 & $6.25 \%$ & & & & \\
\hline \multicolumn{7}{|l|}{ Broad-leaved sweet } \\
\hline pea & 3 & $3.13 \%$ & 6 & 5 & $1.97 \%$ & $2.82 \%$ \\
\hline Old man's beard & 3 & $3.13 \%$ & 3 & 0 & $0.99 \%$ & $0.00 \%$ \\
\hline
\end{tabular}




\begin{tabular}{|c|c|c|c|c|c|c|}
\hline Elrod Dr & 88 & & 155 & 100 & & \\
\hline May & 4 & $4.55 \%$ & & & & \\
\hline Bird's-foot trefoil & 2 & $2.27 \%$ & 1 & 1 & $0.65 \%$ & $1.00 \%$ \\
\hline Common cat's-ear & 1 & $1.14 \%$ & 1 & 0 & $0.65 \%$ & $0.00 \%$ \\
\hline Creeping buttercup & 1 & $1.14 \%$ & 1 & 1 & $0.65 \%$ & $1.00 \%$ \\
\hline Jun & 14 & $15.91 \%$ & & & & \\
\hline Chicory & 1 & $1.14 \%$ & 1 & 1 & $0.65 \%$ & $1.00 \%$ \\
\hline Common cat's-ear & 1 & $1.14 \%$ & 2 & 2 & $1.29 \%$ & $2.00 \%$ \\
\hline Common dandelion & 6 & $6.82 \%$ & 7 & 6 & $4.52 \%$ & $6.00 \%$ \\
\hline Douglas spirea & 3 & $3.41 \%$ & 7 & 6 & $4.52 \%$ & $6.00 \%$ \\
\hline Field mustard & 1 & $1.14 \%$ & 3 & 0 & $1.94 \%$ & $0.00 \%$ \\
\hline Oxeye daisy & 1 & $1.14 \%$ & 1 & 1 & $0.65 \%$ & $1.00 \%$ \\
\hline White clover & 1 & $1.14 \%$ & 1 & 1 & $0.65 \%$ & $1.00 \%$ \\
\hline Jul & 34 & $38.64 \%$ & & & & \\
\hline $\begin{array}{l}\text { Bird's-foot trefoil } \\
\text { Broad-leaved sweet }\end{array}$ & 1 & $1.14 \%$ & 1 & 1 & $0.65 \%$ & $1.00 \%$ \\
\hline pea & 1 & $1.14 \%$ & 1 & 1 & $0.65 \%$ & $1.00 \%$ \\
\hline Canada thistle & 11 & $12.50 \%$ & 28 & 0 & $18.06 \%$ & $0.00 \%$ \\
\hline Chicory & 2 & $2.27 \%$ & 4 & 2 & $2.58 \%$ & $2.00 \%$ \\
\hline Common dandelion & 9 & $10.23 \%$ & 11 & 6 & $7.10 \%$ & $6.00 \%$ \\
\hline Common dogwood & 1 & $1.14 \%$ & 3 & 0 & $1.94 \%$ & $0.00 \%$ \\
\hline Dune tansy & 1 & $1.14 \%$ & 3 & 3 & $1.94 \%$ & $3.00 \%$ \\
\hline Field bindweed & 1 & $1.14 \%$ & 4 & 4 & $2.58 \%$ & $4.00 \%$ \\
\hline Queen Anne's Lace & 2 & $2.27 \%$ & 1 & 1 & $0.65 \%$ & $1.00 \%$ \\
\hline Red-osier dogwood & 3 & $3.41 \%$ & 3 & 1 & $1.94 \%$ & $1.00 \%$ \\
\hline Wild teasel & 2 & $2.27 \%$ & 3 & 3 & $1.94 \%$ & $3.00 \%$ \\
\hline Aug & 34 & $38.64 \%$ & & & & \\
\hline Bird's-foot trefoil & 2 & $2.27 \%$ & 1 & 1 & $0.65 \%$ & $1.00 \%$ \\
\hline Canada thistle & 1 & $1.14 \%$ & 1 & 1 & $0.65 \%$ & $1.00 \%$ \\
\hline Common dandelion & 13 & $14.77 \%$ & 22 & 22 & $14.19 \%$ & $22.00 \%$ \\
\hline $\begin{array}{l}\text { Common evening- } \\
\text { primrose }\end{array}$ & 1 & $1.14 \%$ & 1 & 1 & $0.65 \%$ & $1.00 \%$ \\
\hline Deadly nightshade & 1 & $1.14 \%$ & 1 & 0 & $0.65 \%$ & $0.00 \%$ \\
\hline Douglas spirea & 2 & $2.27 \%$ & 6 & 3 & $3.87 \%$ & $3.00 \%$ \\
\hline Dune tansy & 4 & $4.55 \%$ & 19 & 19 & $12.26 \%$ & $19.00 \%$ \\
\hline Field mustard & 3 & $3.41 \%$ & 4 & 4 & $2.58 \%$ & $4.00 \%$ \\
\hline Old man's beard & 2 & $2.27 \%$ & 2 & 1 & $1.29 \%$ & $1.00 \%$ \\
\hline Queen Anne's Lace & 4 & $4.55 \%$ & 4 & 2 & $2.58 \%$ & $2.00 \%$ \\
\hline Red-osier dogwood & 1 & $1.14 \%$ & 7 & 5 & $4.52 \%$ & $5.00 \%$ \\
\hline Sep & 2 & $2.27 \%$ & & & & \\
\hline Common dandelion & 1 & $1.14 \%$ & 0 & 0 & $0.00 \%$ & $0.00 \%$ \\
\hline Field mustard & 1 & $1.14 \%$ & 0 & 0 & $0.00 \%$ & $0.00 \%$ \\
\hline PGE Corridor & 28 & & 54 & 54 & & \\
\hline
\end{tabular}




\begin{tabular}{|c|c|c|c|c|c|c|}
\hline Jun & 9 & $32.14 \%$ & & & & \\
\hline Bird's-foot trefoil & 1 & $3.57 \%$ & 1 & 1 & $1.85 \%$ & $1.85 \%$ \\
\hline Himalayan blackberry & 7 & $25.00 \%$ & 9 & 9 & $16.67 \%$ & $16.67 \%$ \\
\hline White campion & 1 & $3.57 \%$ & 0 & 0 & $0.00 \%$ & $0.00 \%$ \\
\hline Jul & 6 & $21.43 \%$ & & & & \\
\hline Canada thistle & 2 & $7.14 \%$ & 2 & 2 & $3.70 \%$ & $3.70 \%$ \\
\hline Dune tansy & 1 & $3.57 \%$ & 2 & 2 & $3.70 \%$ & $3.70 \%$ \\
\hline Himalayan blackberry & 2 & $7.14 \%$ & 4 & 4 & $7.41 \%$ & $7.41 \%$ \\
\hline Yarrow & 1 & $3.57 \%$ & 1 & 1 & $1.85 \%$ & $1.85 \%$ \\
\hline Aug & 13 & $46.43 \%$ & & & & \\
\hline Canada goldenrod & 4 & $14.29 \%$ & 22 & 22 & $40.74 \%$ & $40.74 \%$ \\
\hline Cascara & 1 & $3.57 \%$ & 1 & 1 & $1.85 \%$ & $1.85 \%$ \\
\hline Common dandelion & 1 & $3.57 \%$ & 0 & 0 & $0.00 \%$ & $0.00 \%$ \\
\hline Dune tansy & 4 & $14.29 \%$ & 10 & 10 & $18.52 \%$ & $18.52 \%$ \\
\hline Himalayan blackberry & 2 & $7.14 \%$ & 2 & 2 & $3.70 \%$ & $3.70 \%$ \\
\hline Yarrow & 1 & $3.57 \%$ & 0 & 0 & $0.00 \%$ & $0.00 \%$ \\
\hline Rock Creek & 16 & & 16 & 13 & & \\
\hline May & 3 & $18.75 \%$ & & & & \\
\hline American vetch & 1 & $6.25 \%$ & 1 & 1 & $6.25 \%$ & $7.69 \%$ \\
\hline Pacific ninebark & 2 & $12.50 \%$ & 4 & 4 & $25.00 \%$ & $30.77 \%$ \\
\hline Jun & 4 & $25.00 \%$ & & & & \\
\hline Douglas spirea & 3 & $18.75 \%$ & 2 & 1 & $12.50 \%$ & $7.69 \%$ \\
\hline Hairy vetch & 1 & $6.25 \%$ & 1 & 1 & $6.25 \%$ & $7.69 \%$ \\
\hline Jul & 7 & $43.75 \%$ & & & & \\
\hline Douglas spirea & 7 & $43.75 \%$ & 8 & 6 & $50.00 \%$ & $46.15 \%$ \\
\hline Aug & 2 & $12.50 \%$ & & & & \\
\hline Douglas spirea & 1 & $6.25 \%$ & 0 & 0 & $0.00 \%$ & $0.00 \%$ \\
\hline Pacific ninebark & 1 & $6.25 \%$ & 0 & 0 & $0.00 \%$ & $0.00 \%$ \\
\hline St Johns & 89 & & 269 & 167 & & \\
\hline May & 24 & $26.97 \%$ & & & & \\
\hline California figwort & 3 & $3.37 \%$ & 6 & 6 & $2.23 \%$ & $3.59 \%$ \\
\hline Field mustard & 21 & $23.60 \%$ & 51 & 45 & $18.96 \%$ & $26.95 \%$ \\
\hline Jun & 11 & $12.36 \%$ & & & & \\
\hline \multicolumn{7}{|l|}{ Broad-leaved sweet } \\
\hline pea & 3 & $3.37 \%$ & 6 & 3 & $2.23 \%$ & $1.80 \%$ \\
\hline Field mustard & 6 & $6.74 \%$ & 10 & 2 & $3.72 \%$ & $1.20 \%$ \\
\hline Shade phacelia & 2 & $2.25 \%$ & 3 & 3 & $1.12 \%$ & $1.80 \%$ \\
\hline Jul & 16 & $17.98 \%$ & & & & \\
\hline \multicolumn{7}{|l|}{ Broad-leaved sweet } \\
\hline pea & 3 & $3.37 \%$ & 8 & 7 & $2.97 \%$ & $4.19 \%$ \\
\hline Bull thistle & 2 & $2.25 \%$ & 7 & 7 & $2.60 \%$ & $4.19 \%$ \\
\hline Canada goldenrod & 3 & $3.37 \%$ & 32 & 18 & $11.90 \%$ & $10.78 \%$ \\
\hline Canada thistle & 4 & $4.49 \%$ & 32 & 8 & $11.90 \%$ & $4.79 \%$ \\
\hline
\end{tabular}




\begin{tabular}{|c|c|c|c|c|c|c|}
\hline Field mustard & 2 & $2.25 \%$ & 15 & 6 & $5.58 \%$ & $3.59 \%$ \\
\hline Shade phacelia & 1 & $1.12 \%$ & 1 & 1 & $0.37 \%$ & $0.60 \%$ \\
\hline Tansy Ragwort & 1 & $1.12 \%$ & 1 & 1 & $0.37 \%$ & $0.60 \%$ \\
\hline Aug & 29 & $32.58 \%$ & & & & \\
\hline \multicolumn{7}{|l|}{ Broad-leaved sweet } \\
\hline pea & 5 & $5.62 \%$ & 20 & 19 & $7.43 \%$ & $11.38 \%$ \\
\hline Bull thistle & 2 & $2.25 \%$ & 2 & 2 & $0.74 \%$ & $1.20 \%$ \\
\hline California poppy & 1 & $1.12 \%$ & 1 & 1 & $0.37 \%$ & $0.60 \%$ \\
\hline Canada goldenrod & 7 & $7.87 \%$ & 31 & 10 & $11.52 \%$ & $5.99 \%$ \\
\hline Canada thistle & 8 & $8.99 \%$ & 23 & 11 & $8.55 \%$ & $6.59 \%$ \\
\hline Field mustard & 1 & $1.12 \%$ & 1 & 0 & $0.37 \%$ & $0.00 \%$ \\
\hline Gumweed & 1 & $1.12 \%$ & 0 & 0 & $0.00 \%$ & $0.00 \%$ \\
\hline Queen Anne's Lace & 1 & $1.12 \%$ & 0 & 0 & $0.00 \%$ & $0.00 \%$ \\
\hline Shade phacelia & 1 & $1.12 \%$ & 3 & 3 & $1.12 \%$ & $1.80 \%$ \\
\hline Tansy Ragwort & 2 & $2.25 \%$ & 4 & 3 & $1.49 \%$ & $1.80 \%$ \\
\hline Sep & 9 & $10.11 \%$ & & & & \\
\hline \multicolumn{7}{|l|}{ Broad-leaved sweet } \\
\hline pea & 2 & $2.25 \%$ & 1 & 1 & $0.37 \%$ & $0.60 \%$ \\
\hline California poppy & 1 & $1.12 \%$ & 0 & 0 & $0.00 \%$ & $0.00 \%$ \\
\hline Canada goldenrod & 3 & $3.37 \%$ & 3 & 2 & $1.12 \%$ & $1.20 \%$ \\
\hline Canada thistle & 1 & $1.12 \%$ & 1 & 1 & $0.37 \%$ & $0.60 \%$ \\
\hline Tansy Ragwort & 1 & $1.12 \%$ & 5 & 5 & $1.86 \%$ & $2.99 \%$ \\
\hline Tarweed & 1 & $1.12 \%$ & 2 & 2 & $0.74 \%$ & $1.20 \%$ \\
\hline Grand Total & 555 & & 1260 & 861 & & \\
\hline
\end{tabular}

Table A2: Organic Matter Content

\begin{tabular}{|c|c|c|c|c|c|c|c|c|}
\hline $\begin{array}{l}\text { SITE } \\
\text { CODE }\end{array}$ & $\begin{array}{l}\text { UNIQU } \\
\text { E } \\
\text { SAMPL } \\
\text { E }\end{array}$ & $\begin{array}{l}\text { Crucibl } \\
\text { e Label }\end{array}$ & $\begin{array}{l}\text { Crucibl } \\
\text { e } \\
\text { weight }\end{array}$ & $\begin{array}{l}\text { Initial } \\
\text { Soil (g) }\end{array}$ & $\begin{array}{l}\text { oven } \\
\text { dry } \\
\text { weight }\end{array}$ & $\begin{array}{l}\text { Water } \\
\text { lost } \\
\text { (g) } \\
\end{array}$ & $\begin{array}{l}\text { Crucible } \\
\text { Weight } \\
\text { (g) }\end{array}$ & $\begin{array}{l}\text { Organic } \\
\text { Content }\end{array}$ \\
\hline DEC & $D-A$ & 105 & 11.392 & 7.239 & 16.934 & 1.697 & 16.554 & 0.38 \\
\hline DEC & D-B & 96 & 11.367 & 7.041 & 16.892 & 1.516 & 16.076 & 0.816 \\
\hline DEC & D-C & 12 & 11.55 & 7.044 & 16.776 & 1.818 & 15.904 & 0.872 \\
\hline DEC & $D-D$ & 39 & 12.051 & 7.053 & 18.018 & 1.086 & 17.713 & 0.305 \\
\hline DEC & $D-E$ & 73 & 10.985 & 7.037 & 15.801 & 2.221 & 15.02 & 0.781 \\
\hline DEC & D-F & 70 & 11.055 & 7.233 & 15.632 & 2.656 & 14.631 & 1.001 \\
\hline DEC & $D-G$ & 110 & 11.271 & 7.157 & 16.298 & 2.13 & 15.604 & 0.694 \\
\hline DEC & $\mathrm{D}-\mathrm{H}$ & 94 & 12.04 & 7.045 & 16.901 & 2.184 & 16.108 & 0.793 \\
\hline DEC & D-J & B1 & 11.602 & 7.053 & $\begin{array}{r}17.069 \\
9 \\
\end{array}$ & 1.5851 & 16.488 & 0.5819 \\
\hline STJ & S-A & 44 & 10.972 & 7.099 & 16.223 & 1.848 & 15.88 & 0.343 \\
\hline STJ & S-B & 7 & 11.995 & 7.047 & 17.354 & 1.688 & 17.053 & 0.301 \\
\hline STJ & $\mathrm{S}-\mathrm{C}$ & 95 & 11.815 & 7.09 & 17.321 & 1.584 & 17.022 & 0.299 \\
\hline
\end{tabular}




\begin{tabular}{|c|c|c|c|c|c|c|c|c|}
\hline STJ & S-D & 61 & 12.259 & 7.228 & 17.698 & 1.789 & 17.391 & 0.307 \\
\hline STJ & $S-E$ & 20 & 11.529 & 7.011 & 17.559 & 0.981 & 17.418 & 0.141 \\
\hline STJ & S-F & 78 & 12.546 & 7.183 & 17.74 & 1.989 & 17.334 & 0.406 \\
\hline STJ & $S-G$ & 90 & 12.542 & 7.023 & 17.818 & 1.747 & 17.484 & 0.334 \\
\hline STJ & $\mathrm{S}-\mathrm{H}$ & 89 & 11.251 & 7.167 & 16.527 & 1.891 & 16.178 & 0.349 \\
\hline STJ & S-J & 64 & 10.635 & 7.09 & 15.997 & 1.728 & 15.637 & 0.36 \\
\hline ELR & E-B & $\mathrm{A} 02$ & 11.136 & 7.111 & 16.755 & 1.492 & 16.519 & 0.236 \\
\hline ELR & $\mathrm{E}-\mathrm{C}$ & 77 & 11.587 & 7.07 & 17.411 & 1.246 & 17.102 & 0.309 \\
\hline ELR & E-D & 97 & 11.846 & 7.163 & 17.087 & 1.922 & 16.348 & 0.739 \\
\hline ELR & $E-E$ & 111 & 11.504 & 7.251 & 17.015 & 1.74 & 16.732 & 0.283 \\
\hline ELR & E-F & 19 & 11.76 & 7.029 & 17.636 & 1.153 & 17.324 & 0.312 \\
\hline ELR & $E-G$ & 71 & 11.252 & 7.296 & 17.225 & 1.323 & 16.946 & 0.279 \\
\hline ELR & $\mathrm{E}-\mathrm{H}$ & 118 & 11.24 & 7.284 & 17.871 & 0.653 & 17.737 & 0.134 \\
\hline ELR & E-I & 11 & 11.109 & 7.102 & 17.254 & 0.957 & 17.021 & 0.233 \\
\hline ELR & E-J & 5 & 11.473 & 7.065 & 17.77 & 0.768 & 17.595 & 0.175 \\
\hline CAT & C-B & 83 & 11.622 & 7.055 & 16.221 & 2.456 & 15.681 & 0.54 \\
\hline CAT & C-A & 76 & 11.363 & 7.275 & 16.248 & 2.39 & 15.637 & 0.611 \\
\hline CAT & C-C & $\mathrm{A} 03$ & 11.32 & 7.133 & 15.242 & 3.211 & 14.674 & 0.568 \\
\hline CAT & C-D & 115 & 11.074 & 7.272 & 15.233 & 3.113 & 14.683 & 0.55 \\
\hline CAT & C-E & 41 & 11.864 & 7.271 & 16.276 & 2.859 & 15.752 & 0.524 \\
\hline CAT & $\mathrm{C}-\mathrm{F}$ & 100 & 11.352 & 7.064 & 16.405 & 2.011 & 16.012 & 0.393 \\
\hline CAT & $C-G$ & 17 & 11.073 & 7.039 & 16.087 & 2.025 & 15.707 & 0.38 \\
\hline CAT & $\mathrm{C}-\mathrm{H}$ & 85 & 12.467 & 7.308 & 17.586 & 2.189 & 17.09 & 0.496 \\
\hline CAT & C-I & 30 & 11.698 & 7.287 & 16.48 & 2.505 & 15.947 & 0.533 \\
\hline ASHD & A-A & 116 & 12.305 & 7.031 & 17.923 & 1.413 & 17.544 & 0.379 \\
\hline ASHD & $A-B$ & 117 & 11.816 & 7.129 & 17.509 & 1.436 & 17.134 & 0.375 \\
\hline ASHD & $\mathrm{A}-\mathrm{C}$ & 88 & 12.702 & 7.096 & 18.587 & 1.211 & 18.301 & 0.286 \\
\hline ASHD & $A-D$ & 1 & 12.092 & 7.026 & 16.69 & 2.428 & 14.901 & 1.789 \\
\hline ASHD & A-F & 67 & 11.141 & 7.131 & 15.406 & 2.866 & 14.208 & 1.198 \\
\hline ASHD & $A-G$ & 6 & 11.841 & 7.013 & 17.101 & 1.753 & 16.663 & 0.438 \\
\hline ASHD & $\mathrm{A}-\mathrm{H}$ & 84 & 11.529 & 7.065 & 16.428 & 2.166 & 15.614 & 0.814 \\
\hline ASHD & A-I & 42 & 10.852 & 7.038 & 16.567 & 1.323 & 16.249 & 0.318 \\
\hline ASHD & A-J & 57 & 11.827 & 7.058 & 17.128 & 1.757 & 16.716 & 0.412 \\
\hline
\end{tabular}

